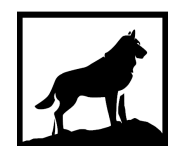

Michigan Technological

18.5 University
Michigan Technological University Digital Commons @ Michigan Tech

TECHNOLOGY FOR INTEGRATED GROYNE-VETIVER EROSION REDUCTION (TIGER): CASE STUDY IN A WEST AFRICAN RIVER

Chase M. West

Michigan Technological University, chasew@mtu.edu

Copyright 2019 Chase M. West

Recommended Citation

West, Chase M., "TECHNOLOGY FOR INTEGRATED GROYNE-VETIVER EROSION REDUCTION (TIGER): CASE STUDY IN A WEST AFRICAN RIVER", Open Access Master's Thesis, Michigan Technological University, 2019.

https://doi.org/10.37099/mtu.dc.etdr/916

Follow this and additional works at: https://digitalcommons.mtu.edu/etdr

Part of the Environmental Engineering Commons, and the Hydraulic Engineering Commons 


\title{
TECHNOLOGY FOR INTEGRATED GROYNE-VETIVER EROSION REDUCTION (TIGER): CASE STUDY IN A WEST AFRICAN RIVER
}

By

Chase M. West

\begin{abstract}
A THESIS
Submitted in partial fulfillment of the requirements for the degree of MASTER OF SCIENCE

In Environmental Engineering
\end{abstract}

MICHIGAN TECHNOLOGICAL UNIVERSITY

2019

(C) 2019 Chase M. West 
This thesis has been approved in partial fulfillment of the requirements for the Degree of MASTER OF SCIENCE in Environmental Engineering.

Department of Civil and Environmental Engineering

Thesis Advisor: $\quad$ Dr. Brian Barkdoll

Committee Member: $\quad$ Dr. Robert Handler

Committee Member: $\quad$ Dr. Audrey Mayer

Department Chair: Dr. Audra Morse 


\section{Table of Contents}

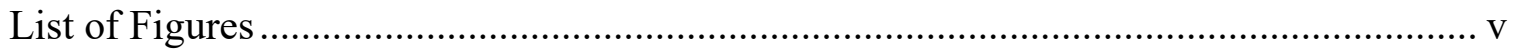

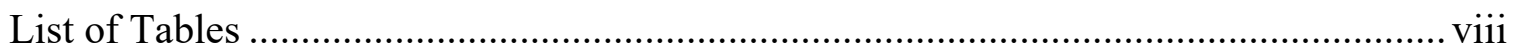

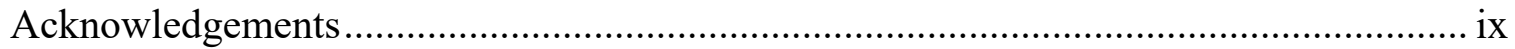

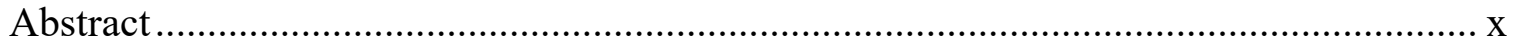

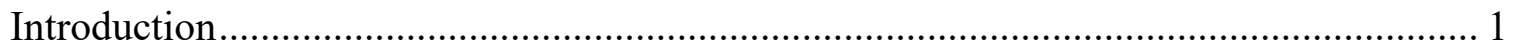

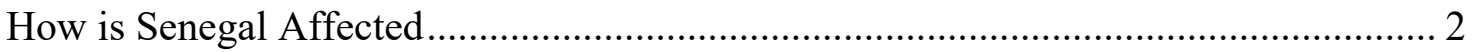

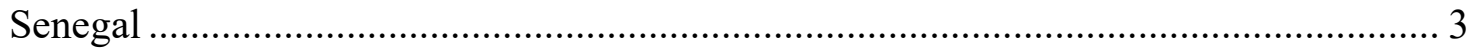

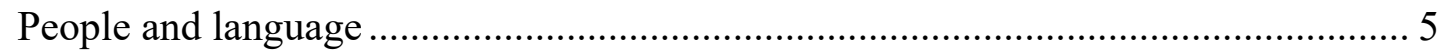

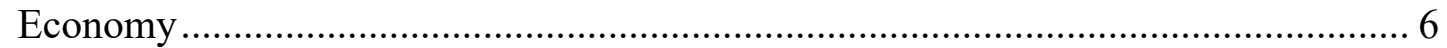

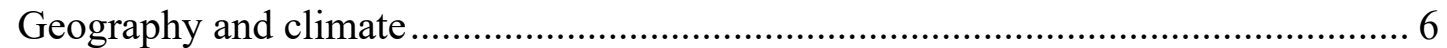

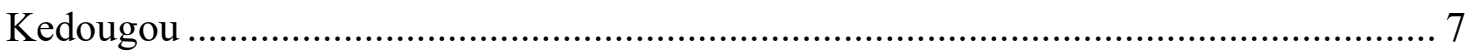

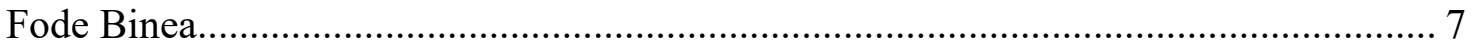

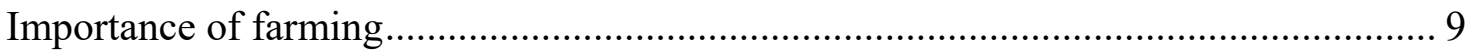

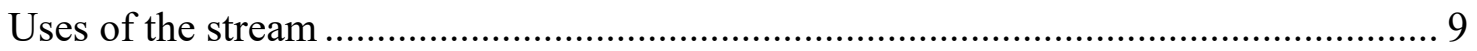

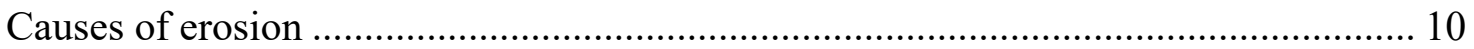

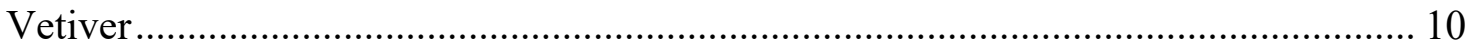

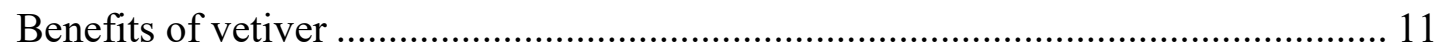

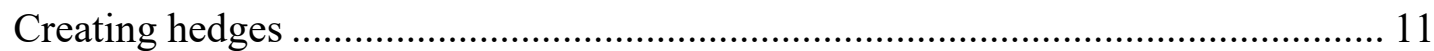

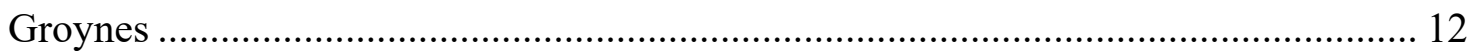

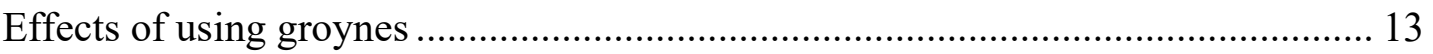

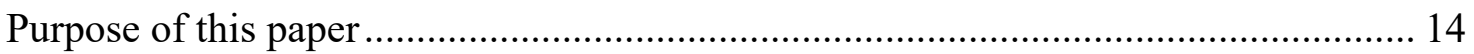

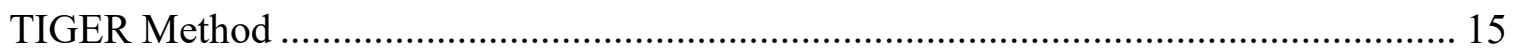

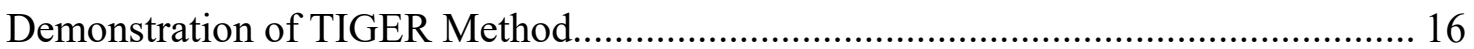

Description of demonstration site ..................................................................... 18

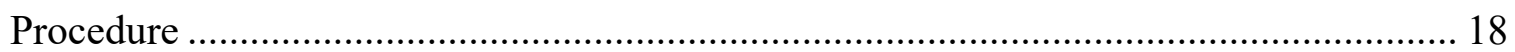

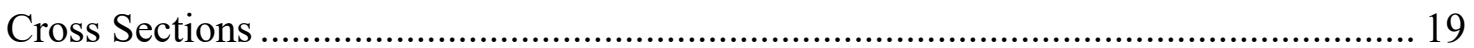

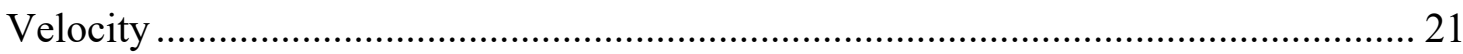

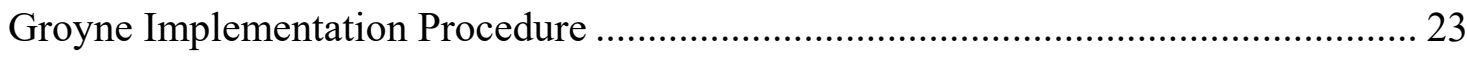

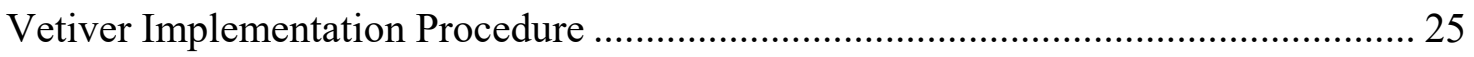

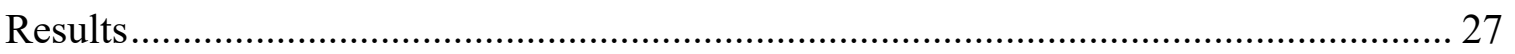

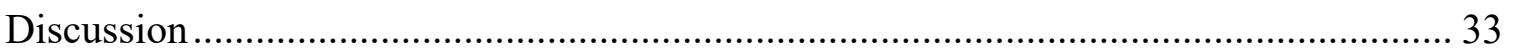


Conclusion

34

References...

36

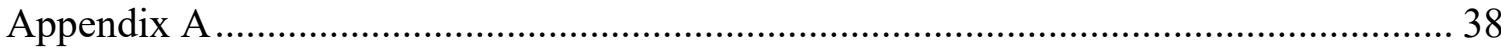

Appendix B 


\section{List of Figures}

Figure 1. Map of Africa showing where Senegal is (Adapted from Google Maps)

Figure 2. Map of Senegal and its regions. Image source:

https://commons.wikimedia.org/wiki/File:Senegal,_administrative_divisions_-

_en_-_monochrome.svg. See Appendix B for Full attribution and copyright

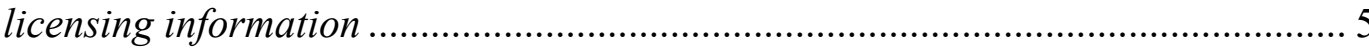

Figure 3. Breakdown of language groups in Senegal (adapted from Leclerc, 2015) ....... 6

Figure 4. Study site, Fode Binea, and its surrounding cities. Region of Kedougou is encompassed in the red box (Image source: Google Earth) ................................ 8

Figure 7. Different types of groynes (image adapted from Pitroda, 1994)..................... 13

Figure 8. Swirling vortices created by groynes in a stream (photo created by author) ... 14

Figure 9. Stream flow lines interrupted by groyne placement (photo adapted from

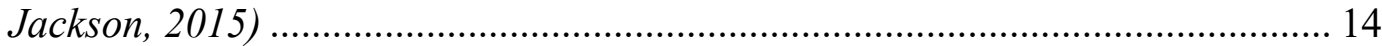

Figure 5. Erosion mechanisms (image created by author) .......................................... 15

Figure 6. Implementation of the TIGER method (image created by author) ................... 16

Figure 10. Position of cross sections around the test site (Ariel photo obtained from ESRI Basemaps, diagram created by author in ArcGIS)........................................... 17

Figure 11. Land cover/Land use surrounding the test site (Ariel photo obtained from ESRI Basemaps, diagram created by author in ArcGIS )................................ 18

Figure 12. Extent of entire stream reach and where each cross section is located, and boundary of village to show for reference. (Ariel photo obtained from ESRI Basemaps, diagram created by author in ArcGIS )

Figure 13. Helpers using the Egyptian Water Level pointing at the water elevation on each stick. (photo by author)

Figure 14. Velocity contours at stream cross sections: (left) in a relatively straight section of channel, and (right) at a bend in the channel. In both cases, V4>V3>V2> V1. Adapted from Gordon, McMahon, \& Finlayson, 1992

Figure 15. Vertical Velocity Profile of a stream channel. Adapted from Gordon, McMahon, \& Finlayson, 1992. 
Figure 16. Photo of 2 groynes built and placed at the end of the test site. (photo by author).

Figure 17. Layout of groyne placement in test area (figure by author). 25

Figure 18. Vetiver grasses spaced out at $20 \mathrm{~cm}$ spacing along the bank (photo by author). 26

Figure 19. Layout of vetiver grass placement at test site (figure by author). 27

Figure 20. Precipitation data at the Fode Binea Rain Gage and times of TIGER implementation and cross section data collection. 28

Figure 21. Cross section data for all times at a location upstream of the TIGER Method

deployment.

Figure 22. Stage-vs.-velocity graph upstream of the TIGER Method installation.

Figure 23. Cross section data at the location of the TIGER Method implementation location. 30

Figure 24. Cross section data downstream of the TIGER Method implementation site... 32 Figure 25. Stage-vs-velocity data downstream of the TIGER Method location. 33

Figure A.1 Layout of entire stream in study with each cross-section location labeled (photo by author) 38

Figure A.2 Cross section data at the Top of Reach location. ......................................... 39

Figure A.3 Stage-velocity data downstream of the Top of Reach location. ..................... 39

Figure A.4. Cross section data at the Downstream of Top of Reach location. 40

Figure A.5 Stage-velocity data downstream of the Downstream of Top of Reach location. ..................... 40

Figure A.6 Cross section data at the $2^{\text {nd }}$ Downstream of Top of Reach location. 41

Figure A.7. Stage-velocity data downstream of the $2^{\text {nd }}$ Downstream of Top of Reach location. 41

Figure A.8. Cross section data at the $3^{\text {rd }}$ Downstream of Top of Reach location. 42

Figure A.9. Stage-velocity data downstream of the $3^{\text {rd }}$ Downstream of Top of Reach location. 
Figure A.10. Cross section data at the Upstream of the Big Erosion Curve location..... 43

Figure A.11. Stage-velocity data downstream of the Upstream of the Big Erosion Curve

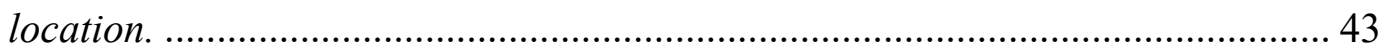

Figure A.12. Cross section data at the Big Erosion Curve location. ............................... 44

Figure A.13. Cross section data at the Downstream of the Big Erosion Curve location. 45

Figure A.14. Stage-velocity data downstream of the Downstream of the Big Erosion

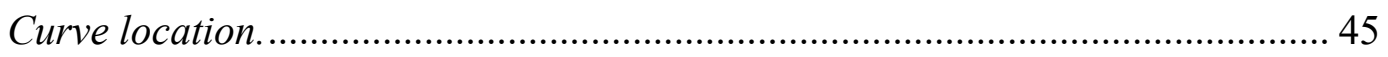

Figure A.15. Cross section data at the Upstream of the TIGER Method location.......... 46

Figure A.16. Stage-velocity data downstream of the Upstream of the TIGER Method

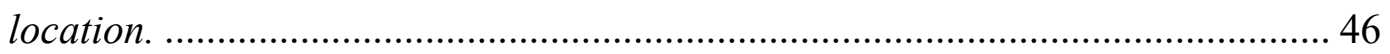

Figure A.17. Cross section data at the Middle of TIGER Method location ..................... 47

Figure A.18. Cross section data at the downstream of TIGER method location.............. 48

Figure A.19. Stage-velocity data downstream of the TIGER Method location............... 48

Figure A.20. Cross section data at the $2^{\text {nd }}$ Upstream of the End of Reach location. ....... 49

Figure A.21. Stage-velocity data downstream of the $2^{\text {nd }}$ Upstream of the End of Reach

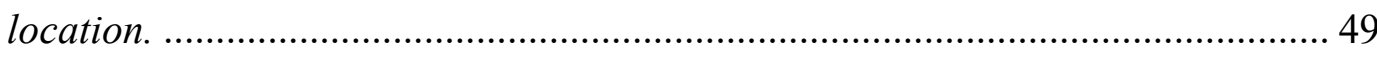

Figure A.22. Cross section data at the End of Reach location ...................................... 50

Figure A.23. Stage-velocity data downstream of the End of Reach location. .................. 50 


\section{List of Tables}

Table 1. Cost of cropland degradation. Adapted from Sow, Nkonya, Meyer, \& Kato, 2016 (ASFM= Integrated Soil Fertility Management; BAU=Business as Usual or the traditional farming practices .................................................................. 3

Table 2. Coefficient to correct surface float velocities to mean channel velocities.

Source: Reclamation, 2001

Table 3. Percent changes in cross section area upstream of TIGER Method installation. (Red and green shading denote positive (more erosion) and negative (less erosion) change, respectively.

Table 4. Percent changes between when cross sections taken at TIGER Method installation site. (Green shading denotes negative change.)

Table 5. Percent changes between cross sections measurements at section downstream of TIGER Method installation. (Red and green shading denote positive and negative change, respectively.). 32 


\section{Acknowledgements}

I would first like to thank my advisor, Dr. Brian Barkdoll, for always pushing me, allowing me to think differently and always encouraging me to keep going. I would like to also thank my committee, Dr. Robert Handler, and Dr. Audrey Mayer for the continuous support during my service and the constant reminder that "I don't need to reinvent the wheel."

I would like to thank my Mom, Dad, Paige and Lindsey for always being a phone call away, even though the service was never good and there was always a delay. But there was always support and a push to keep doing what I am doing and trying to stay a little bit sane.

I would like to thank all my volunteer friends that let me rant about my research to them. Especially Claire Brisse, Ellen Hendrix, Archie Creech, and Andrew Baer. Without you all I would not have been able to get any of these measurements. Especially during hot season in the middle of the day and everyone always asking what we are doing. I nin sege kende kende!

I would like to thank Dembo Keita, Bala Keita, Mosori Keita, Fode Keita, and Tete Keita for helping me with all the manual labor and measuring random things that probably didn't make sense. For helping the crazy white kid that was always in the stream. Thank you for helping me carry rocks to build the groynes and teaching me how to work hard. I would also like to thank Mamadou Diallo and Diankunda Damba for allowing me to do research on your field and for not giving up on me. You all believed in me when other people did not and pushed me to do the best that I could. And thank you for all the fun conversations and laughs we had in the rice fields. 


\begin{abstract}
River erosion is a problem all over the world. The effects of river erosion are especially hard for farmers in developing countries, where the river is an important part of their farming practices and daily lives. A case study was done in the small village of Fode Binea in Senegal, West Africa to reduce this stream erosion. A new hybrid approach, Technology for Integrated Groyne-Vetiver Erosion Reduction (TIGER) method, was developed. The method includes combining groynes at the toe of the riverbank to reduce toe erosion in the channel and planting a buffer strip with vetiver grass to reduce erosion caused by over land flow. Groynes of large rocks were installed at a riverbend with particularly high erosion. Vetiver grass was installed in a buffer strip along the top of the outside bend of the river. Erosion was measured for several months. It was found that there was a reduction in stream area during moderate flow events, thereby indicating erosion reduction. The vetiver grass did not take as fast as hoped but did show promise to taking root and filling in a full buffer strip. Further study should be undertaken to fully understand how the stream preforms under normal conditions as well as monitoring the new method once it is implemented. Therefore, this method shows promise of reducing stream erosion since it works, is low-cost, and made of inexpensive local materials.
\end{abstract}




\section{Introduction}

Throughout history, people have consolidated and inhabited near streams and rivers to gain access to the necessity of life: water. People have built up communities surrounding water for living or for food. However, it is such inhabitation and building that has started to change the rivers. Rivers and streams have become much more fragile as land is being clear cut for fields and becoming impervious, which is adding more water or runoff to the stream networks than can be handled.

Land degradation due to erosion has a huge effect on the whole country of Senegal. People are forced to work harder on land that is degraded and washing away for much less in return. The causes of erosion include many factors such as deforestation, grassland degradation, land use/cover change, salinity, and other human activities. All these actions lead to disruption to the natural environment, leaving soils exposed to the elements which cause larger amounts of soil lost.

Deforestation can be seen to Senegalese people as making more room to live or work. Lands are cleared for charcoal production, agriculture, mining, and urbanization. Traditional cooking puts high demands on the country's forests with $45 \%$ of the energy demand met by firewood (with 31\% from firewood and 14\% from charcoal) even though the price has more than doubled in the past ten years. The urban area of Dakar is now demanding firewood and charcoal from up to $500 \mathrm{~km}$ away (Energypedia, 2018). As much as $60 \%$ of the total forested area in Senegal is designated for charcoal production, whereas only $18 \%$ is protected or for conservation. The creation of cropland has also aided in deforestation. From 2001-2009, cropland has increased by $175 \%$, mainly for groundnut production (Sow, Nkonya, Meyer, \& Kato, 2016). With this increase in groundnuts, monoculture has been performed year after year with $50 \%$ of all lands dedicated to this crop. Peanuts are planted in the same fields, which depletes the soil of its nutrients and drastically lowers production. Once production has hit an all-time low, the field is abandoned and left as non-arable land (Gundlach, 2015). Due to all these actions, deforestation leads to an annual forest loss of $0.5 \%$ for the country (Energypedia, 2018).

Another primary activity that accelerates land degradation is land use/cover change. Land degradation is the act of changing the original land cover to a use that is more desirable but, in the process, also causing increased runoff and soil erosion, which can end up in streams. The main change that is taking place is changing grasslands to cropland. This change is taking a high ecological value grassland biome, which holds soil back from the wind and keeps moisture in and converting it to a low value biome that will only be used part of the year. In the past, grasslands covered $72 \%$ of the total land area of Senegal but has dropped by $21 \%$ in 2009 (Sow et 1. 2016). This main drop is partially since croplands have increased so much. Making up $72 \%$ of land cover, 
grasslands in Senegal play a vital role in the landscape by holding soil and protecting it from natural processes. Grasslands provide areas with protected soils which stay moist longer, as well as a diversity in animals to the area. Between 1982 and 2006, 20\% of the grassland was degraded and $36 \%$ of the sparse vegetation was reduced. The loss of this grassland and vegetation exposes the land and soil to the harsh wind and water erosion. Bush fires play another role in the loss of grasslands. Bush fires are normally started by locals. This practice is normally done to get rid of the tall weeds from the previous rainy season, to be able to see predators in the bush, be proactive and keeping fires from coming into the village or field, or the creation of new crop or garden land. Because of these reasons, it is estimated that an average of 169,000 hectares of grasslands are burnt per year (Sow et al., 2016). Grassland burning results in ash, which could either infiltrate into the soil and thereby add nutrients or could be washed off by overland flow increased by the elimination of the grass.

\section{How is Senegal Affected}

Degraded land affects everyone in the country, no matter the profession or lifestyle. $65 \%$ of the agricultural land is degraded (Sow, Nkonya, Meyer, \& Kato, 2016).

Approximately $22.2 \%$ of Senegal's population lives in degraded areas. This means that by living in these degraded areas, people struggle to work the lands, develop the area or even living their day to day lives. $77 \%$ of all this land degradation is due to water erosion (Planchon \& Dieye).

With all this land degradation, farmers must work harder in order to gain enough crop yield to provide for themselves. Subsistence farming is the main activity that occurs in Senegal. Farmers have to walk further into the bush to create an area to farm. By doing so, farmers abandon the old fields, leaving them barren and degraded, and causing them to clear an area to create a new area, which opens the area up to the extreme elements. Crop productivity has decreased dramatically also due to these degraded agriculture lands. Table 1 shows the decrease in field crop yields over the last 10 years. Integrated Soil Fertility Management (ISFM) is a practice using both mineral and locally-available soil amendments that has been taught to farmers to gain better yields in place of Business as Usual (BAU) or the traditional farming practices (IFDC 2019). Table 1 shows the productivity differences between the traditional farming practices and how much better it would be to adopt the ISFM practice 
Table 1. Cost of cropland degradation. Adapted from Sow, Nkonya, Meyer, \& Kato, 2016 (ASFM= Integrated Soil Fertility Management; BAU= Business as Usual or the traditional farming practices

\begin{tabular}{|c|c|c|c|c|c|}
\hline \multirow[b]{2}{*}{ Crop } & \multirow[b]{2}{*}{ Technology } & \multicolumn{2}{|c|}{ Average Yield } & \multirow[b]{2}{*}{$\begin{array}{l}\text { Percent } \\
\text { Change }\end{array}$} & \multirow{2}{*}{$\begin{array}{l}\text { Cost of Land } \\
\text { Degradation } \\
\text { (US\$ } \\
\text { million) }\end{array}$} \\
\hline & & $\begin{array}{c}\text { First } \\
10 \\
\text { years }\end{array}$ & $\begin{array}{c}\text { Last } \\
10 \\
\text { years }\end{array}$ & & \\
\hline \multirow{2}{*}{ Irrigated Rice } & ISFM & 7.5 & 6.2 & $17.4 \%$ & 12.45 \\
\hline & BAU & 6.7 & 5.1 & $24.6 \%$ & \\
\hline \multirow{2}{*}{ Rainfed Rice } & ISFM & 7.8 & 4.9 & $21.4 \%$ & 48.53 \\
\hline & BAU & 7.7 & 4.8 & $35.0 \%$ & \\
\hline \multirow{2}{*}{$\begin{array}{l}\text { Rainfed } \\
\text { Maize }\end{array}$} & ISFM & 2.4 & 1.9 & $36.9 \%$ & 41.78 \\
\hline & BAU & 1.9 & 1.3 & $38.1 \%$ & \\
\hline Total Cost & & & & & 102.76 \\
\hline
\end{tabular}

Rice is a major crop that is grown in the country and a crop that Senegalese use to cook traditional meals. Because of the increase in land degradation, the potential of $\$ 48.53$ million is being lost in rainfed rice production. This alone shows how the same amount of work that is put in year after year does not equal the same amount of yield. Farmers must work harder every year to just have a better year than the last.

Since the main erosion activity is caused by water erosion, this means that more sediment is being washed away from the lands. After it is washed away from the land, it is then deposited into the streams when there are low flow events. As more sediment is deposited in the stream, the stream bed will rise over time, causing the water levels to rise. Once these water levels have risen, there is less land area available to be farmed.

\section{Senegal}

Senegal is the western most country in Africa as shown in Figures 1 and 2. It is bordered by the Atlantic Ocean to the west, Mauritania to the north, Mali to the east, Guinea and Guinea-Bissau to the south, and is surrounding the Gambia in the middle. The capital is Dakar on the most western side of Senegal. Senegal is approximately $196,722 \mathrm{~km}^{2}$, which is about the same size as South Dakota. (CIA, 2019). 


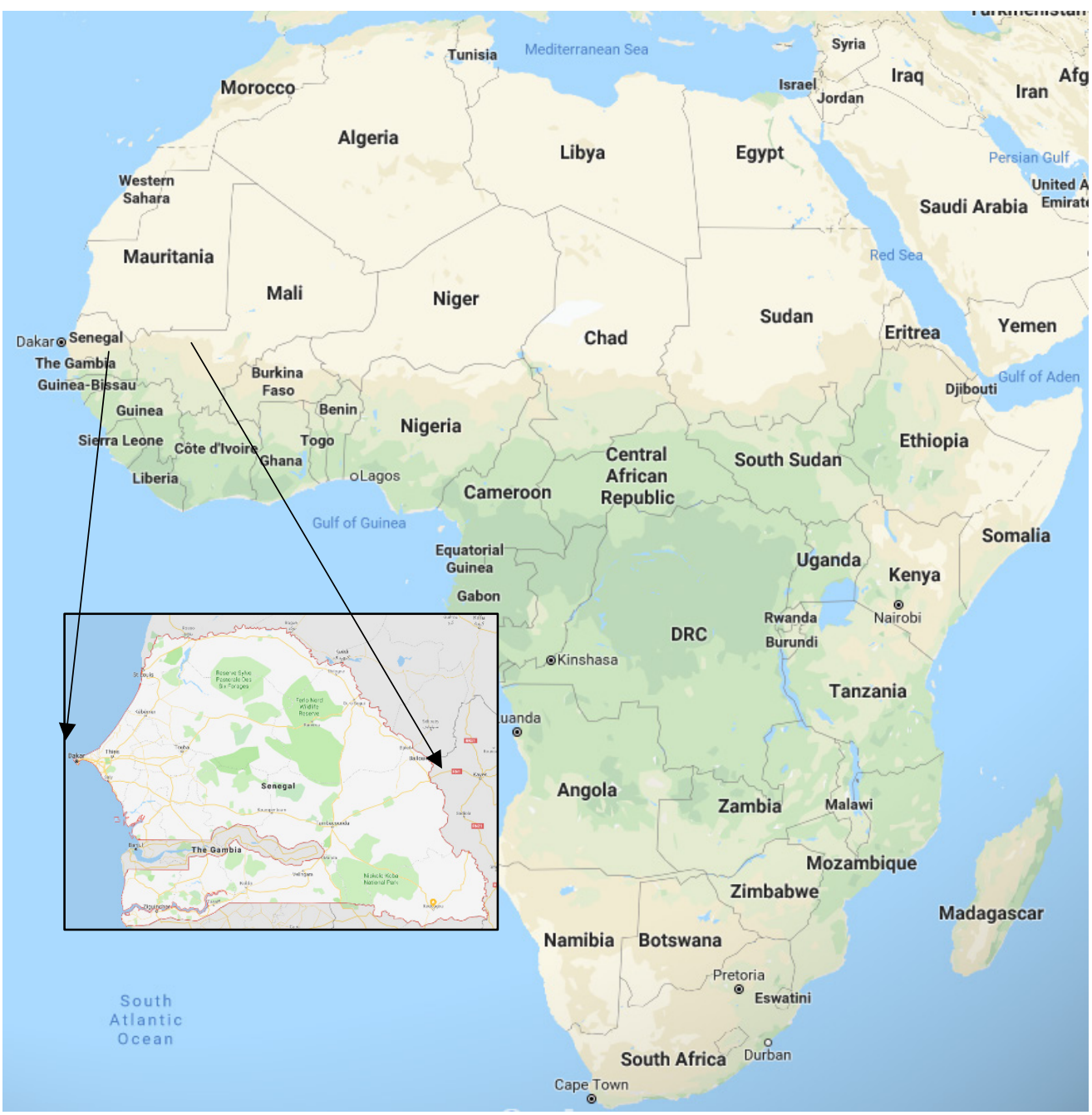

Figure 1. Map of Africa showing where Senegal is (Adapted from Google Maps) 


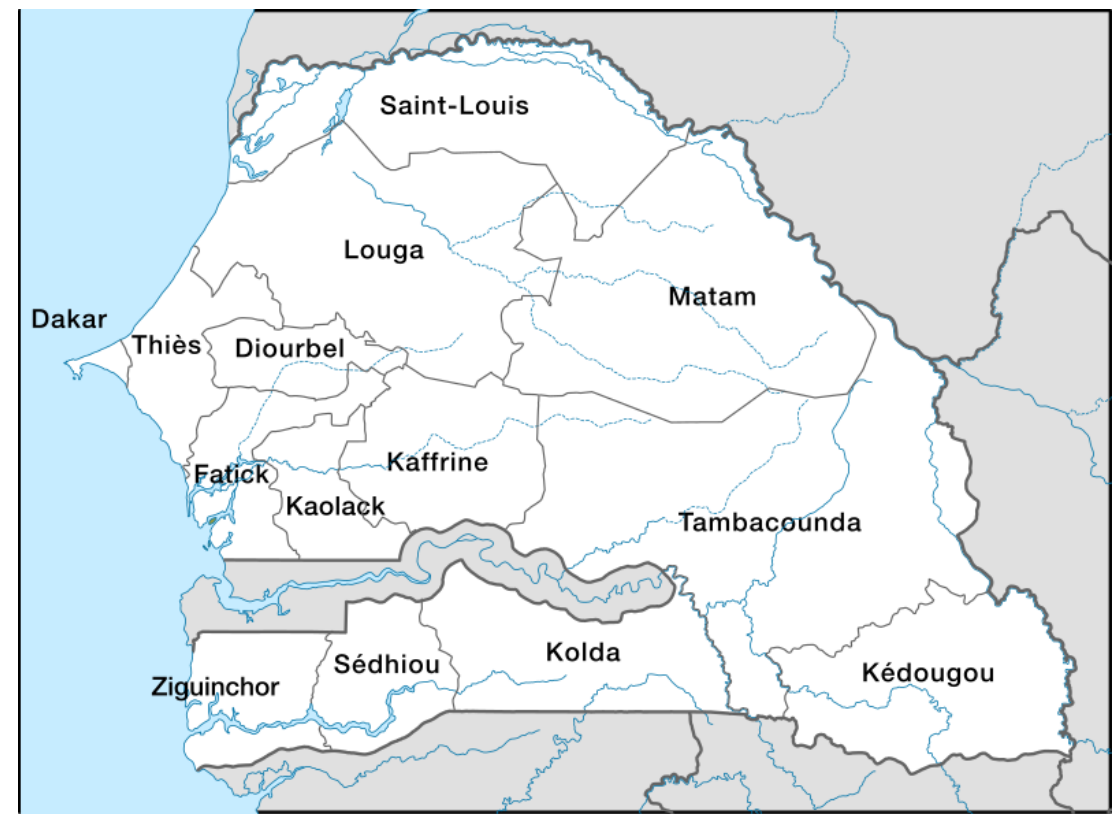

Figure 2. Map of Senegal and its regions. Image source:

https://commons.wikimedia.org/wiki/File:Senegal,_administrative_divisions_-_en__monochrome.svg. See Appendix B for Full attribution and copyright licensing information

\section{People and language}

The country of Senegal is home to 15.02 million people with a growth rate of $2.36 \%$. Most of that population is located in the west, where the capital of Dakar is, and decreases to the east. The country is a demographically young country with a median age of 19 years old. Approximately 55.6\% of the country is living in rural conditions (Clark, Camara, \& Hargreaves, 2019). The amount of people living below the poverty line is $46.7 \%$ of the population (CIA, 2019).

French is the official language, but not the main language, only being taught in the schools and spoken in businesses. Only $15 \%-20 \%$ of men and $1 \%-2 \%$ of women speak French (Leclerc, 2015). Most Senegalese first learn the local language from their families, which is often different from the official French language. The country has many different local languages scattered throughout such as Wolof, Pular, Serer, Jola, and Mandinka (AfricaW: Africa and the World, n.d.) as seen in Figure 3. Each of these different language groups have their own distinct cultures and practices. Even with so many different culture groups in Senegal, Islam is still the main uniting force between them all with $95 \%$ of the population practicing this religion (Clark, Camara, \& Hargreaves, 2019). 


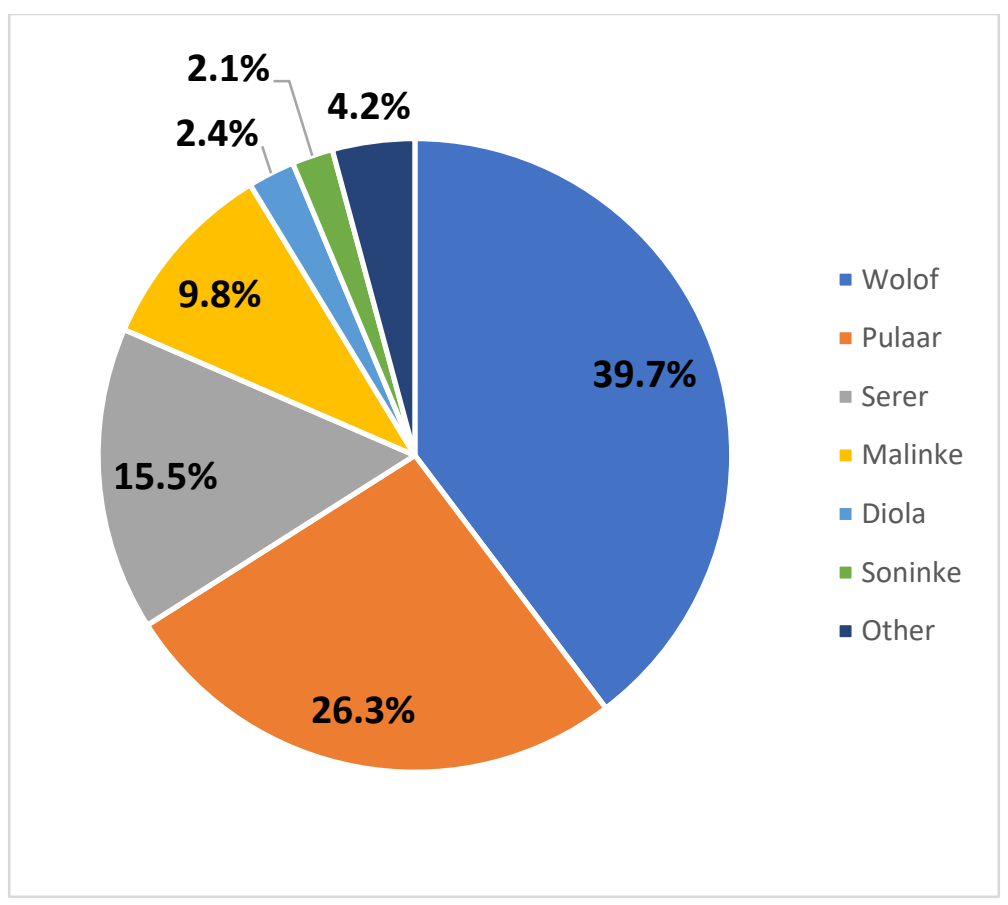

Figure 3. Breakdown of language groups in Senegal (adapted from Leclerc, 2015)

The people of Senegal face many challenges today such as health, poverty, and the environment. Health issues can affect how people can work to support their families. Health challenges such as bacterial and protozoal diarrhea, hepatitis A, malaria, and schistosomiasis, can all make the person's body weak and unable to work to provide. Even though Senegal has an abundance of natural resources, $46.7 \%$ of the population is under the poverty line (CIA, 2019). Along with all the poverty and health challenges, the surrounding environment makes living very difficult. Droughts and seasonal floods, deforestation and desertification, overgrazing, soil erosion, overfishing, and weak environmental protective laws make farming difficult when the soil is bare and depleted. Herding when there are limited places for herds to feed is also detrimental to vegetation. (AfricaW: Africa and the World, n.d.).

\section{Economy}

Senegal's main sources of employment are mining, construction, tourism, fisheries, and agriculture. The main exports are fish, peanuts, petroleum products, phosphates, and cotton, whereas the main imports are food and beverages, capital goods, and fuels (CIA, 2019).

\section{Geography and climate}

Senegal is a flat country for the most part. It sits in the transitional zone called the Sahel, where the Sahara Desert is to the north and Sudanian Savanna is to the south. The Sahel runs through the northern part of Senegal. This area is very hot and dry, getting about 14 
inches $(36 \mathrm{~mm})$ of rainfall a year. Whereas the Sudanic zone, or the southern part of the country, is vastly different. It is a very hot and humid climate, getting rainfall that averages between 29 inches $(740 \mathrm{~mm})$ to 39 inches $(990 \mathrm{~mm})$ (Clark, Camara, \& Hargreaves, 2019). The southeastern region is at the foothills of the mountains of Guinea which results in many more rain events.

\section{Kedougou}

The region of Kedougou is in the far south east corner of Senegal bordering the foothills of the Guinea mountains and Mali. This region broke off from the Tamacounda region in 2008 to become its own region (Revolvy, n.d.). Kedougou is home to 151,357 people (City Population, n.d.) where the main local languages are Malinke and Pulaar. There are even more remote local languages that are scattered throughout this region. Kedougou is known for long rainy seasons and many trees and mountains. The main activity in this region is subsistence farming during the rainy season, and gold mining in the dry season.

\section{Fode Binea}

Fode Binea is a small rural Malinke village in the region of Kedougou and department of Saraya as shown in Figure 4. The village of Fode Binea is about $70 \mathrm{~km}$ northeast of Kedougou city and about $8 \mathrm{~km}$ southeast of Saraya. There are about 200 people living in this village with their main activity is farming during the rainy season. During the drier months of the year, people will do some small-scale gardening to take the produce to market for money or to add to their dishes. Other activities that are included in this village are wood working, hunting, animal husbandry, and the young men going to the gold mines. The households are usually made up of many mud brick round or square huts with straw roofs that house the large families. 


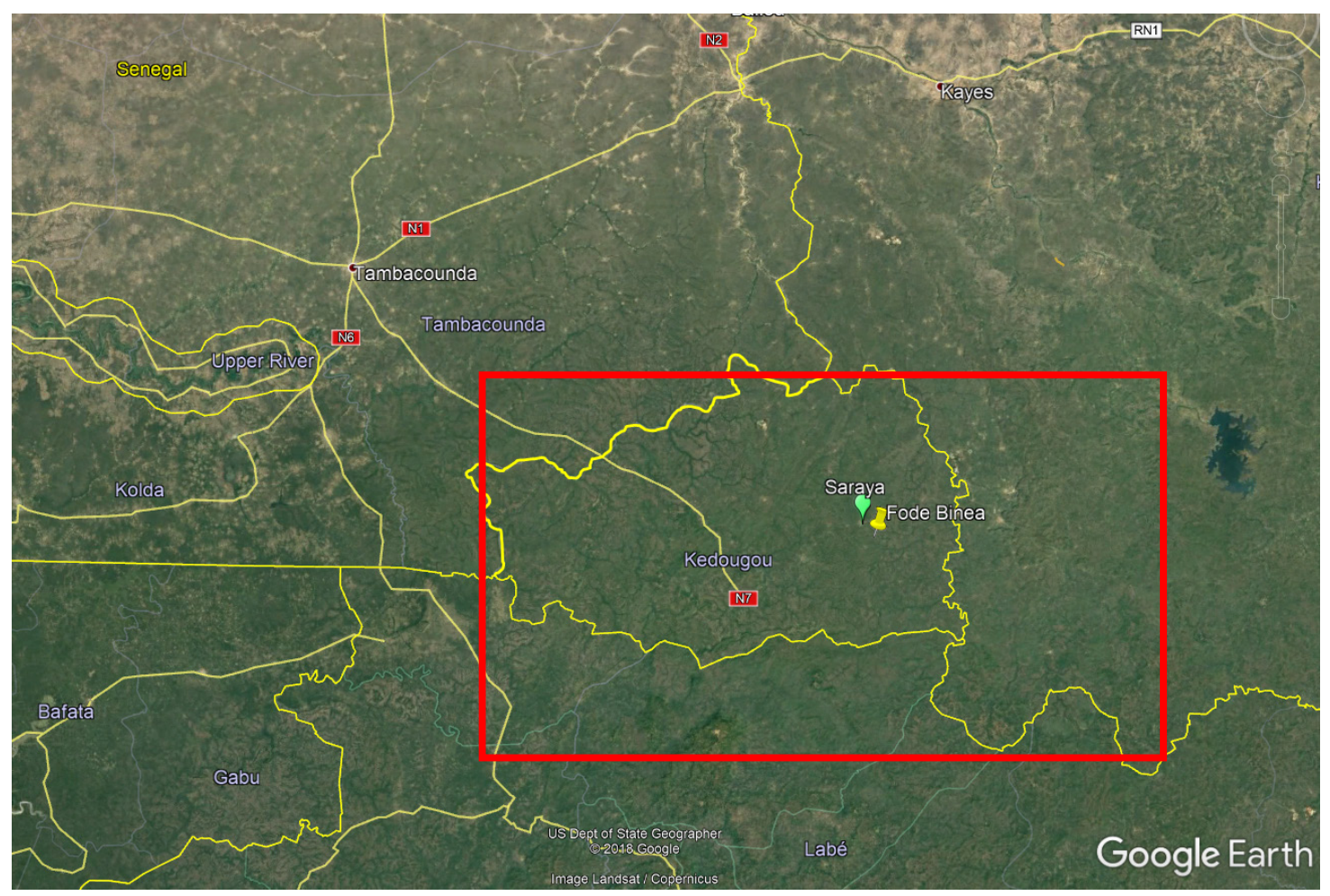

Figure 4. Study site, Fode Binea, and its surrounding cities. Region of Kedougou is encompassed in the red box (Image source: Google Earth)

There is a small seasonal stream that runs behind the village where many farmers' fields are located. Everyone in the village uses this stream in some way. The farmers use this stream mainly to help them grow rice. The rice is planted on the banks of the stream at the beginning of the rainy season to allow it to sprout and root into the ground before the heavier rains come. When the heavier rains come and the stream is full, men take a break from farming every once and awhile to go fishing on the stream to provide some meat for their families. Once the stream has gone down some, men will build fish dams along the stream that will catch fish in small hand-built "torpedoes" nearly every day. Then once the rains have ended and the stream is starting to dry up, small pools are left that are full of fish with nowhere to go. Certain days will occur when the all the men and boys in the village will go to the small pools with handmade nets and scoop up all the fish that are trapped. Additionally, during this time, women will make small gardens near the stream so that they can walk to the stream to gather water for their plants. The women also use the stream to wash clothes and dishes and to bathe themselves and their kids. It is much easier to bring clothes and dishes to the stream and wash everything there, than to carry buckets full back to the compound to do all the work there. At the same time, utilizing the stream serves as a social time for the women to gather and do work together. All in all, this stream is very important to all members of this village. 


\section{Importance of farming}

Subsistence farming is the main activity during the rainy season in Senegal. The rainy season in Kedougou is usually from May to November, so all of the work to be able to feed a family for an entire year has to be done in this short amount of time. The typical crops that are grown in this area are: peanuts, corn, rice, beans, and fonio (a traditional West African grain). The rice is usually planted on the banks of streams to be able to get the flood/drain cycle for maximum growth. The rest of the crops are planted on higher ground to protect from high water damaging and flooding out the crops.

Traditional farming practices in this area include clear cutting and plowing. When a farmer clear cuts the field, the entire land that will be farmed has all its trees, shrubs, and grasses cut. Once all of these are cleared out, then all the debris is collected and gathered around unwanted stumps. The collected debris is then lit on fire to get rid of all the matter. This can be a huge issue due to the fact that the fire alone burns all the nutrients that are left over in the field. Clearing all the organic matter from the field does not allow the nutrients to naturally decompose in the field which could in turn give nutrients to the

field. Depleting the land of crops before the rains begin causes greater overland flow and soil erosion.

\section{Uses of the stream}

As mentioned before, streams take pressure off everyday life. The stream will flow through the village about 4-5 months of the year, the rest of the time it is dry. When the stream is dry women are forced to walk to the borehole and gather buckets of water and carry them back to the house. This is done as many times as needed for the women to wash clothes, bathe kids, cook, and drink. During the rainy season, women go to the fields early in the morning and work there all day. The time it takes to gather all the water needed during the day as well as going to the fields and working all day physically and mentally wears people down. Most of the fields are located near the stream. When the stream is flowing, this allows for the women to take a break from carrying water and take clothes to be washed to the stream.

The stream also benefits the people with food. Throughout the rainy season, the men take breaks from working in the fields and go to the stream in hopes of catching a fish to take home for food. This is done by throwing a fishing line in the water with a worm on the end and waiting for a fish to grab on. The other way the men catch fish in the village is wait until the rains have ended for the year and the stream is starting to dry up. As this stream dries up, it creates little pools from the low spots in the stream. Once these pools are formed, fish get trapped. As a village, all the men and children go out and build up temporary dams to keep the fish in a small area and jump in with net and catch all the fish in this small pool.

Even though the stream is only running for part of the year, it plays a huge role in the village with survival and ease of work. 


\section{Causes of erosion}

Further expanding on causes of erosion alluded to before, the main causes of stream erosion in this area are: clear cutting fields near the stream to gain maximum crop area, plowing the fields- and high intensity rainfall events. Farmers will cut down all the trees and shrubs when creating a new field. Usually these fields are located near some part of a stream. When all these trees are cut down, they are piled near existing stumps and burned, getting rid of everything on the surface. This process kills the trees, which then kills all the roots holding all the soil together. After all this area is burned, the farmers will then plow the fields to loosen the soil to aid in better root growth for their crops. They do this by using a donkey or cow to pull a plow the area. Or in some instances, if money is there, a tractor is hired to come, and plow large areas very fast. All this plowing loosens the topsoil, and when the rains come and the stream rises, it can all be washed away due to overland flow. Overland flow occurs when the soil becomes saturated and no more water can infiltrate, therefore making the water flow down the slope, picking up soil particles along the way. As the soil particles are taken away, a small channel is formed, and overland flow combines to that point. As the water accumulates along the way, the velocity of the water will increase.

\section{Vetiver}

Vetiver grass (vetiveria zizanioides) is perennial grass that is in the same family as maize, sorghum, sugarcane, and lemongrass. The locals call vetiver grass "xamaree". The natural habitat for this grass is in wild, damp, low sites, such as swamps or rivers. Although the exact origin of vetiver is unknown, most botanists say that it originates from northern India. It is important to note that there are two types of vetiver grass; one type is from North India which is considered a wild type. This first type creates a fertile seed that is easily sown and germinates, which if not taken care of properly, can become a weed and create long-term problems. The second type is more of a domesticated type from South India and is sterile. This vetiver has been cultivated for many years which has resulted in a nonflowering, non-seeding grass. The only way to plant more is by vegetative propagation. In other words, the only way this type will spread is by humans planting it. (National Research Council, 1993). Vetiver has been used extensively in Africa for many years as well (Rachmeler 2019).

The crown of the plant is slightly underground. This is where the transition between the roots and the stems happens. The crown contains older, dead material as the plant grows. The plant concentrates more energy towards growing new leaves, while the older leaves die off and get trapped in the crown. Along with the dead material, there are also very small rhizomes or shoots that will eventually breech out, but due to the tight knit of a ball the crown is in, they are often turned back on themselves.

The leaves and clums (stem) of vetiver grasses are very strong. The clum is the jointed hollow stem of the grass. It is hard and lignified has nodes that can produce roots. The leaf can grow to ranges of $45-100 \mathrm{~cm}$ long and 6-12 cm wide (Mekonnen, 2000). It is 
these strong and hard stems that gives the plant rigidity, thereby allowing vetiver to prevent erosion (National Research Council, 1993).

The flowers of vetiver grass are very tall reaching up to $1.5 \mathrm{~m}$ high, usually brown or purple in color. The male and female parts are separated, with the male florets being at the top of the flower. Below that the parts of the flower are hermaphrodite (both male and female) (National Research Council, 1993).

The roots of vetiver grass are what gives it its anchoring strength. The huge root mass is intertwined and tap deep into the earth's surface. Roots can reach up to lengths of 3-4 m in depth. This allows them to reach deep into the soil where it is moist, allowing the grass to be much more drought tolerant. This massive anchor allows the plant to withstand and hold up to high velocities in streams and heavy downpours. These roots are very fast-growing allowing the plant to become very stable quickly (National Research Council, 1993). Vetiver grass is also robust in that it will regenerate after having been burned, although cattle and donkeys can sometimes eat the leaves.

\section{Benefits of vetiver}

Vetiver grass has a variety of different uses in both developed and developing countries. The most common benefit is erosion control. The strong clums and leaves create a barrier that will slow down runoff, and sediment and debris will get trapped at the base of the grass. This helps with slowing down and mitigating erosion as it also helps with fertility of the soil. As the debris or organic matter break down next to the grass, it adds beneficial nutrients to the soil.

On the opposite side of the plant, the roots dive deep down, thereby holding in soil. With the roots growing down to a depth of $3-4 \mathrm{~m}$, all of that soil is being held in place to create a stronger berm. Planting this grass along banks of streams will hold the bank in place, giving it more stability.

Cutting the tops of the vetiver grass promotes more tillers or lateral growth. The tops of these cuttings can be used with mulching around the base to keep in moisture. Additionally, these also can be given to animals as food or bedding.

Senegalese locals used to use the roots to make a tea. An unofficial conversation with a local described how the women in the village used to dig up the roots and boil them in water to make a tea. This tea was supposed to help digestion problems. There are many other things that can be made from the leaves of the grass as well, such as thatch for houses and can be spun into ropes.

\section{Creating hedges}

All land has some sort of slope. This means that when rain events happen, that water that lands on the earth must flow somewhere. If enough rain or water collects in an area and 
all runs off together, that could increase velocity. With increased velocity, rifts or valleys will form eventually digging out the soil and causing larger amounts of erosion. This idea becomes very important for farmers regarding how fields are plowed and how crops are planted. If the land gets plowed perpendicular to the contour line, then that will give the water a perfect channel to flow through, completely missing the crops. The high velocity will also cause, depending on the amount of water, sediment and nutrients to be carried off the land, away from the crops and into a larger stream. This can eventually create major rifts within the land resulting in major erosion problems. The method famers plant their crops is also very important. Crops have to be thought about in stages and how they are affected with rainfall. When crops have just germinated, their roots have not fully established, and the body is not strong. So, when rain falls, it will follow the path of least resistance, possibly pulling out crops if they are planted perpendicular to the contour line. But as a crop gets bigger, they start to fill out the land and the roots hold more of the soil back, therefore helping slow down the water when it starts running on the land.

Berms or hedges will slow down runoff and allow it to sink into the ground if they are constructed parallel to the contour lines. Berms can be constructed by digging out the topsoil and placing it just down from the hole, creating a valley. This method is inexpensive due to the fact that all a farmer needs is a digging device to move the soil. The valley that is created can be constructed across the contour allowing the water to be transported to a different location. Over time, the valley will fill in with sediment, causing farmers to rebuild areas, or completely start over when a high rain event overwhelms a berm and subsequently ruins a field (World Bank, 1990).

However, if plants are used for the berm rather than soil, then this could create a sustainable method of erosion protection. Vetiver grass can be planted in place of the topsoil berm. This disturbs a smaller amount of soil which would reduce how much soil could be washed away (World Bank, 1990).

Over time, a berm will form uphill of the vetiver plant. This is caused by the water being forced to slow down once it reaches the vetiver berm. The water will then filter through the plant, causing the sediment in the water to settle out and build up at the uphill side of the plant. The grass will grow through the collected sediment, securing it in place. Because of this process, the berm will stay in place for many years to come and become a permanent feature in the land and still remain effective (World Bank, 1990).

\section{Groynes}

Groynes are man-made structures that are built in the stream to deflect water. They are anchored into the bank and extend out into the middle of the stream. Some are perpendicular to the flow while others are angled to the flow to deflect water away from the bank. Groynes are usually made of stone, trees, or earth and can be solid or permeable. The main reasons for constructing groynes are flood control, improved navigation, and erosion control (Yossef, 2002). 
Description of a groyne can be classified into many different variables: the method and materials of construction, submergence, action on the stream flow, and design shape. When each variable is changed, there can be different effects on the stream.

A groyne can be permeable, which reduces the velocities of the stream by allowing some of the water to flow through, or impermeable or solid which deflects water away from the bank. The permeable groynes are usually constructed from trees whereas solid groynes are constructed using concrete or gabions.

Groynes can be submerged or breaching. A submerged groyne is usually permeable due to the fact that it disturbs less flow, whereas breaching groynes are usually solid. They are designed this way due to the fact that the flow over the top of a solid groyne is very violent and can cause unwanted erosion around the groyne itself.

The angle at which a groyne is placed in a stream can have different effects depending on the orientation. The angle can be classified as attracting, deflecting, or repelling. An attracting groyne points downstream, which allows the stream flow to be attracted to the bank and does not repel the flow to the other bank. A deflecting groyne is usually short and used to protect a local area. A repelling groyne is pointed upstream and is used to repel the flow away from the bank.

The last classification is how each groyne is designed in this demonstration case study. Figure 7 shows all the different ways that groynes can be constructed and each has its own benefits and drawbacks. This is why it is important to understand how each of these classifications works and what effect it has on stream flow (Yossef, 2002).

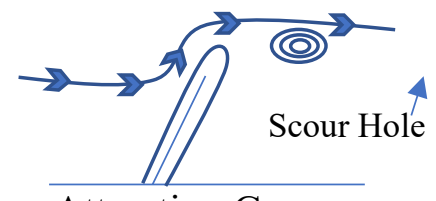

Attracting Groyne

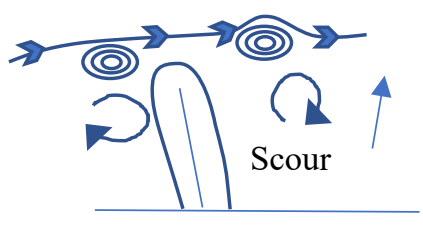

Deflecting Groyne

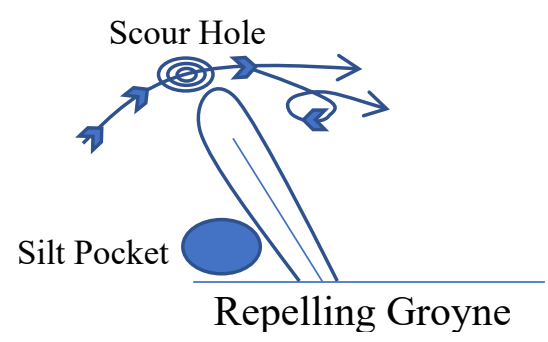

Figure 5. Different types of groynes (image adapted from Pitroda, 1994).

Normally, groynes can be placed in a series to help slow down flow near the banks for a longer stretch, thereby resulting in more sediment deposition. Each groyne can protect three to five times its own length of bank (Strom, 1962).

\section{Effects of using groynes}

The main action that makes groynes so useful is that they interrupt flow streamlines near the bank (Gordon, McMahon, \& Finlayson, 1992). This creates an area of low flow near 
the bank which allows sediment to settle out in this area. This can be very beneficial to the stream as it rebuilds the stream over time. And once sediment has settled out, vegetation can be planted in that area to help secure that sediment and allow it to last a long time.

A big reaction that occurs once groynes are placed are vortices and scour as shown in Figures 8 and 9. Vortices are a mass of whirling fluid in a stream. These can occur when obstructions are added to the stream and the flow lines are interrupted. When a groyne is added, the velocity at that point increases because the channel width is decreased. This points to the need for inspecting and replacing groyne rocks when needed.

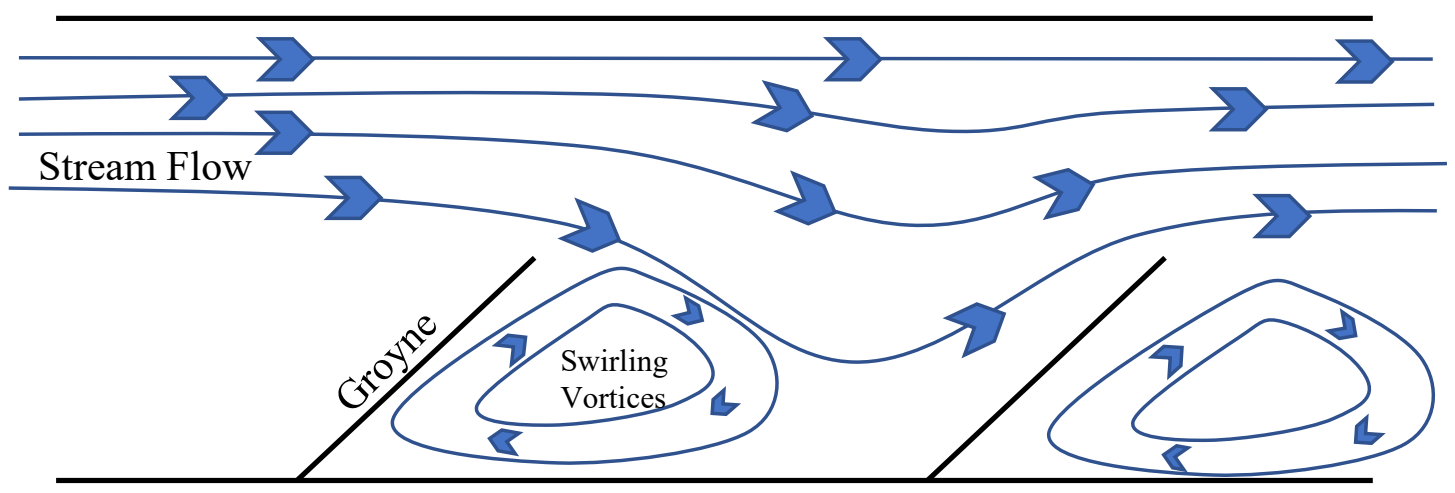

River Bank

Figure 6. Swirling vortices created by groynes in a stream (photo created by author)

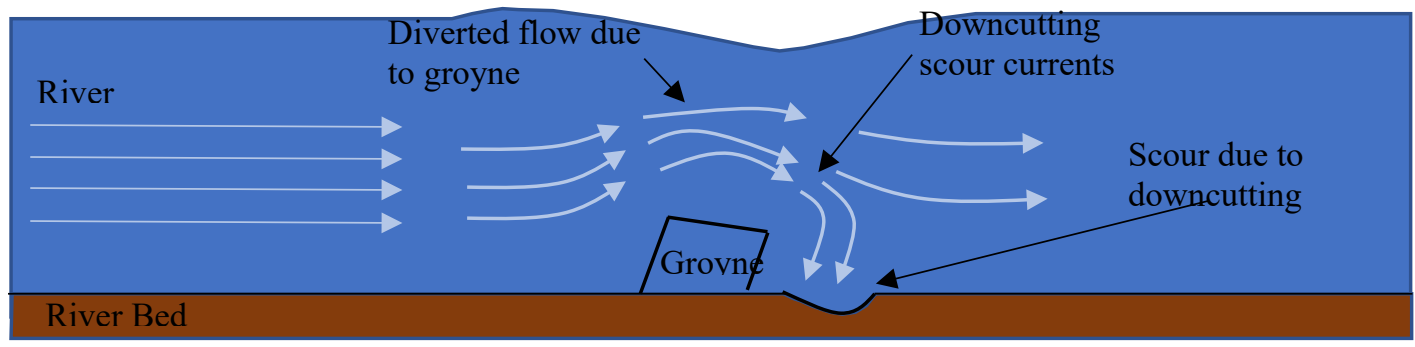

Figure 7. Stream flow lines interrupted by groyne placement (photo adapted from Jackson, 2015)

\section{Purpose of this paper}

The purpose of this paper is to demonstrate a new erosion reduction method that combines two different technologies: buffer strips and groynes. This method could 
potentially slow down stream erosion and allow for more farmland to be available. Implementation of these technologies have been combined and tested on the stream described above to see how they preform together.

\section{TIGER Method}

The Technique for Integrated Groyne-Vetiver Erosion Reduction, or TIGER method, is a hybrid approach combining groyne placement and vetiver cultivation as a hedge to reduce stream and land erosion. These two technologies work together by stabilizing the bank with the roots of the vetiver grass, creating a buffer strip on the surface, and redirecting high velocity stream flows away from critical parts of the streambank toe with the groynes. This combined action results in a stronger, more protected stream bank.

As shown in Figure 5 and mentioned earlier, when precipitation occurs and the ground becomes fully saturated from infiltration, the excess water then flows down slope called overland flow. This overland flow can become problematic when the land is not protected and can then cause impact erosion along the bank due to the overland flow falling into the stream. In the stream also, there is a mechanism called swirling vortices. This occurs in nonuniform sections of channels where the flow lines are interrupted. Having the overland flow falling into the stream along with swirling vortices from steam velocity, extreme erosion can occur at the bottom of the bank.

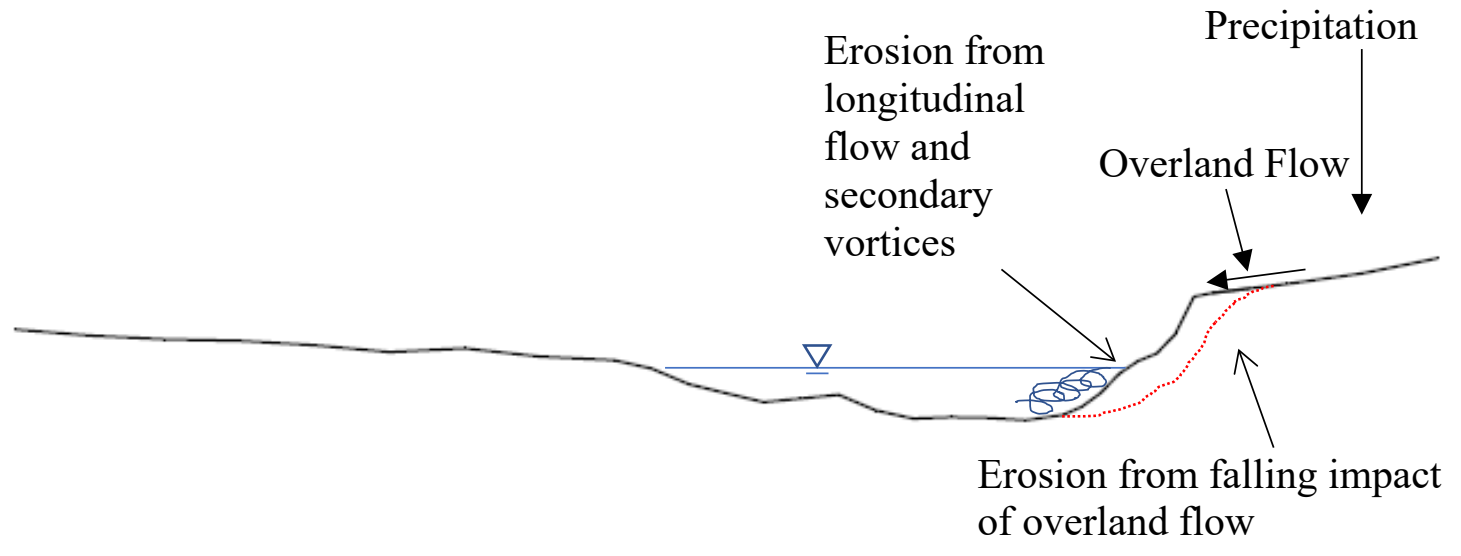

Figure 8. Erosion mechanisms (image created by author)

Implementing the TIGER method by building groynes in the stream bed and planting vetiver grass on the top of the bank is hypothesized here to help slow down impact erosion as shown in Figure 6. The vetiver grass on top of the bank will slow down overland flow by allowing it to infiltrate into the ground. This result is beneficial since 
the vetiver grass will appropriately allow sediments to settle out as it meets the vetiver grass. This correction will help minimize the overland flow that falls into the stream. The groynes redirect the high velocity flows along the bank of the stream into the middle of the stream bed. This action minimizes erosion-inducing swirling eddies which ultimately reduces erosion along the bank toe.

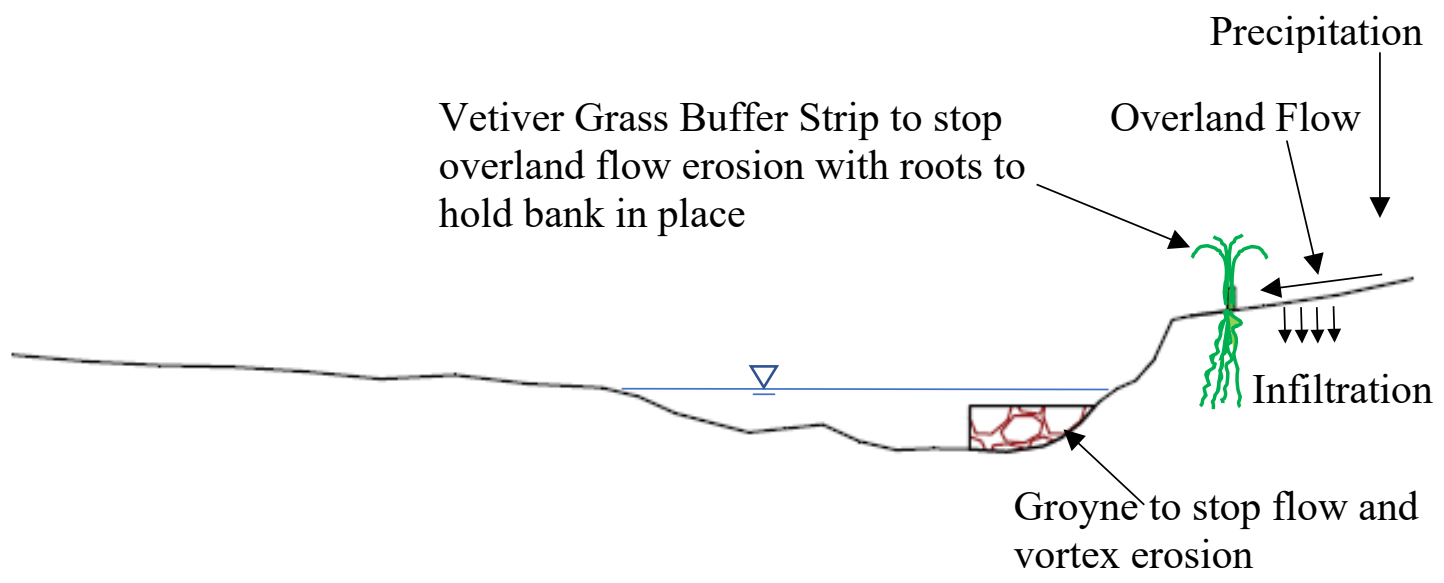

Figure 9. Implementation of the TIGER method (image created by author)

\section{Demonstration of TIGER Method}

The new TIGER Method was demonstrated on a section of the stream. The section of river was a horseshoe bend. There were high levels of erosion around the outside bank of the horseshoe and downstream of the bend. Because of these high levels of erosion and instability, the TIGER method was implemented here. Cross sections elevations were measured both upstream and downstream, to see the change in the stream bed over time. A cross section was also taken in the middle of the horseshoe section, where the TIGER method was implemented, to monitor how the method affected the stream as shown in Figure 10. 


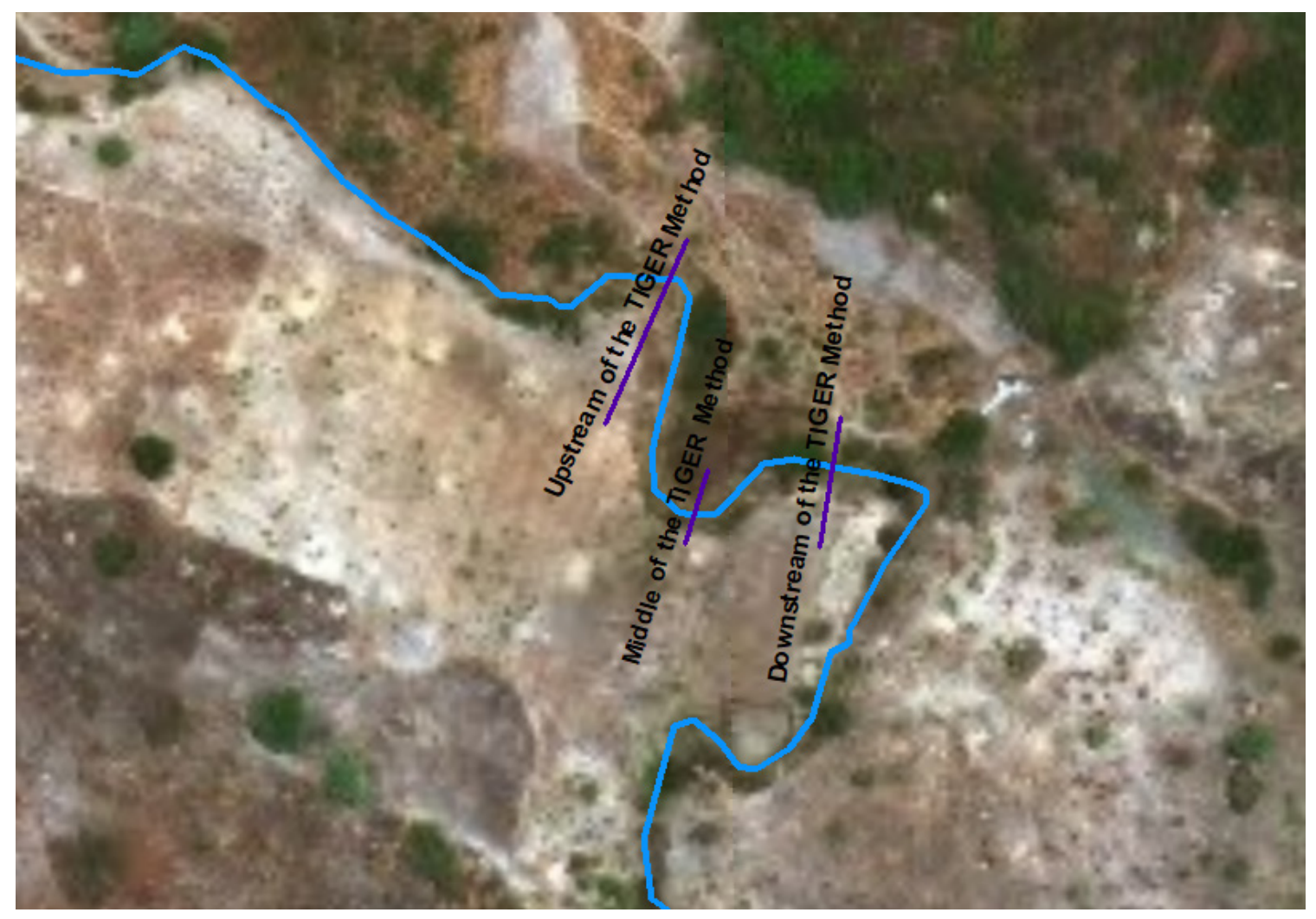

Figure 10. Position of cross sections around the test site (Ariel photo obtained from ESRI Basemaps, diagram created by author in ArcGIS).

The length of stream from upstream cross section to downstream cross section is approximately 90 meters. The section of stream runs through farmland. The right bank has rice fields up to the stream near the upstream and downstream cross sections, and corn fields along the middle cross section. The left bank is more natural, having rice fields around the upstream cross section. There is a little bit of a natural buffer strip left around the middle and downstream cross sections as shown in Figure 11. 


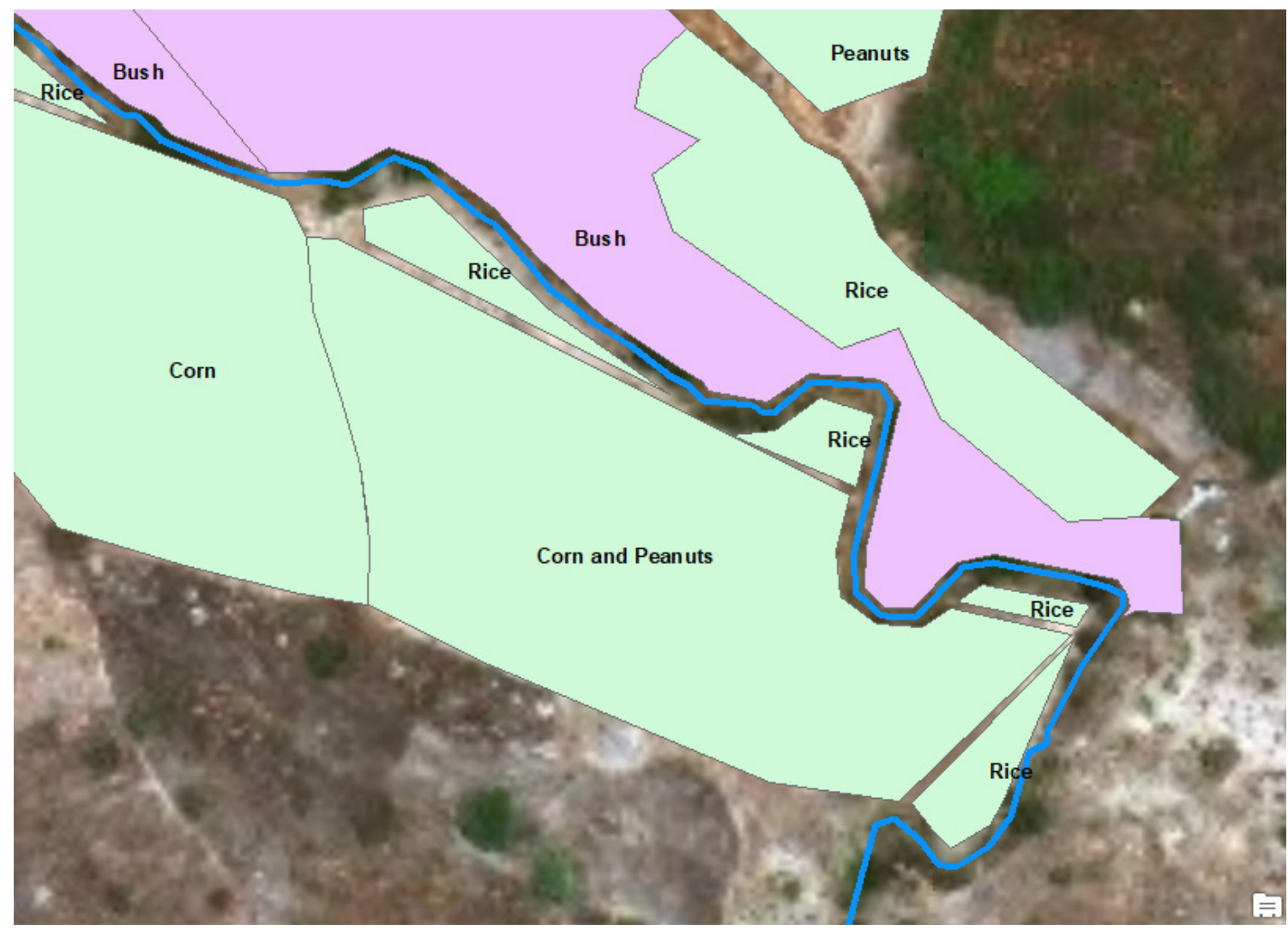

Figure 11. Land cover/Land use surrounding the test site (Ariel photo obtained from ESRI Basemaps, diagram created by author in ArcGIS).

\section{Description of demonstration site}

The channel widths in this section vary from 5-8 meters. In this channel, the velocities vary from $0-0.41 \mathrm{~m} / \mathrm{s}$ upstream with an average of $0.22 \mathrm{~m} / \mathrm{s}$ and $76 \mathrm{~cm}$ stage height. Downstream, the velocities vary from $0-0.92 \mathrm{~m} / \mathrm{s}$ with an average velocity of $0.35 \mathrm{~m} / \mathrm{s}$ and an average of $43 \mathrm{~cm}$ stage height. The sediment is a sandy clay sediment with the average sediment diameter between $0.002-2 \mathrm{~mm}$. The upstream section was more clayey and the downstream was sandier.

\section{Procedure}

Cross sections measurements were taken at 12 separate locations along the stream. Velocities were taken many times throughout the two years to be able to establish stageheight-versus-velocity graphs and gain an understanding of how the stream reacts. Once data had been gathered for one year, a test site was built in which rock groynes were placed in the stream and vetiver grass was planted on top of the bank at one place along 
the stream. Further measurements were taken on the stream as well as in detail around the test site to gain an understanding of how the implementation of the TIGER method affected the stream.

\section{Cross Sections}

Throughout the two years, 12 cross sections were taken. These sections became baselines to be compared over the time. These sections were chosen by getting a wide variety of stream stability conditions on the stream (prevalence of erosion). Some of the sections are healthy streams with very little erosion, while the other sections were unstable and had major erosion problems. There were also sections that fell in between these extremes. The channel was walked many times in the first rainy season to determine where this variety of cross sections could be measured. Most of the sections were chosen for ease of accessibility. Because of this ease of access, some of the sections shared banks with farmer's fields. Due to some thick brush and trees, some long stretches of the stream were not able to be measured. Figure 12 shows the extent of the $2.9 \mathrm{~km}$ river and where the cross sections were taken, along with the village.

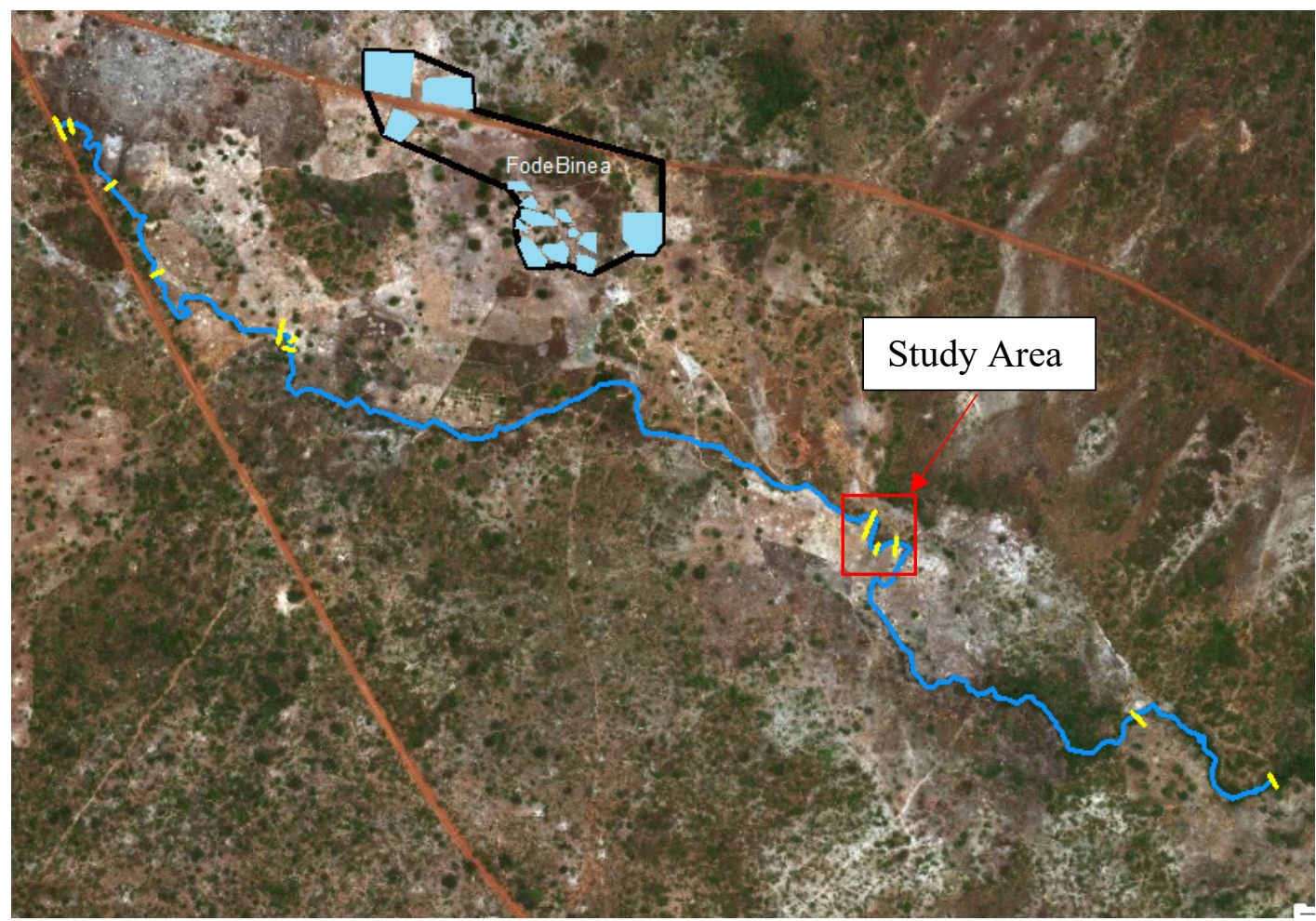

Figure 12. Extent of entire stream reach and where each cross section is located, and boundary of village to show for reference. (Ariel photo obtained from ESRI Basemaps, diagram created by author in ArcGIS)

On all these sections, the Egyptian Water Level or Bunyip Water Level Method was used to measure the change in elevation across the cross section (Lancaster, Rain water Harvesting for Drylands and Beyond: Volume 2, 2010). This method is inexpensive and 
easy to use. The Egyptian Water Level is a device made up of sticks and clear tubing as shown in Figure 13. All the materials were gathered locally. The tubing was 400 CFA $(\$ 0.68)$ per meter, and the sticks were collected locally from a neem tree, whose limbs are very straight.

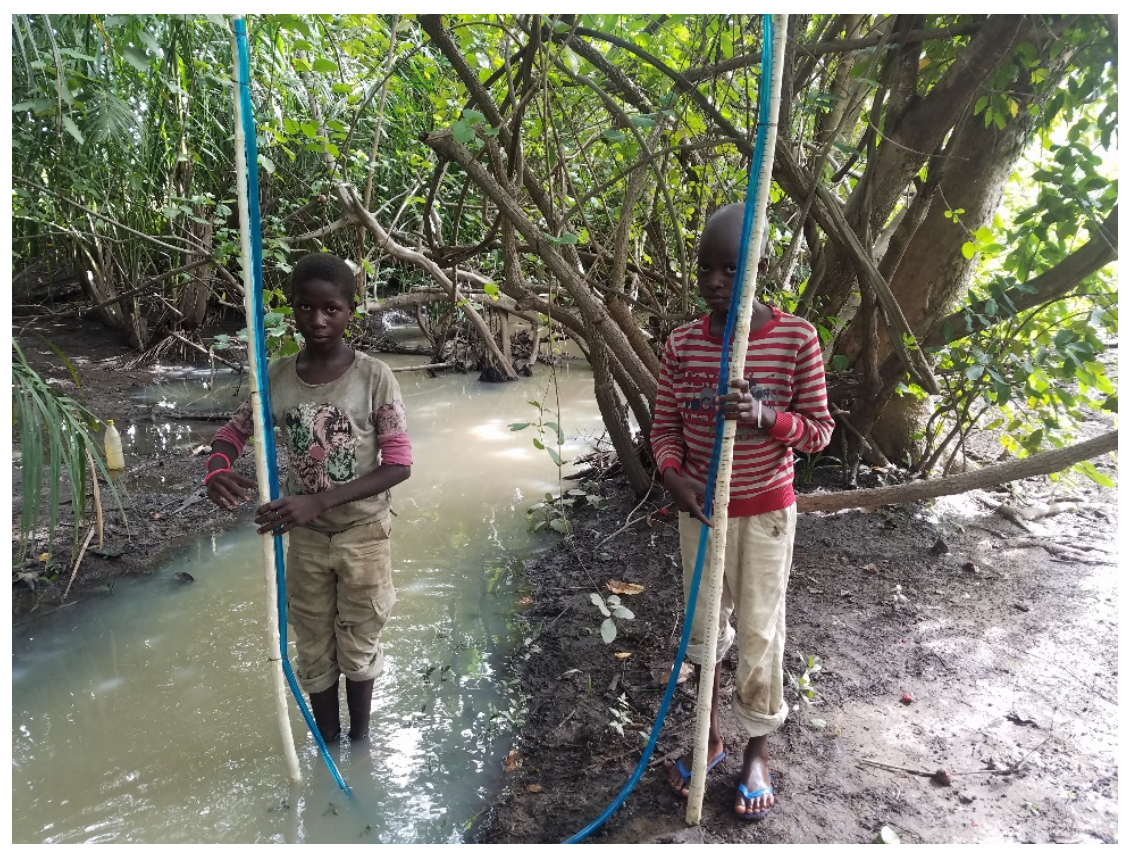

Figure 13. Helpers using the Egyptian Water Level pointing at the water elevation on each stick. (photo by author)

The sticks are measured and marked. In this case, the sticks were two meters in length and measuring lines were marked every centimeter. This allows the change in elevation to be measured down to the nearest centimeter. Then the clear tube was tied onto the sticks. The tube was five meters in length and allowed for easy transportation and mobility. The tube was then filled with water, making sure that all the air bubbles and kinks were out of the tube, which can cause false readings. The water can be seen through the tube and readings can be seen on the marked sticks. The water surface is always horizontal, so the difference in the readings between sticks is the change in elevation over that known distance.

In order to measure the elevation, values of various points along the stream cross sections, the sticks were leap frogged across the section, perpendicular to the flow of the stream. The first stick was placed at a known point that would not move, such as a tree or stump, between cross section measuring times. Then the next stick was placed a known distance away from the first one. The distances between the sticks varied between one meter to 0.25 meters. These distances were chosen depending on the makeup of the terrain. On the floodplains, where the slope was more gradual and consistent, one meter was used between the sticks. Whereas where more detail was needed in places where elevation changed dramatically over a short distance, then a spacing of 0.25 meters was used. Once the readings were taken from each stick, the first stick was then moved to the 
other side of the second stick to a known distance. Cross-sections lateral extent was increased after the rainy season due to extensive flooding.

GPS points were taken with a handheld unit (Garmin eTrex 10) at both the start and stop positions of each cross section. The goal of doing this was to ensure repeatability and take the same cross section every time. However, this had its own challenges due to the accuracy of the GPS device. Garmin states that this device is typically accurate to within 3 meters (Garmin, 2017). The reference points that were used were usually trees or stumps or something that would not move over time. This was important since the accuracy of the GPS was close, each point was averaged to bring the point recorded closer to the point in the real world. In places that were on a farm field or a clear area, sticks placed into the ground and a conversation with the landowner was had in order to keep the stick undisturbed over time. But due to termites in the area, each time a stick was placed in the ground, the termites would eat it and the stick would constantly fall over and/or be moved from the original place. Some other encountered difficulties also included GPS points changing, not keeping a perfectly straight line, and unknown starting elevations. It was noted that over the sites of the river adjacent to farms had more run off and erosion than sections without farms.

\section{Velocity}

As stated above, measuring velocity is relevant to bank erosion. Velocity and water surface stage height are important together because each specific stage height has a specific velocity. This can play a large role in monitoring and predicting flows and flooding.

The method that was used to determine velocity was the float method. This method is easy to use if velocity meters are not available, such as was the case here (Rantz, 1982). This method involves throwing leaves in the stream and timing the amount of time they travel over a specified distance.

The velocity was measured many times over the two-year testing duration at each spot there was a cross section taken. A straight channel section, within which cross section measurements were taken, was used. The length of that section was then measured to know the distance water had traveled. Once this distance was known, leaves were taken from trees along the bank and thrown in just above the starting point of the distance. This allowed for the leaves to be at the velocity when the timer starts rather than them sitting for a small period of time. Once the leaves crossed that starting line, a timer was started to determine the time traveled. As the leaves cross the finish line of the specified distance, then the timer was stopped. This process was done at least three times at each location. In some instances, when the data was observed and there was a very fast or slow time, then one or two more tests were done. A check was preformed after the set of timings were done to compare the data with themselves to see if they were consistent and reliable. After the timings were completed, velocity was then calculated as shown in Equation 1. This is important in that it shows that the test is consistent, and an average is 
meaningful. After each set of timings, the stage height was recorded by taking a straight stick and placing at the thalweg or lowest point in the cross section. Once the thalweg was determined, the stick was measured and recorded.

$$
\text { Velocity }=\frac{\text { Travel distance }}{\text { average travel time }}
$$

This float method determines surface velocity. The velocity of a stream varies throughout the vertical profile as well as longitudinally with the fastest velocity being near the center of the stream and just under the free water surface of the stream as shown in Figure 14.
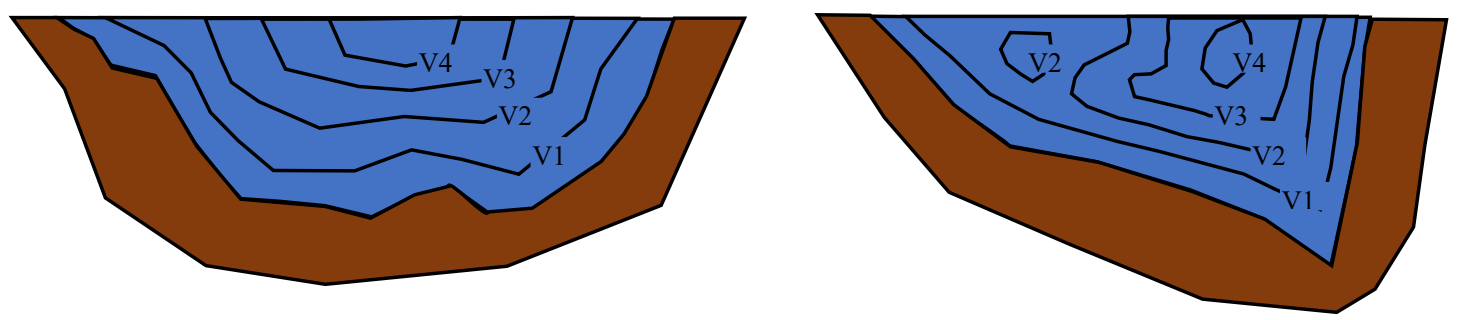

Figure 14. Velocity contours at stream cross sections: (left) in a relatively straight section of channel, and (right) at a bend in the channel. In both cases, V4 $>V 3>V 2>V 1$. Adapted from Gordon, McMahon, \& Finlayson, 1992

The understanding of how the velocity is distributed throughout an actual channel becomes important when calculating the actual flow. The average velocity of a velocity profile is approximately $40 \%$ of the way from the bottom of the stream as shown in Figure 15 (Gordon, McMahon, \& Finlayson, 1992). However, this is for a uniform channel with uniform flow. The average velocity of the velocity profile will vary due to many different factors of a natural stream. One of those factors is stage height. (Table 2 shows the coefficients correlated with the corresponding stage height).

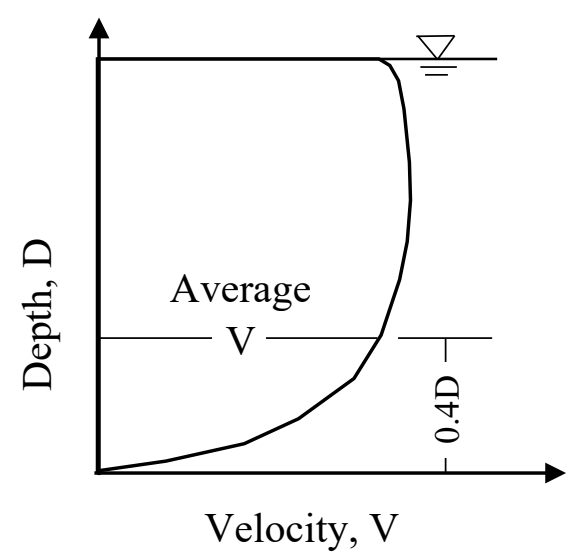


Figure 15. Vertical Velocity Profile of a stream channel. Adapted from Gordon, McMahon, \& Finlayson, 1992

Table 2. Coefficient to correct surface float velocities to mean channel velocities. Source: Reclamation, 2001

\begin{tabular}{|c|c|}
\hline \multicolumn{2}{|c|}{$\begin{array}{c}\text { Coefficient to correct surface float } \\
\text { velocities to mean channel velocities }\end{array}$} \\
\hline $\begin{array}{c}\text { Average depth in } \\
\text { reach (ft) }\end{array}$ & Coefficient \\
\hline 1 & 0.66 \\
\hline 2 & 0.68 \\
\hline 3 & 0.7 \\
\hline 4 & 0.72 \\
\hline 5 & 0.74 \\
\hline 6 & 0.76 \\
\hline 9 & 0.77 \\
\hline 12 & 0.78 \\
\hline 15 & 0.79 \\
\hline$>20$ & 0.8 \\
\hline
\end{tabular}

These coefficients were then multiplied by the average surface velocity in order to get the average velocity of the whole cross section. Some experienced setbacks were wind pushing leaves, flow non-uniformity, trees, sticks, and plants catching leaves.

\section{Groyne Implementation Procedure}

After the first year of the rainy season, high erosion areas were detected. Conversations were held with the landowners whose land had high erosion areas to gain their understanding on why the erosion was happening on their land, as well as why it happened in general. The test area that was chosen was a horseshoe bend in the stream that was touching a field. The crops that were farmed in this field were corn, peanuts, and rice, which affects how runoff is created or absorbed. This site was also a good placement because there was a rock field nearby, which made transporting the groyne rocks much easier.

Experiments that were done by Krishna Prasad determined that out of a groyne angle range of $45^{\circ}-135^{\circ}$, the $135^{\circ}$ angle protected the most amount of stream bank (Krishna, Indulekha, \& Balan, 2015). It is because of this experiment that this angle was used in this study. The rest of the design considerations were done by following the IS 8408 guidelines (Pitroda, 1994). IS 8408 recommends using a value of $1 / 5^{\text {th }}$ the flow width as 
the maximum groyne length. A groyne length of one meter was chosen. IS 8408 recommends a spacing of 2-2.5 times the groyne length. A spacing of 2.5 meters was chosen between each groyne to give the maximum protection.

Just offsite, an area where bedrock has been broken up by trees and plants provided numerous rocks for collecting. Rocks were collected and transported using a cart that was pushed by local helpers. Larger rocks were mostly collected to cover the most area and to stay in place when high flows occur. There were also smaller rocks that were collected and used to fill in the gaps that the larger rocks had made.

Once all the rocks were collected, placement started. The first groyne was place in the upstream portion of the horseshoe just upstream of the major erosion area. The type of groyne that was built was permeable, submerged, attracting, and straight. This was since the groynes can protect both upstream and downstream. So, the sediment will be starting to settle out just as the erosion areas are beginning as well as in front to reinforce the whole bank. The first one was built with a base of about 0.5 meters wide and measured one meter out from the bank into the stream as shown in Figure 16. Once the meter-long base was placed, rocks were carefully selected to sit on top of this base so that they will not dislodge during high flows. They were placed to a height of 0.5 meters. This was decided due to rock availability and the hard work of transporting and placing each rock. Once the first groyne was placed, the bank was measured 2.5 meters downstream from the first groyne, where the next groyne was placed. This was done until seven groynes were placed.

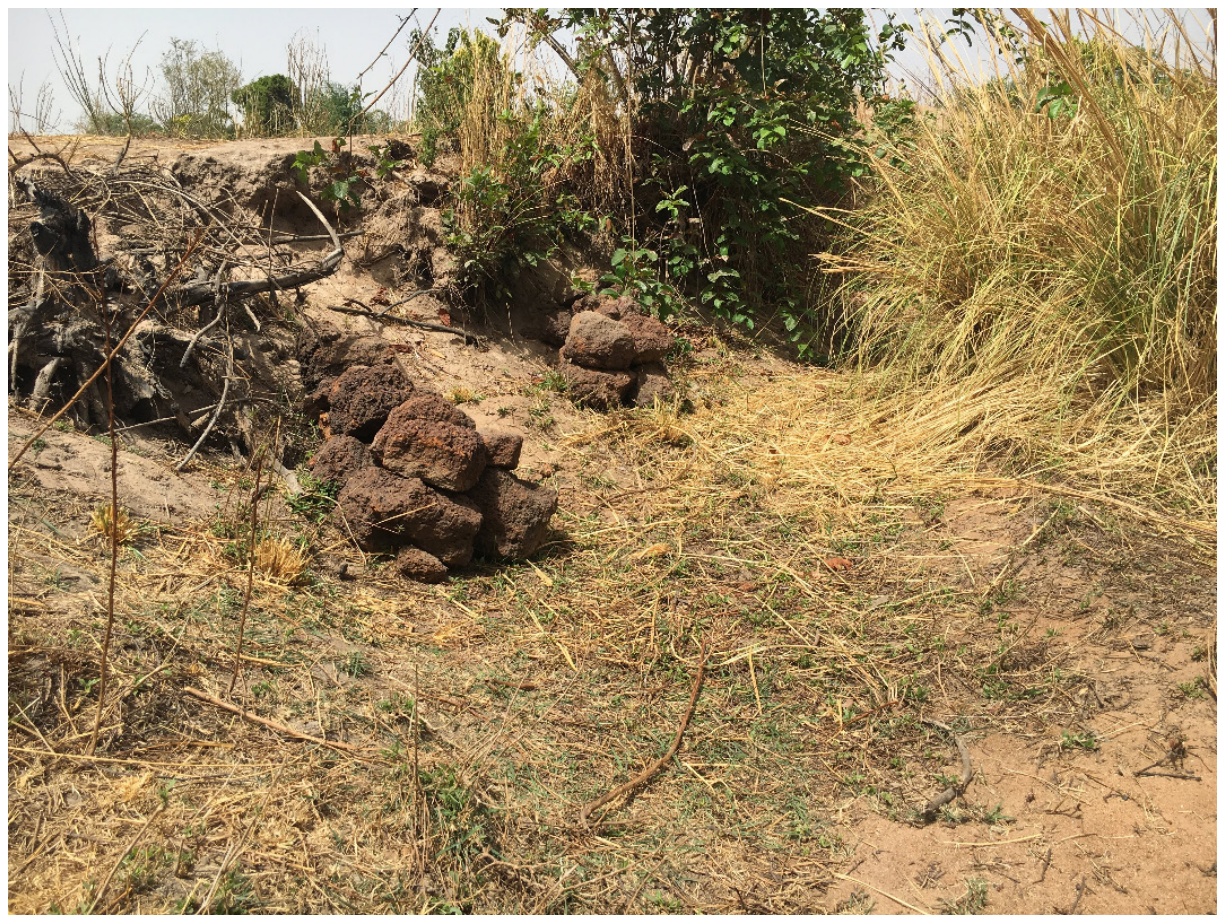

Figure 16. Photo of 2 groynes built and placed at the end of the test site. (photo by author). 
The rock supply was running low and time before the rains started was getting shorter. Because of this, it was decided to measure out the rest of the places for the groynes and move downstream to the end of the horseshoe and built some there, working back upstream in attempts to fill the entire area. This area at the end of the horseshoe was the area of the highest erosion and needed the most protection. Wanting to protect the area, two groynes were placed at this point. The final layout of the built groynes can be seen in Figure 17.

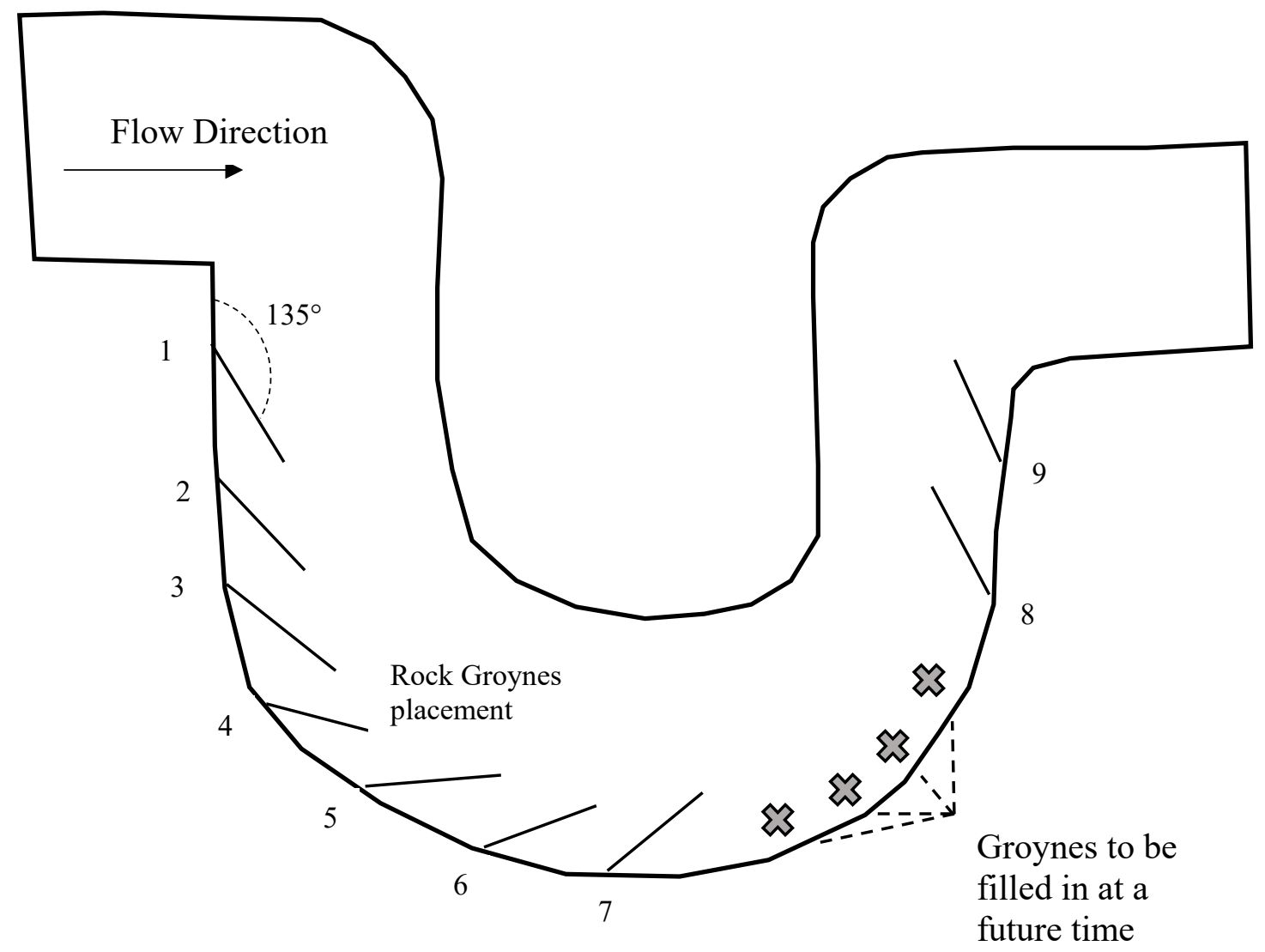

Figure 17. Layout of groyne placement in test area (figure by author).

\section{Vetiver Implementation Procedure}

Vetiver grass is very common at the study site. There are large clumps scattered all over the stream. Slips were taken from this same area since they grow well in that soil. Once 
the rains had started and the soil was moist, the vetiver grass was dug up in a variety of ways. These ways include digging up an entire plant and then separating out all the slips, pulling out entire plants in the stream where the soil was saturated and easier to move, or pulling individual slips off a parent plant that was in the stream. In all instances for all the slips, the roots were cut back to $10 \mathrm{~cm}$ and the leaves were cut back to $20 \mathrm{~cm}$. This process helps with the transferring and planting as it slows down the drying out process and it also promotes new root growth.

Once all the slips were obtained, a line was drawn in the soil to indicate where they will be planted. This line was drawn with the contour line $1 \mathrm{~m}$ away from the stream bank. The slips were planted along this line at $20 \mathrm{~cm}$ spacing as shown in Figure 18 . This spacing is a little bit sparse, but still starts to establish a hedge and will fill in over time. It was chosen due to timing issues and workload. The $20 \mathrm{~cm}$ spacing is a good starting point and can then be filled in as time allows.

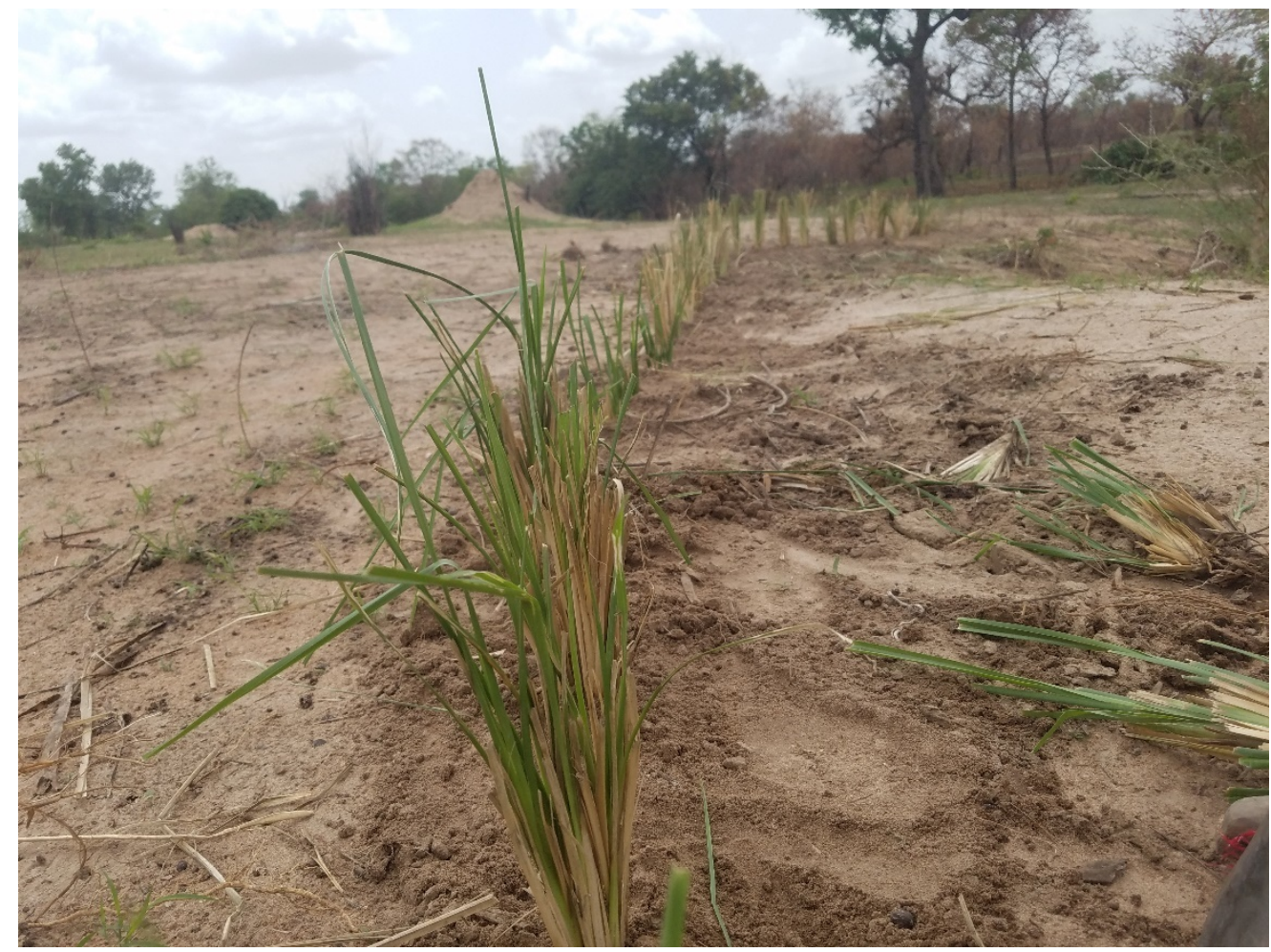

Figure 18. Vetiver grasses spaced out at $20 \mathrm{~cm}$ spacing along the bank (photo by author).

The vetiver hedge was then monitored through the beginning of the rainy season. As the new slips started to take root and grow, some of them died due to the planting retrieval process, and a few got washed away due to flood waters. In both instances, the slips that went missing or died were replaced to ensure a gap-free hedge. Figure 19 shows the layout of the vetiver grass along the bank of the stream. 


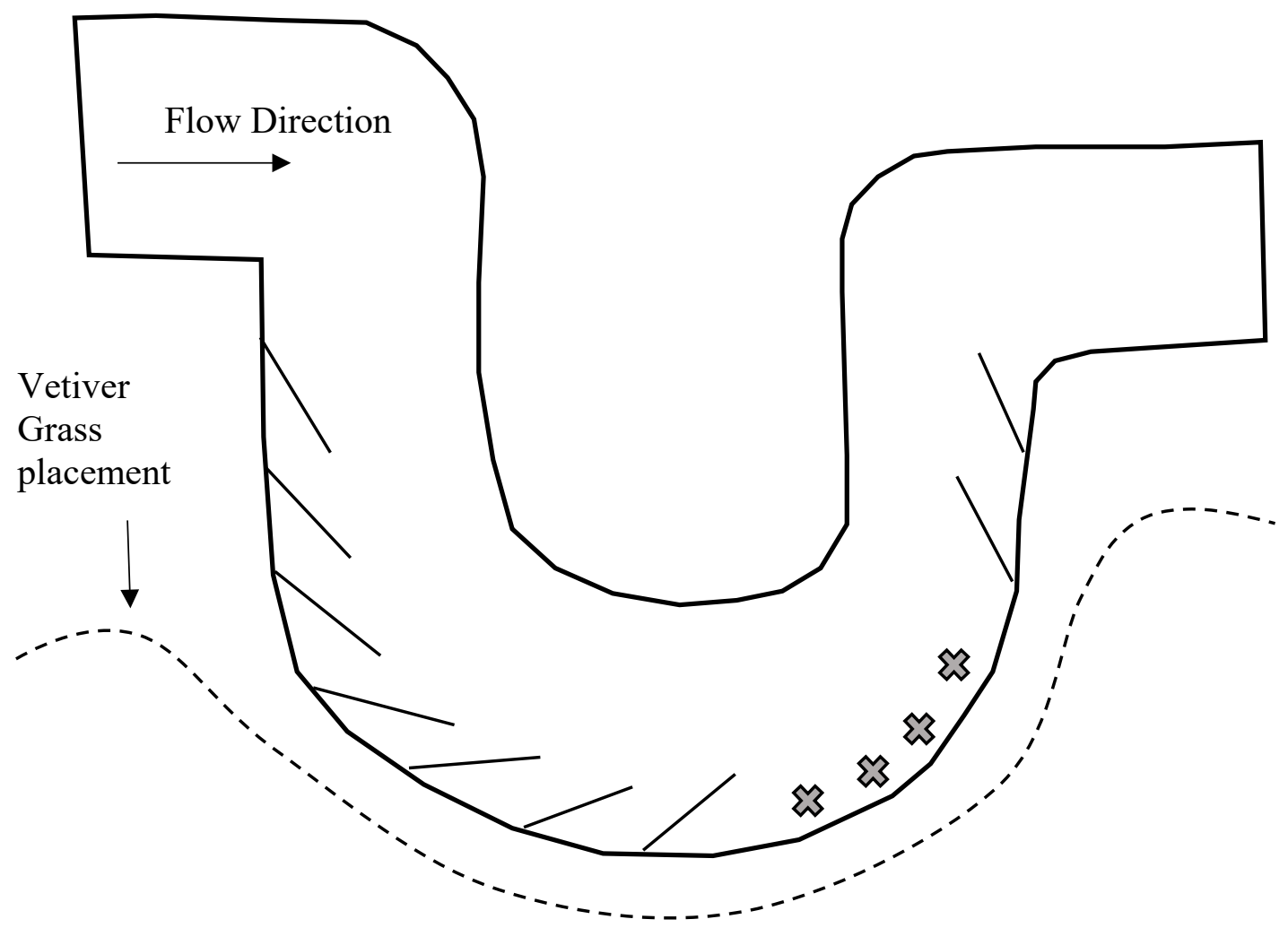

Figure 19. Layout of vetiver grass placement at test site (figure by author).

The tops were cut back once they reached a height of $50 \mathrm{~cm}$ (or about every 2 weeks). This allowed more of the plant's energy to be put in to creating tillers and filling in as a complete hedge. These cuttings from the plants were placed along the base of the plants to help fill in as an artificial hedge and slow down the runoff in that area. Setbacks included constant replanting, the short growing season, and slow vetiver growth to the leaves.

\section{Results}

Figure 20 shows the rainfall from 2016 to 2018. This is important to see when the cross sections, mentioned below, were taken compared to the rainfall. It is noted that in 2017, the heavy rainfall events were much later in the rainy season as compared to 2018 where the heavy rainfall events occurred much earlier. The timing of the heavy rainfall events 
played a role on when the method was implemented. The times when the cross sections were taken are also plotted on the graph in order to see the relationship between the two. For erosion to be reduced, the cross sections would show reduced area.

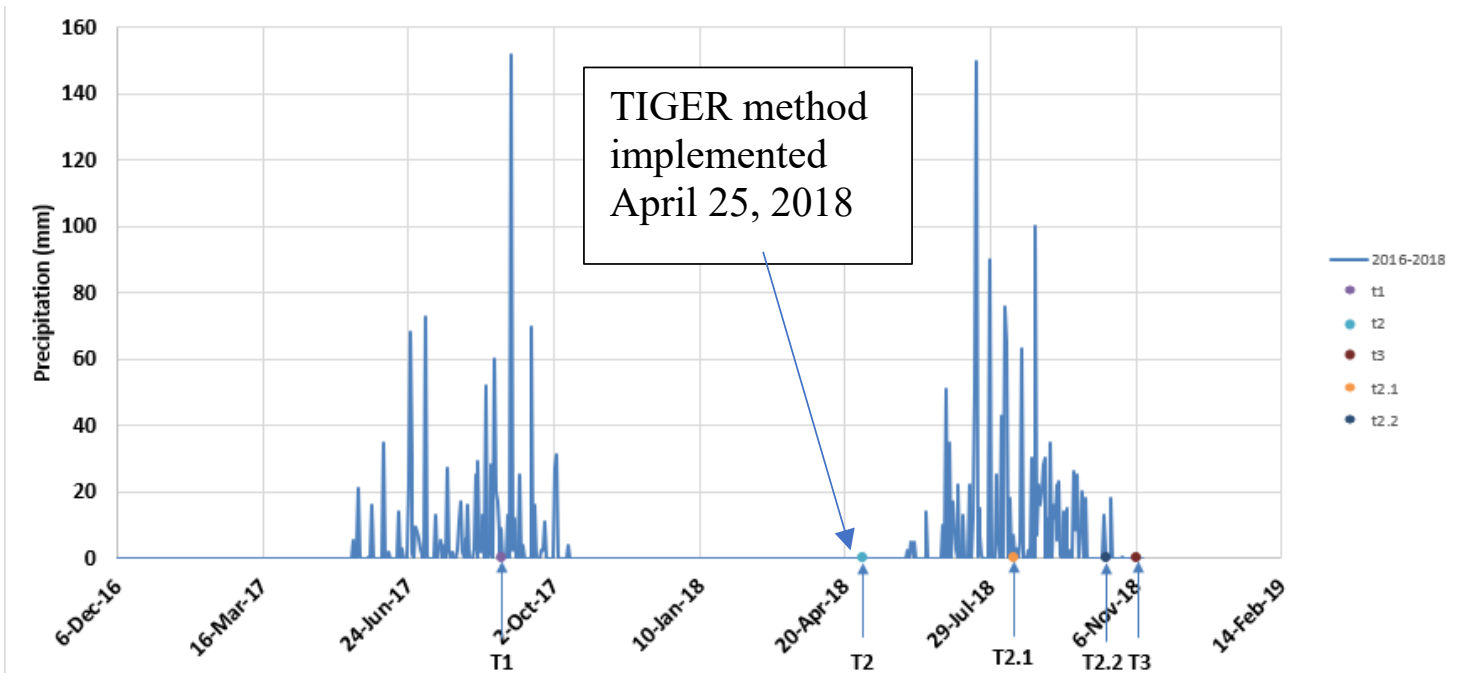

Figure 20. Precipitation data at the Fode Binea Rain Gage and times of TIGER implementation and cross section data collection.

The results of this study looked at the three cross sections surrounding the TIGER implementation site. The rest of the cross sections in the stream can be viewed in Appendix A. The three main sites included a cross section upstream and downstream of the TIGER method. This was to determine if there were any observable upstream or downstream affects due to the addition of this method. These two sites were measured more throughout the second year to see how the channel bed was changing throughout the year. The water surface elevation that is shown on the figures are the average stage height over the two years.

Examining erosion at the section upstream of the TIGER Method location (Figure 10) to see if the TIGER Method affected erosion upstream, as seen in Figure 21, the stream channel bed was constantly increasing on the right bank. The right bank and right floodplain were where rice was farmed in this area. Because of this activity, the land and soil were always loose and free of vegetation which allowed for major erosion to occur during flood stages. There is also a $90^{\circ}$ right bend just downstream of this section with a higher bank, so when the high flood stages occurred, the right side would flood first and the flow would be higher on that side. The stage-height-vs-velocity relationship is shown in Figure 22, and shows that, given the same stage height, the second-year velocities were faster than the first. This could be since the areas increase, allowing for more flow and faster velocities to occur. It should be noted that these measurements were taken when conditions were safe. There were many flood events that were higher than shown here, but to do safely, the sections were not able to be measured. 


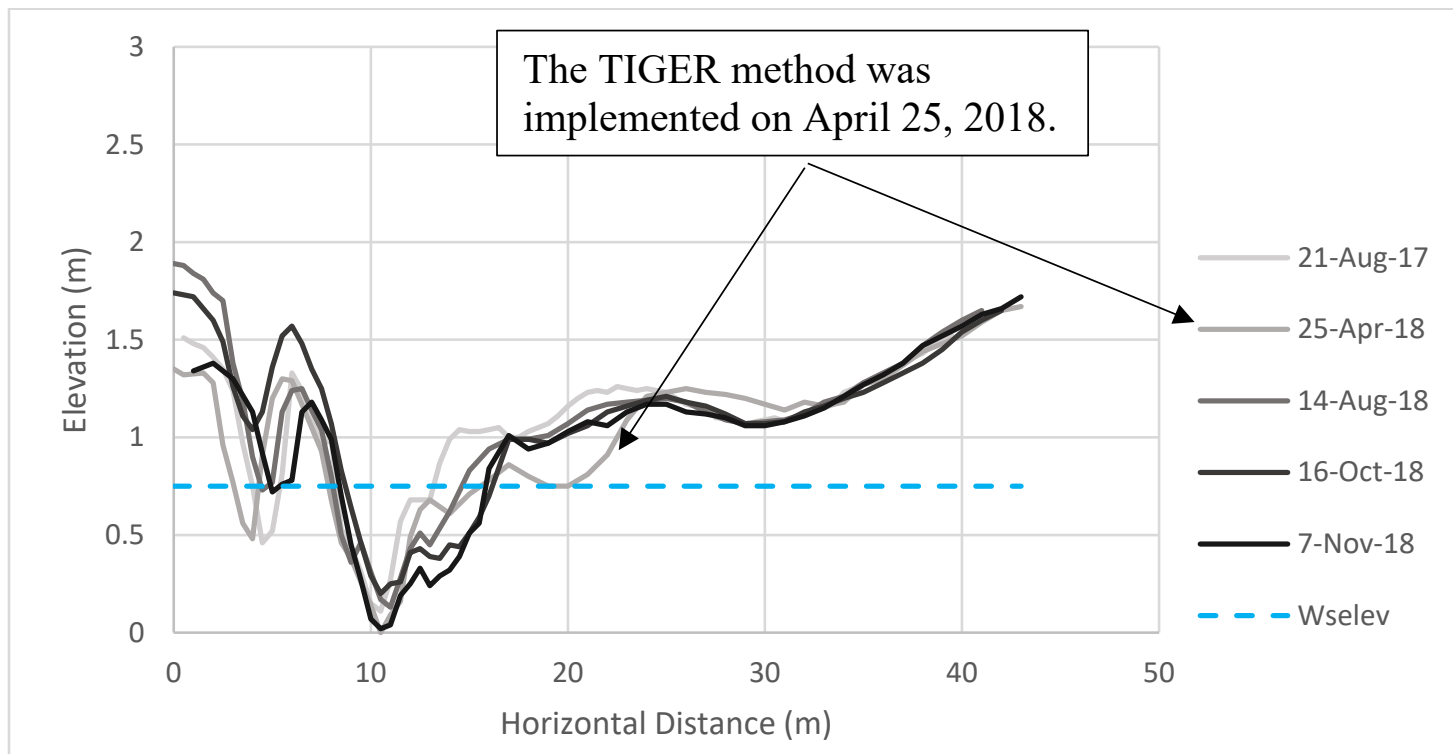

Figure 21. Cross section data for all times at a location upstream of the TIGER Method deployment.

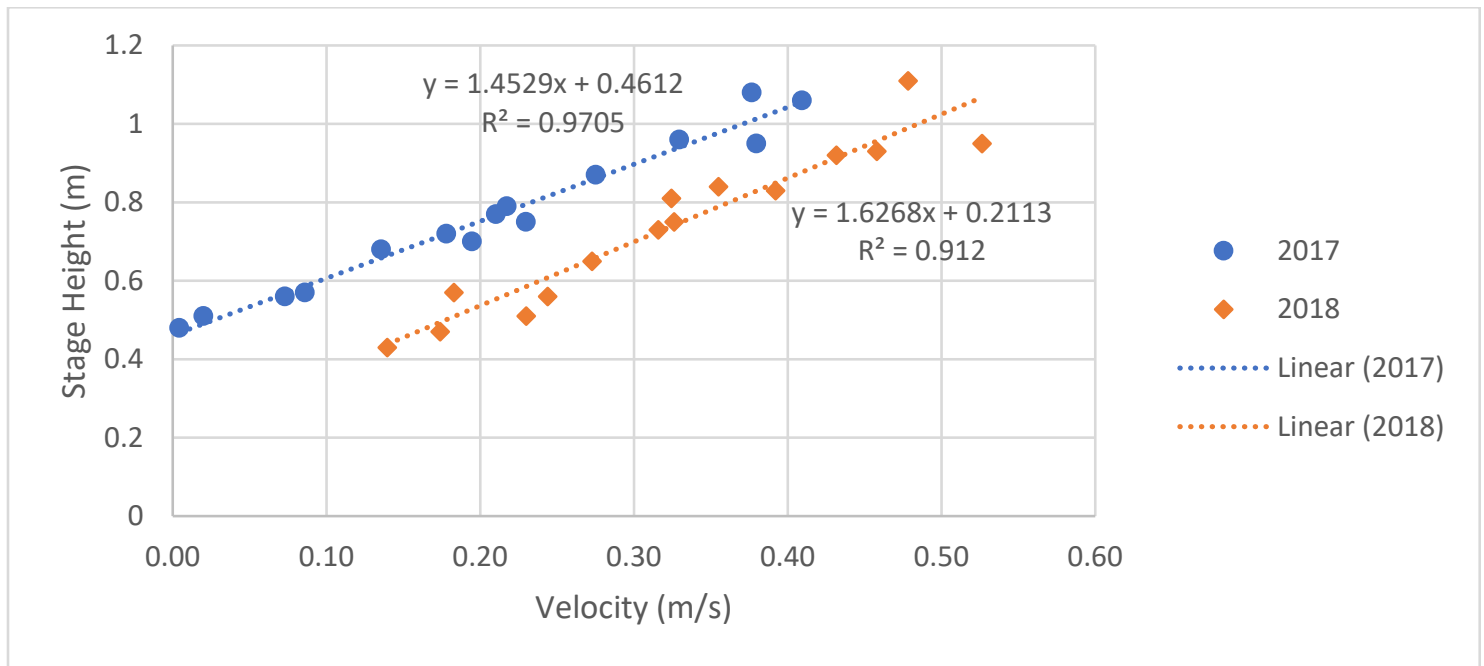

Figure 22. Stage-vs.-velocity graph upstream of the TIGER Method installation.

Table 3 shows the percent changes in cross section area at the measured times. At an average stage height of 0.75 meters, there was an increase in all areas except for between T2 (April 25, 2018) to T2.1 (August 14, 2018). There was a 16\% decrease in area which means that sedimentation occurred. The groynes were implemented on April 25, 2018, which could be the cause of sedimentation while the flows were lower. 
Table 3. Percent changes in cross section area upstream of TIGER Method installation. (Red and green shading denote positive (more erosion) and negative (less erosion) change, respectively.

\begin{tabular}{|c|c|c|c|c|c|}
\hline Cross Section & T1 and T2 & $\begin{array}{r}\text { T2 and } \\
\text { T2.1 }\end{array}$ & $\begin{array}{l}\text { T2.1 and } \\
\text { T2.2 }\end{array}$ & $\begin{array}{r}\text { T2 and } \\
\text { T3 }\end{array}$ & $\begin{array}{r}\text { T1 and } \\
\text { T3 }\end{array}$ \\
\hline Before TIGER & $45 \%$ & $-16 \%$ & $14 \%$ & $32 \%$ & $92 \%$ \\
\hline
\end{tabular}

The location of the TIGER Method deployment is shown in Figure 23. This cross section shows that the right portion of the channel, the groyne side, had more change in bed elevation. This could be since during the beginning of the rainy season, there was sedimentation, but as the rains got heavier and the flows got faster, the recently settled sediment could have been eroded easier leaving the right channel vulnerable. On the left side of the channel, however, there seemed to be more sedimentation around the bank. This could be because as the upstream flow got directed towards the center of the channel and sediment deposited on the right bank. The middle of the channel also had sedimentation occur. This could be because there a decrease in velocity that occurred at the end of the groyne which could have allowed sediment to settle out. Only two cross sections were able to be taken at this location due to safe access difficulties. Vetiver grass was established but will fill in more in the future, thereby providing additional erosion and runoff reduction.

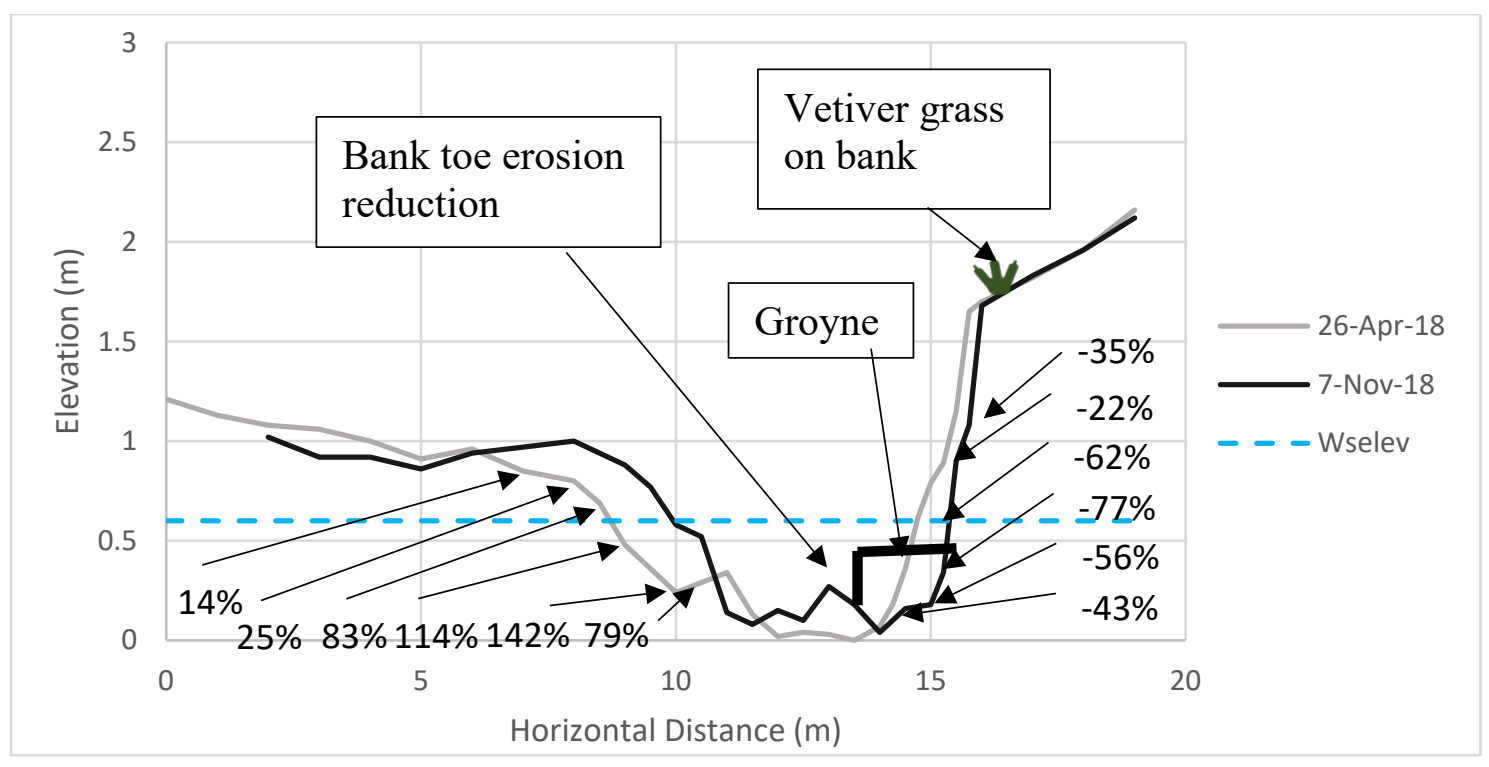

Figure 23. Cross section data at the location of the TIGER Method implementation location. 
Table 4 shows the change in cross section area from T2 (April 26, 2018) to T3

(November 7,2018) at a stage height of 0.6 meters. The change in area shows that there was a $13 \%$ decrease in area meaning that sedimentation occurred. Table 4 gives a change in total area, but as seen back in Figure 24, the cress section area changes show the change in bed elevation from T2 to T3. It should be noted that on the right side (where the groyne is), there is a decrease in bed elevation at each measured point with an average of $49.2 \%$ decrease in bed elevation. There is also a large increase at the base of the groyne where sediment could have settled out there. Whereas on the left side there was an average increase of bed elevation of $76 \%$ at each measured point. These changes could have happened due to the groyne on the right side of the channel redirecting the flow to the left side where it could be settling out.

Table 4. Percent changes between when cross sections taken at TIGER Method installation site. (Green shading denotes negative change.)

\begin{tabular}{|l|l|}
\hline Cross Section & T2 and T3 \\
\hline Middle of TIGER & $-13 \%$ \\
\hline
\end{tabular}

The section that was measured just downstream of the TIGER method implementation to see if the TIGER Method affected erosion downstream can be seen in Figure 24. These sections show that after the first year (2017), there was a large amount of erosion on the right side of the channel. In contrast, the second year (2018), when the TIGER method was implemented, shows that the channel held close to its original shape at the beginning of that year. 


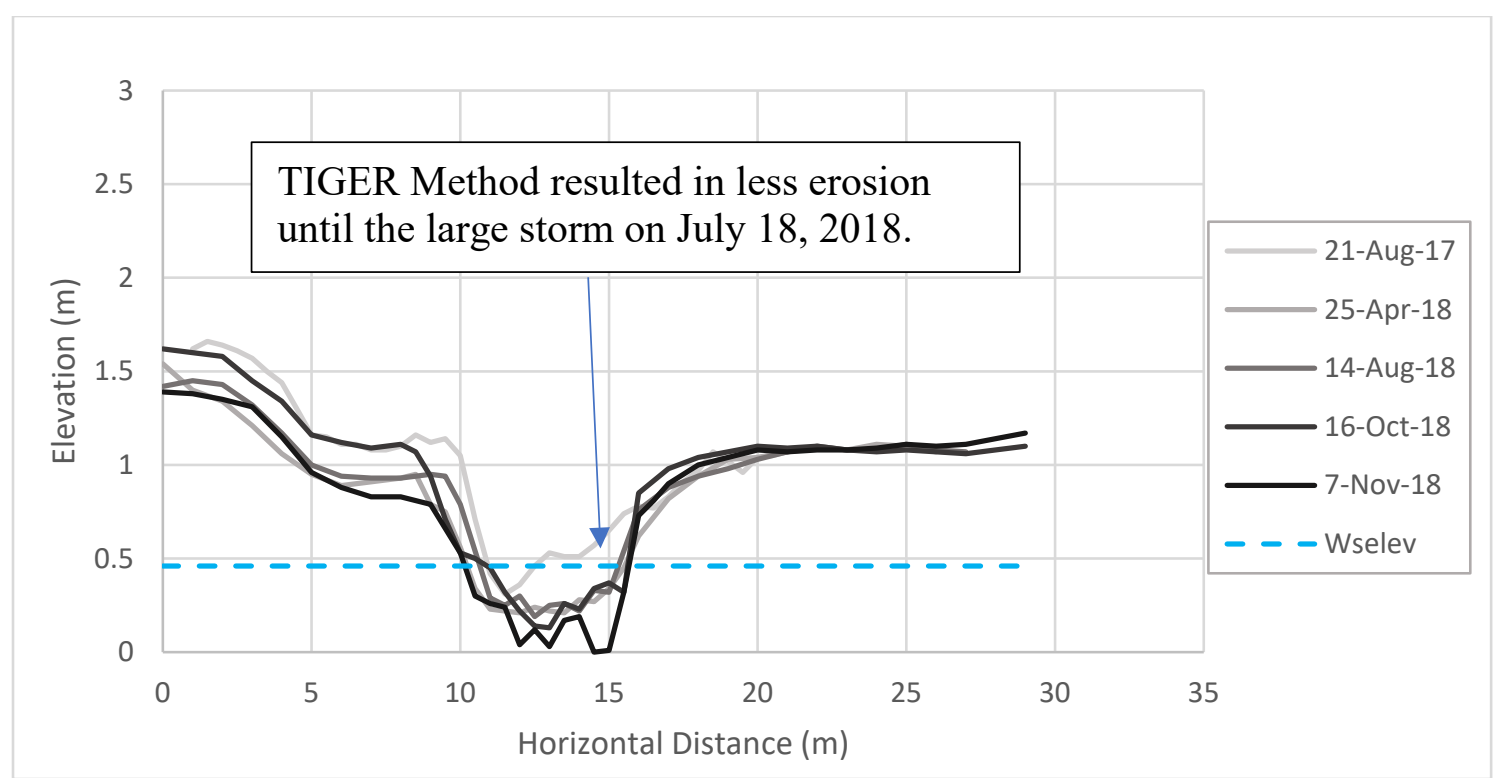

Figure 24. Cross section data downstream of the TIGER Method implementation site.

Table 5 shows the percent change in cross section area for the section downstream of the TIGER implementation section. The table shows that all the areas are increasing which means erosion is occurring. But the time between T2 (April 25, 2018) and T2.1 (August 14,2018 ) shows that there was a decrease in area by $17 \%$. The TIGER method was implemented on April 25, 2018 which allowed sediment to settle out early on when the flows were lower.

Table 5. Percent changes between cross sections measurements at section downstream of TIGER Method installation. (Red and green shading denote positive and negative change, respectively.)

\begin{tabular}{|c|r|r|r|r|r|}
\hline Cross Section & T1 and T2 & T2 and T2.1 & T2.1 and T2.2 & T2.2 and T3 & T1 and T3 \\
\hline After TIGER & $639 \%$ & $-17 \%$ & $6 \%$ & $64 \%$ & $1113 \%$ \\
\hline
\end{tabular}

Figure 25 shows the stage-height-vs-velocity relationship. This shows that, given the same stage height both years, the second year had higher velocities than the first year. This could be because the channel area increased allowing for more flow area which causes higher velocities. 


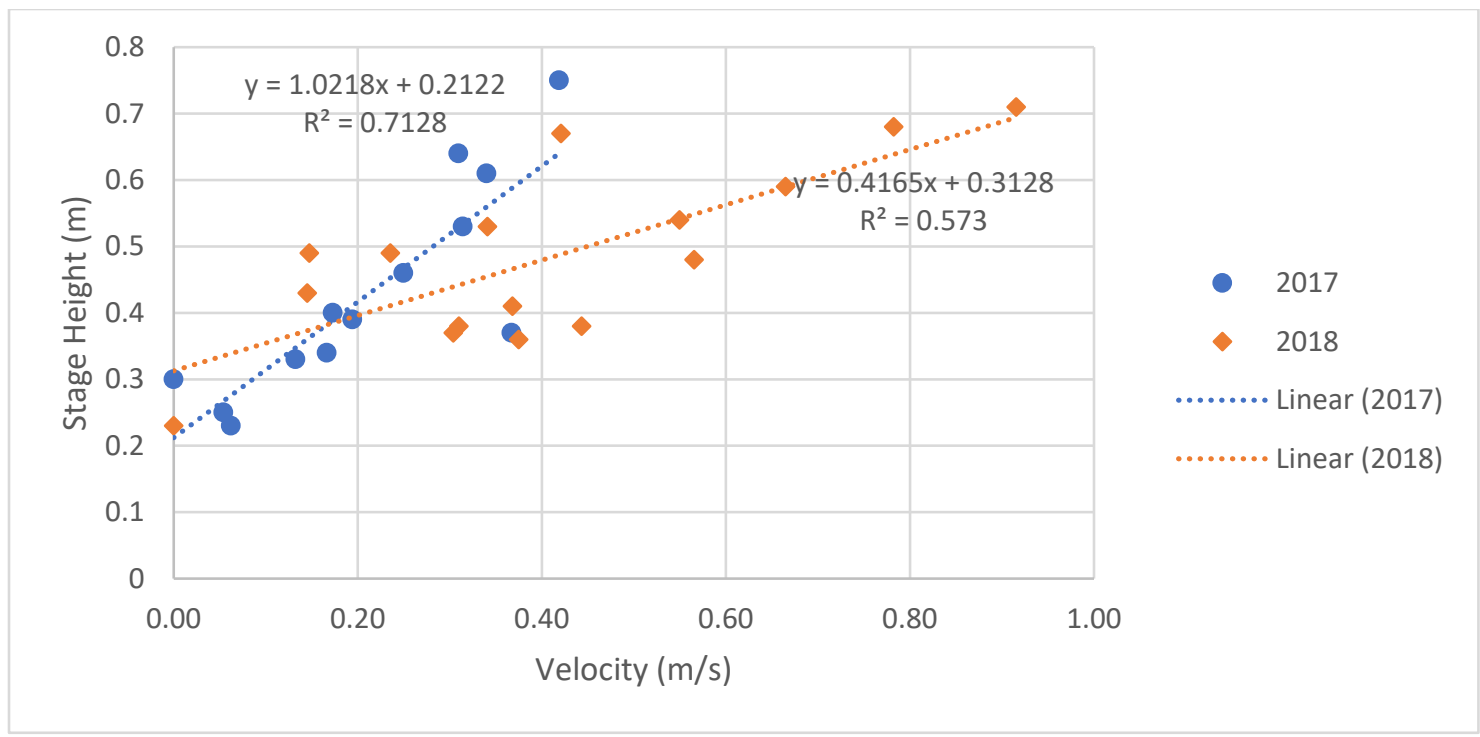

Figure 25. Stage-vs-velocity data downstream of the TIGER Method location.

It was observed that there was sediment deposition around the groynes during the beginning of the rainy season. This is when the stream flow was lower and allowed for the groynes to divert the water and slow the flow down around the banks. Once the highrainfall events occurred and the flows were much higher, it was observed that the sediment that had once settled out around the groynes had been washed out.

Measurements of the groynes were not able to be taken during the rainy season because the stage heights were high, and the water was cloudy, which made it difficult to see through the water and what was happening to the groynes. There was some rocks dislodged at the two groynes furthest downstream in a heavy rain in July 2018 and points out the need for groyne maintenance.

It was noticed that for most cross sections, the stage-height-vs-velocity relationship increased during the second year.

\section{Discussion}

The TIGER Method did work, especially in the low flows that it was designed for, although higher flow did cause some damage to the groynes and some vetiver.

The main limitation that was encountered was control of the project. The environment played a huge role in the success of this project. The large storm just after the TIGER method was installed took out many of the vetiver slips that were planted which delayed how fast these slips could have rooted and anchored into the ground because they constantly had to be replanted. The storm also eroded all the sediment that had just settled out around the groynes during the first rains and lower flows. 
The large storms also made it difficult to be able to take measurements. When the large storms occurred, measurements were not able to be taken until the river receded and conditions were safe to work in. These measurements included velocity measurements at each of the cross sections, and also taking cross sections at an appropriate time around the TIGER method installation to see how the channel reacted to the big storms.

Because of limited access to resources, measurements were possibly not able to be as accurate as desired. Because of this possible imprecision, locations that were visited frequently were not always recorded at the same location, which in turn, resulted in the cross sections not always the same length. Benchmarks using sticks in the ground were placed, but due to termites, the sticks were constantly eaten, falling, and moved from their locations.

Due to these limitations and accuracies, it is being recommended that further research and study be done to fully understand the area and to gain finer accuracy.

Possible negative aspects for groynes could be increased local flooding if they are designed to be excessively wide or tall and possibly local erosion right around the groyne that could cause groyne collapse. Similarly, fertile vetiver could spread to unwanted areas.

\section{Feasibility}

This method should be able to be translated to any stream. Because water acts the same way no matter where it is in the world, it can be assumed that if there is enough data on a stream in question and the right materials available, then this TIGER method will be effective, as shown in this study, especially at flow rates lower than the design flow rate. The buffer strip hedge would have to be a local hardy grass that would grow into a hedge, and the groynes can be made of any natural material that will hold in place through heavy flows, as did the rocks used in this study.

Further study is needed to gain a better baseline for the stream and see the variety of flows that occur in the area. This should be done by a more precise method of taking the velocity measurements as well as being able to take measurements during high flow events. An understanding of the stream velocity and flow will give greater insight at the height and width needed for the groynes. It will also allow for better placement of the buffer strip so that it does not get washed away in high floods.

\section{Conclusion}

The scarcity of rain in Senegal causes people to become dependent on the local stream for daily activities and farming, mainly rice farming. It is due to these activities and lifestyles which makes keeping the health of the local streams important. The purpose of this study was to implement a new way to reduce stream erosion and create a healthier 
stream. It is recommended that the implementation of the TIGER method can be used in streams. This recommendation is made because:

1. The groynes allowed for local sedimentation to occur along the bend during low flow events, thereby reducing erosion.

2. The vetiver grass showed some growth and is expected to grow further and provide additional erosion and overland flow reduction.

It is therefore concluded that the TIGER Method is successful under the conditions that it is designed for and shows promise as an effective and appropriate erosion protection strategy. 


\section{References}

AfricaW: Africa and the World. (n.d.). Retrieved Feburary 26, 2019, from Major problems facing Senegal today: https://www.africaw.com/major-problems-facingsenegal-today

CIA. (2019, February 14). The World Factbook. Retrieved March 1, 2019, from Senegal: https://www.cia.gov/library/publications/the-world-factbook/geos/sg.html

City Population. (n.d.). Retrieved Feburary 26, 2019, from Kedougou: http://www.citypopulation.de/php/senegal-admin.php?adm1id=SN06

Clark, A., Camara, C., \& Hargreaves, J. D. (2019, Feburary 28). Encyclopaedia Britannica. Retrieved March 1, 2019, from Senegal: https://www.britannica.com/place/Senegal

Dodge, R. (2001). Water Measurement Manual: A water Resources Technical Publication. Washington DC: United States Department of the Interior Bureau of Reclamation.

Energypedia. (2018, July 10). Retrieved March 28, 2019, from Senegal Energy Situation: https://energypedia.info/wiki/Senegal_Energy_Situation

Garmin. (2017). What is GPS? Retrieved May 29, 2019, from Garmin Website: https://www8.garmin.com/aboutGPS/

Gordon, N. D., McMahon, T. A., \& Finlayson, B. L. (1992). Stream Hydrology: An Introduction for Ecologists. West Sussex: John Wiley and Sons.

Gundlach, M. (Director). (2015). Saving the soil in Senegal's peanut basin [Motion Picture].

IFDC (2019). " Integrated Soil Fertility Management." IFDC, https://ifdc.org/integratedsoil-fertility-management/

Jackson, A. (2015, March 1). River Landforms. Retrieved June 2019, from Geography AS Notes: https://geographyas.info/rivers/river-landforms/

Krishna, P. S., Indulekha, K. P., \& Balan, K. (2015). Analysis of groyne placement on minimising river bank erosion. Elsevier Ltd.

Lancaster, B. (2010). Rain water Harvesting for Drylands and Beyond: Volume 2. Tucson: Rainsource Press.

Lancaster, B. (2010). Rainwater Harvesting for Drylands and Beyond Volume 2. Tucson: Rainsource Press.

Leclerc, J. (2015, Dec 24). Senegal. Retrieved May 2019, from Tlfq.ulaval.ca: http://www.axl.cefan.ulaval.ca/afrique/senegal.htm 
Mekonnen, A. (2000). HandBook on Vetiver Grass Technology -- From Propagation to Utilisation. For Ethiopia. Ethiopia.

National Research Council. (1993). Vetiver Grass: A Thin Green Line Against Erosion. Washington, DC: The National Academies Press.

Pitroda, S. G. (1994). IS 8408 (1994): Planning and design of groynes in alluvial river Guidelines. New Delhi: BIS.

Planchon, F. L., \& Dieye, A. M. (n.d.). Land Degradation in Senegal. Dakar: Centre de Suivi Ecologique.

Rantz, S. E. (1982). Measurement and Computation of Streamflow: Volume 1. Measurement of Stage and Discharge. USGS.

Reclamation, U. D. (2001). Water Measurement Manual. Washington DC.

Rachmeler, D. (2019). " Vetiver in Africa: A Continent-Wide Solution An Examination of Vetiver Use in African Countries and a Presentation of Lessons Learned As a Guide for Future Expansion." http://www.vetiver.org/ETH_WORKSHOP_09/ETH_G2a.pdf

Revolvy. (n.d.). Retrieved Feburary 26, 2019, from Kedougou Region: https://www.revolvy.com/page/K\%C3\%A9dougou-Region

Sow, S., Nkonya, E., Meyer, S., \& Kato, E. (2016). Cost, Drivers and Action Against Land Degradation in Senegal. In E. Nkonya, A. Mirzabaev, \& J. von Braun, Economics of Land Degradation and Improvemnet - A global Assessment for Sustainable Development. Springer, Cham.

Strom, H. G. (1962). River Improvement and Drainage in Austrailia and New Zealand. Victoria, Australia: State Rivers and Water Supply Comm.

World Bank. (1990). Vetiver grass: the hedge against erosion. Washington, DC: The World Bank.

Yossef, M. F. (2002). The Effect of Groynes on Rivers. Delft University of Technology. 


\section{Appendix A}

Figure A.1 shows all the locations of all of the cross-section sites that were studied over the two years. Figures A.2-A.23 show the data of each of those cross-sections. That data includes the cross-section plot over the two years as well as the stage height vs. velocity of each cross section, which allows for understanding of the flow that is carried through each cross section.

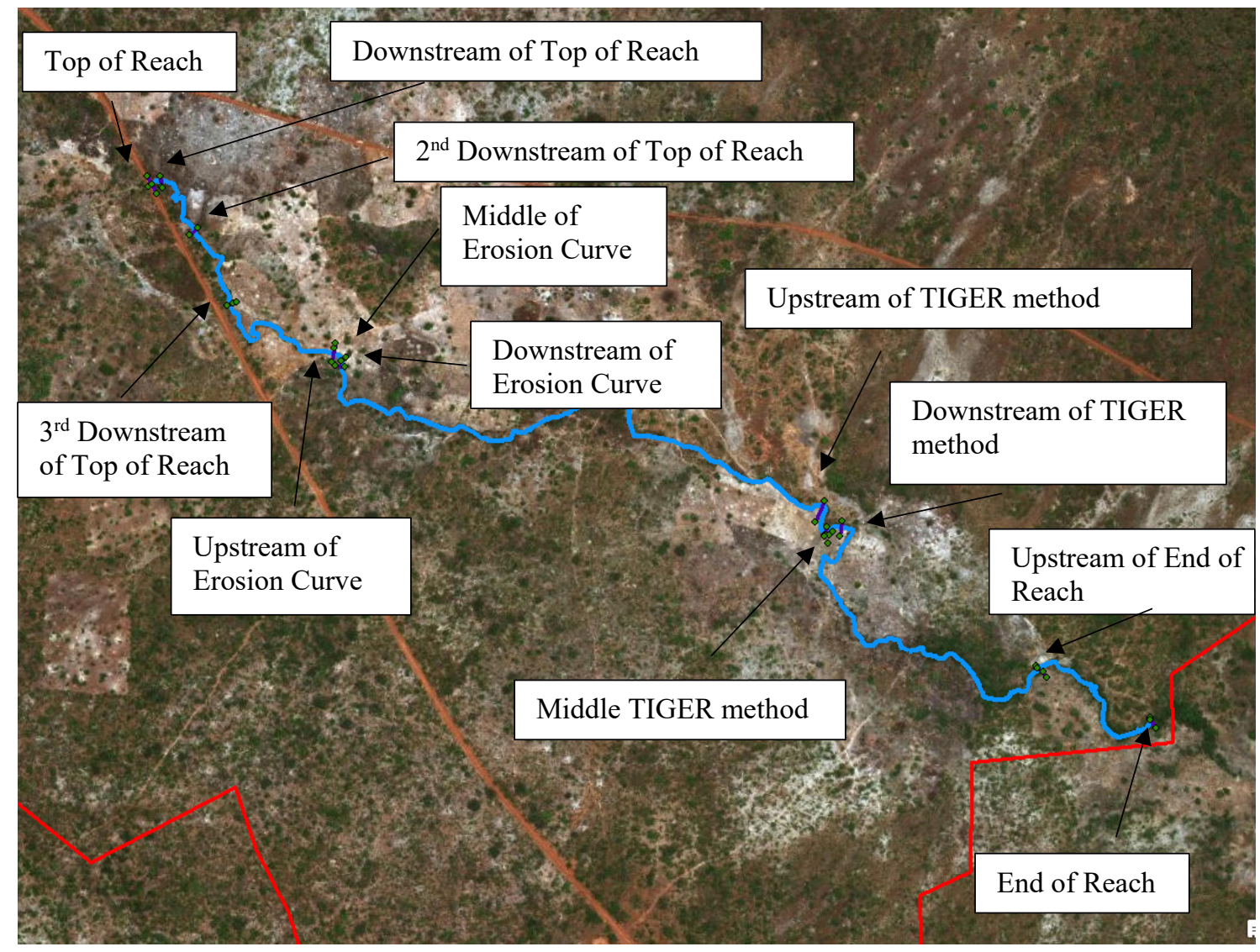

Figure A.1 Layout of entire stream in study with each cross-section location labeled (photo by author) 


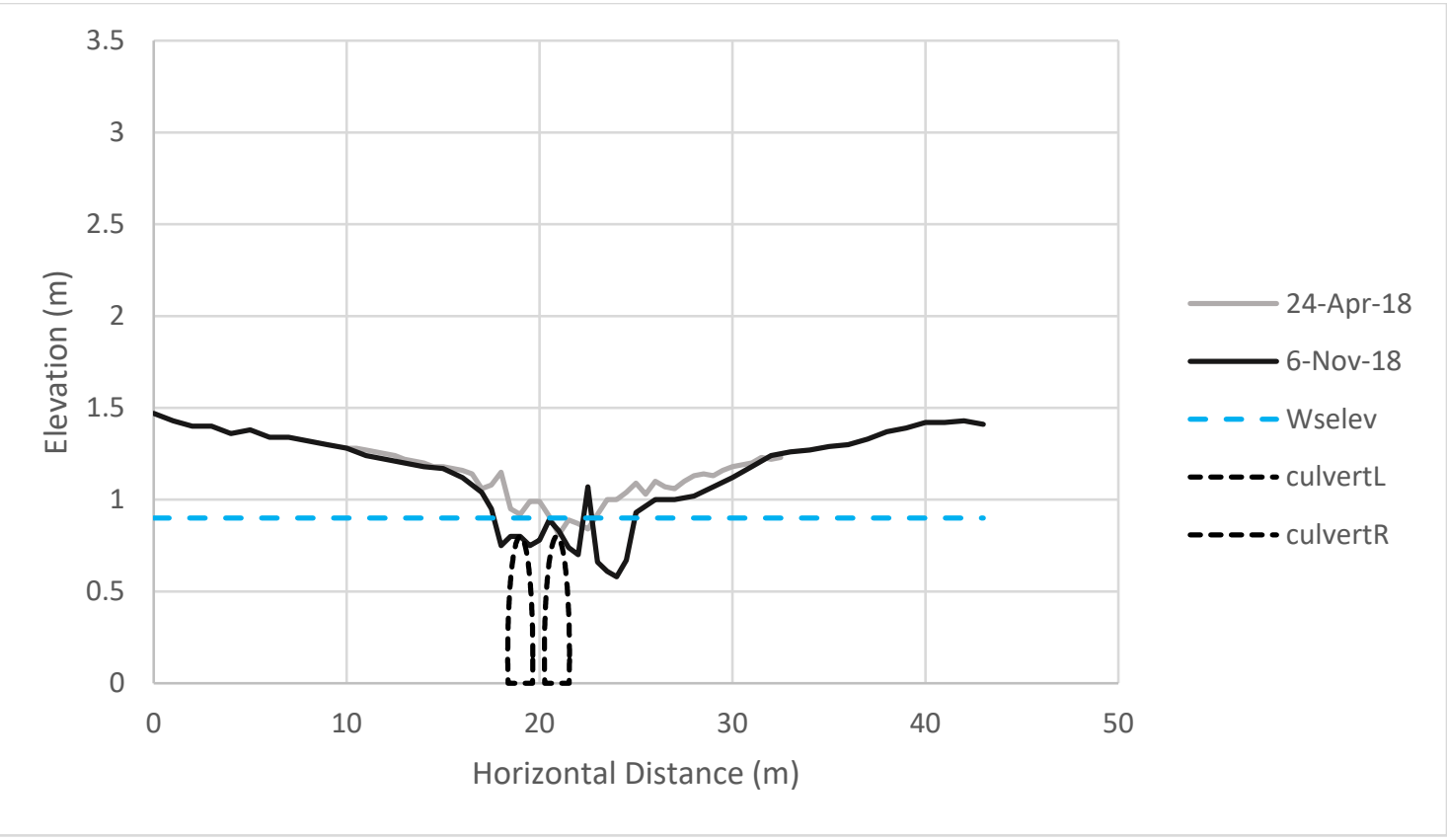

Figure A.2 Cross section data at the Top of Reach location.

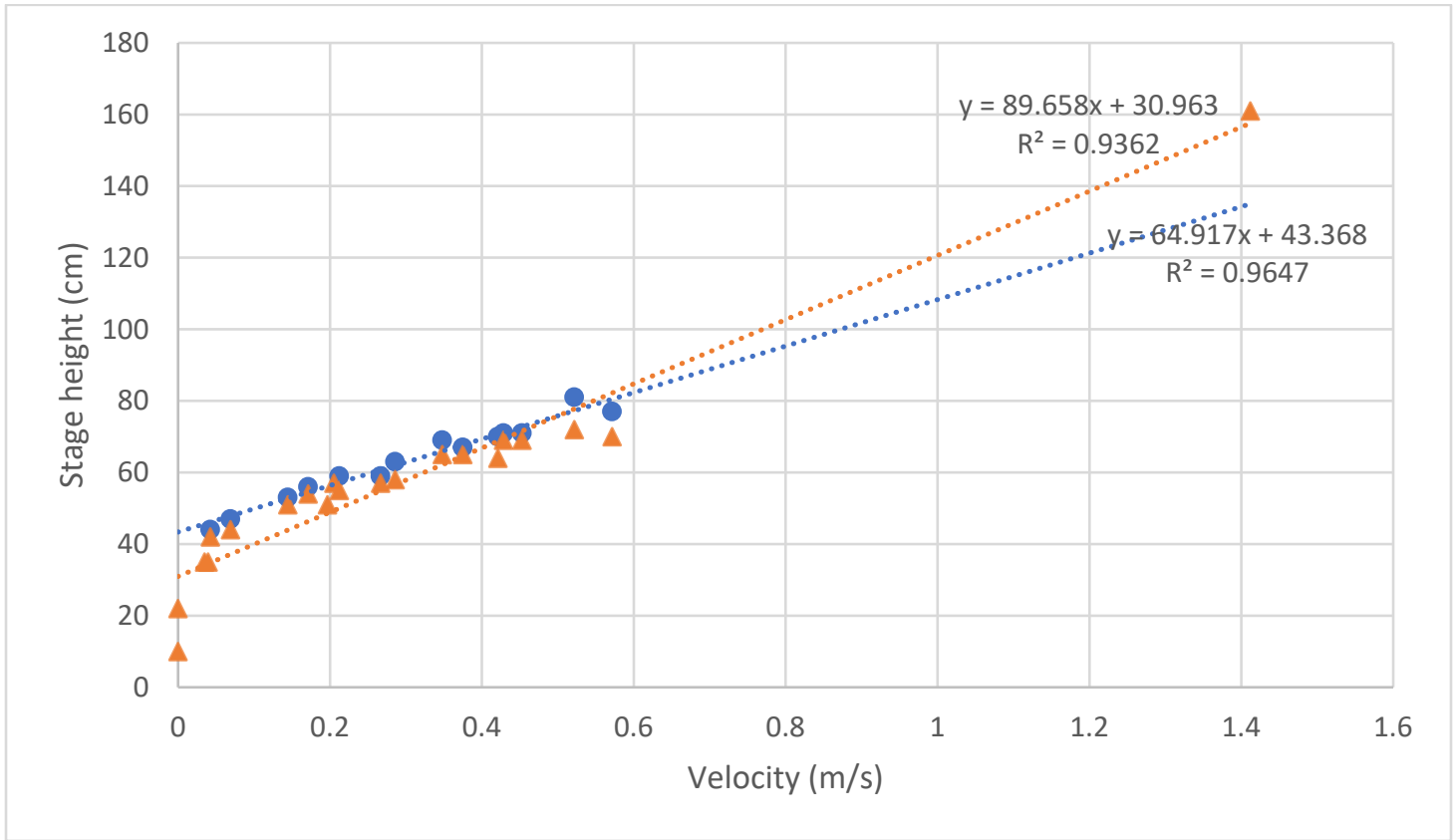

Figure A.3 Stage-velocity data downstream of the Top of Reach location. 


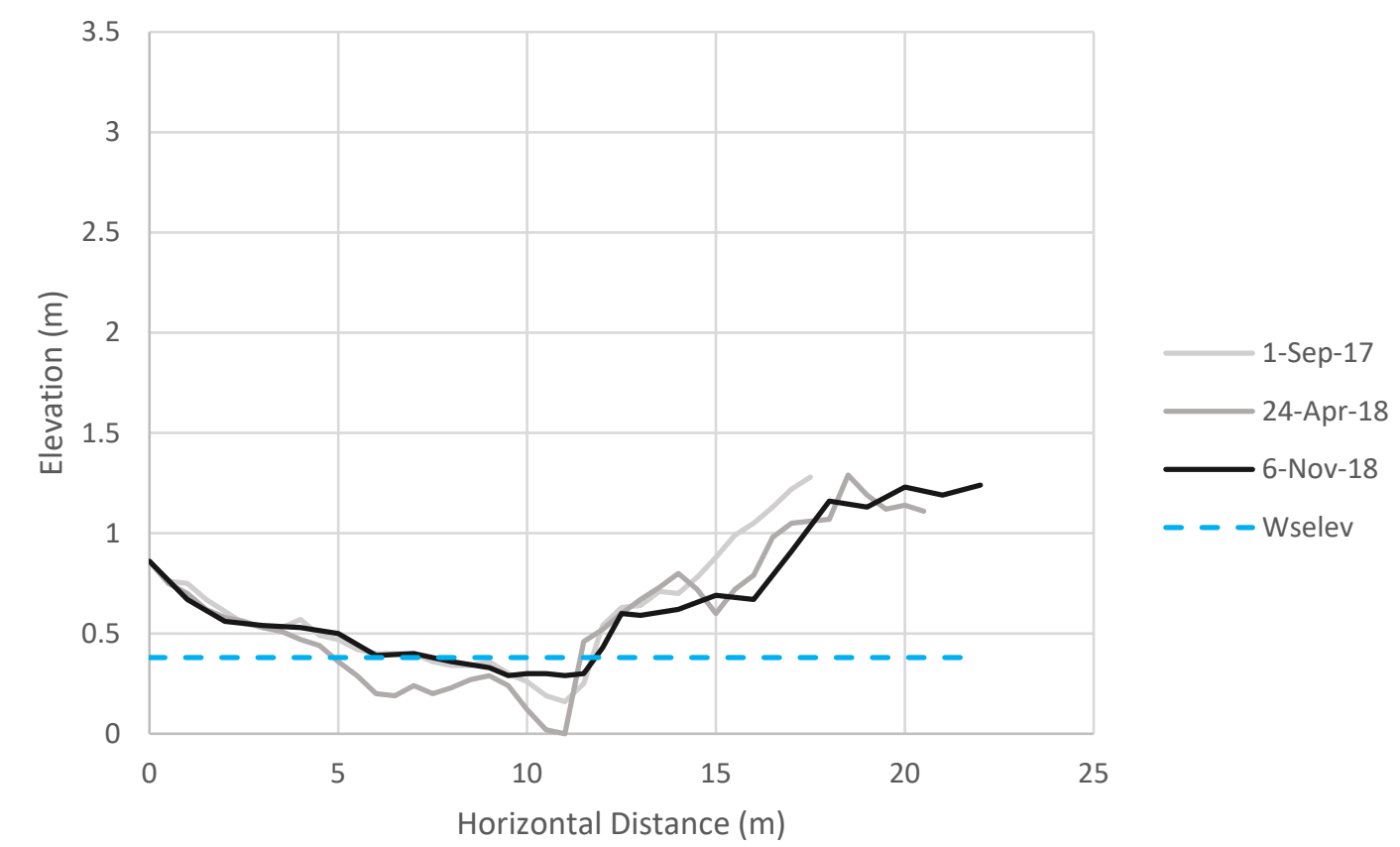

Figure A.4. Cross section data at the Downstream of Top of Reach location.

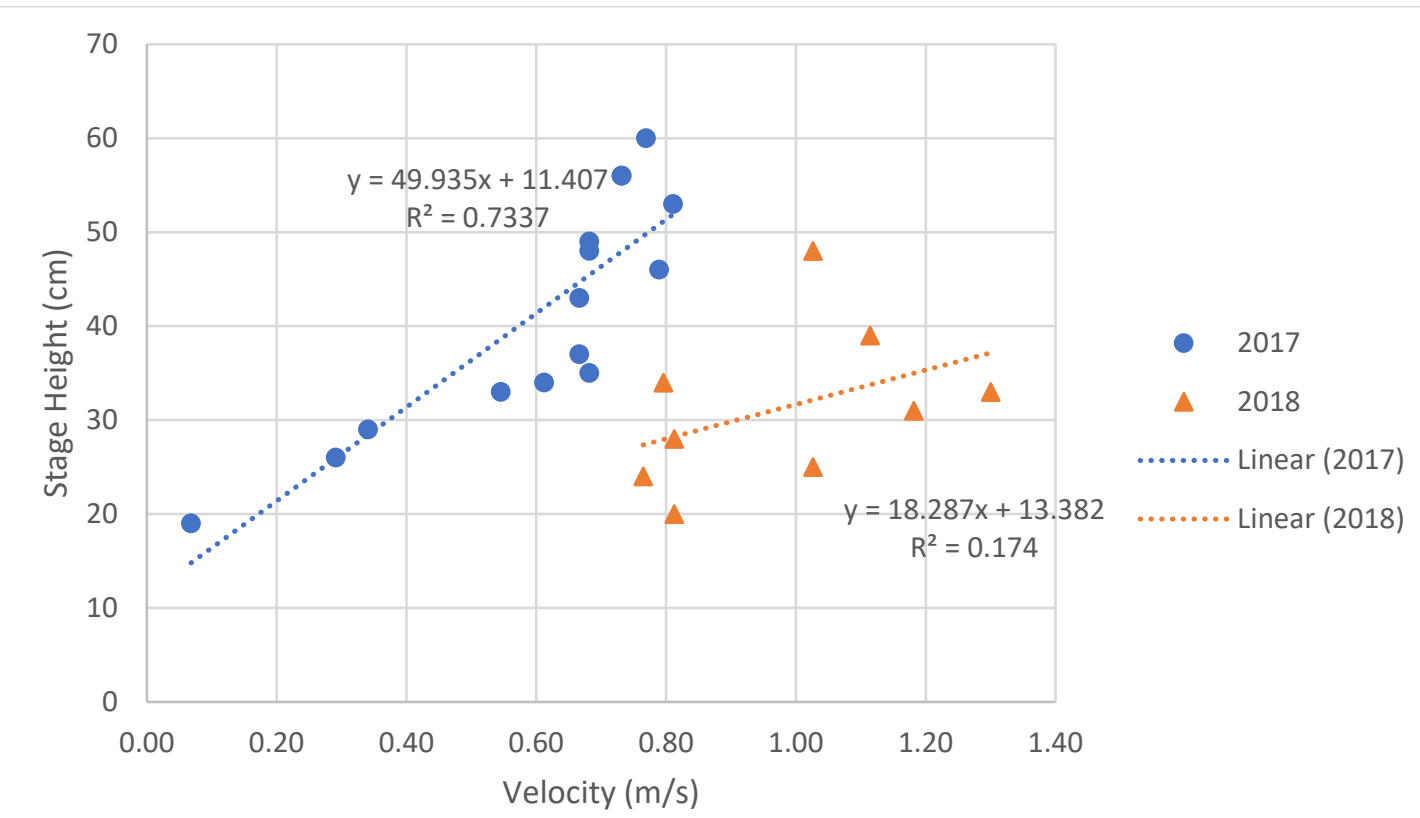

Figure A.5 Stage-velocity data downstream of the Downstream of Top of Reach location. 


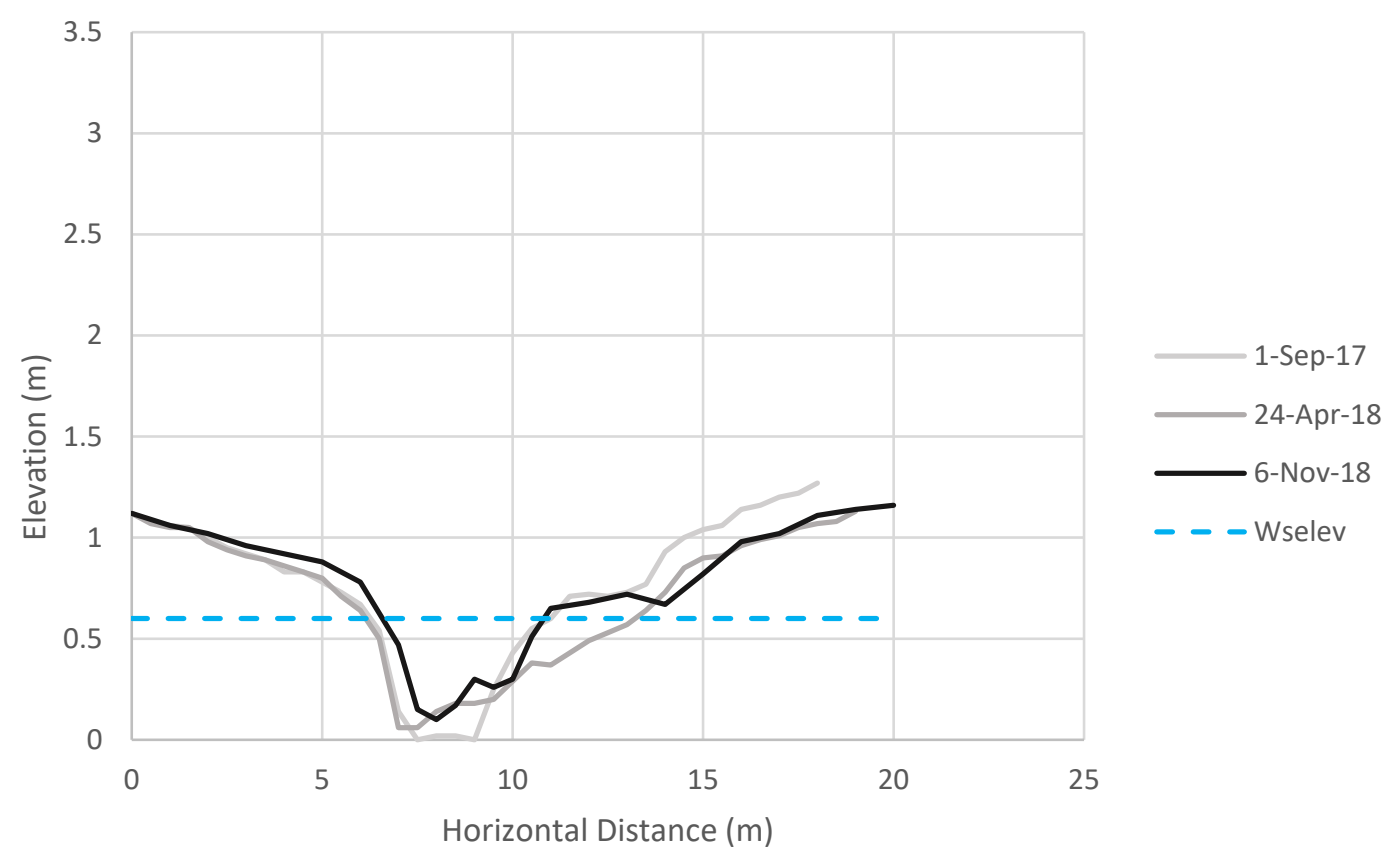

Figure A.6 Cross section data at the $2^{\text {nd }}$ Downstream of Top of Reach location.

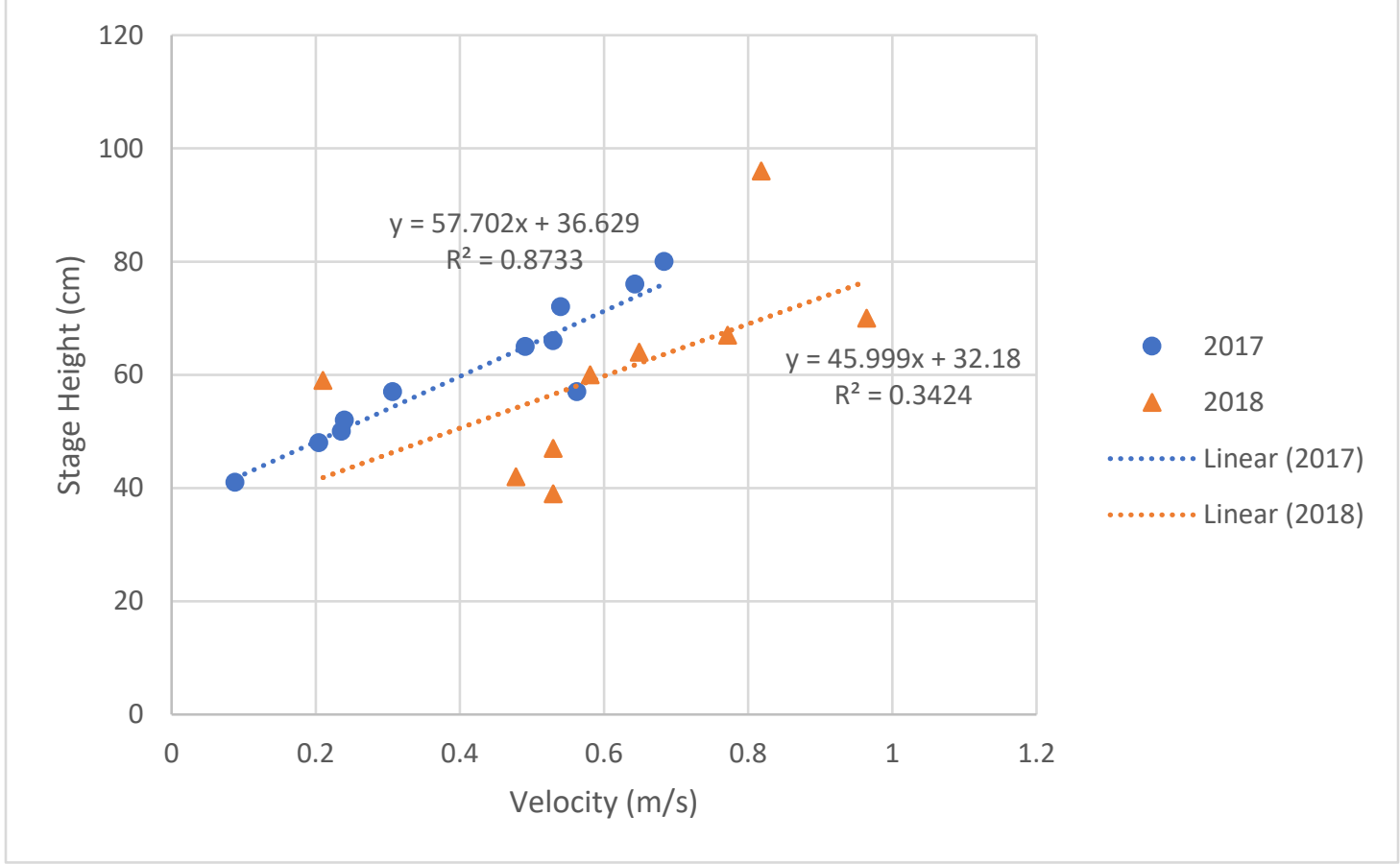

Figure A.7. Stage-velocity data downstream of the $2^{\text {nd }}$ Downstream of Top of Reach location. 


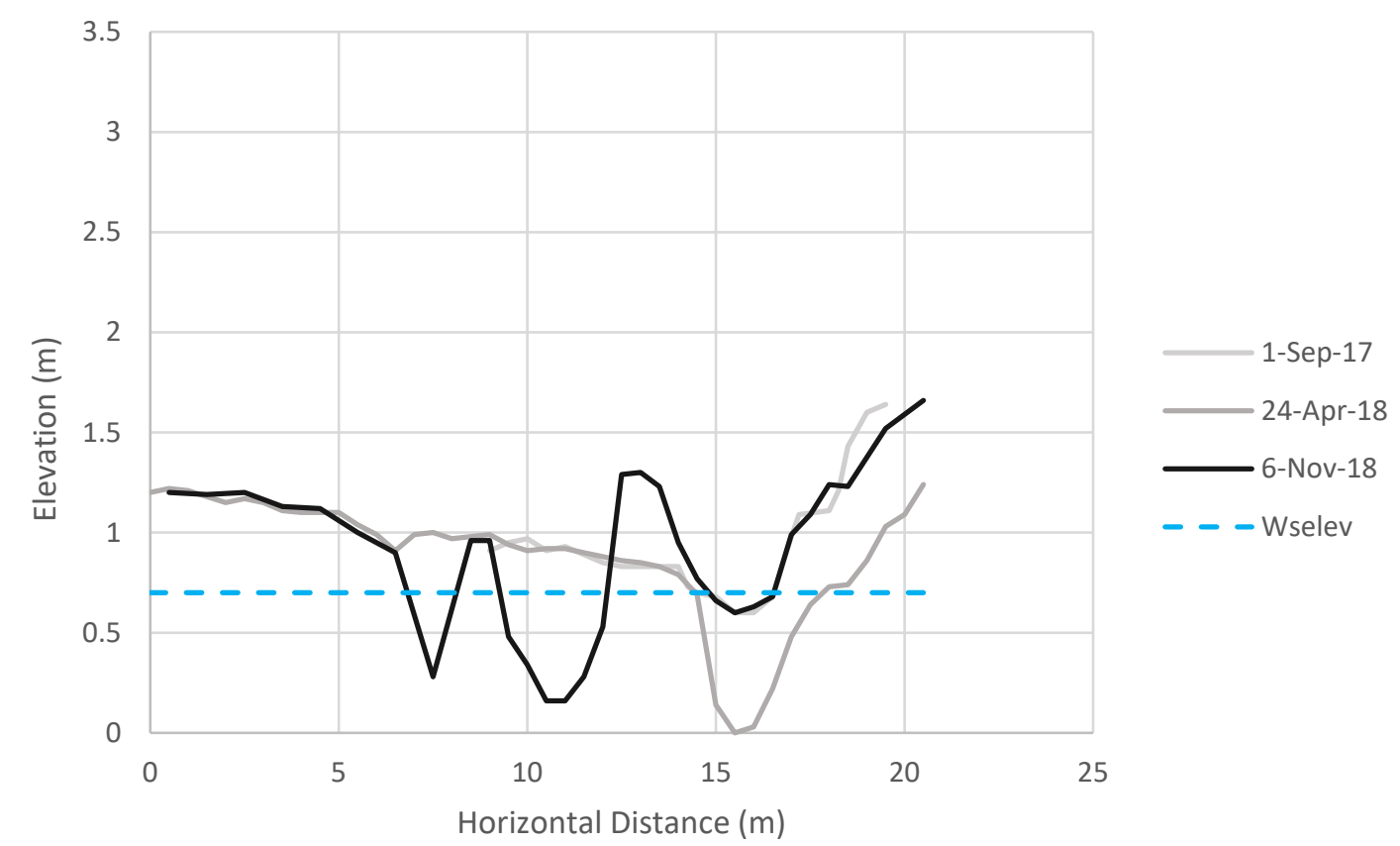

Figure A.8. Cross section data at the $3^{\text {rd }}$ Downstream of Top of Reach location.

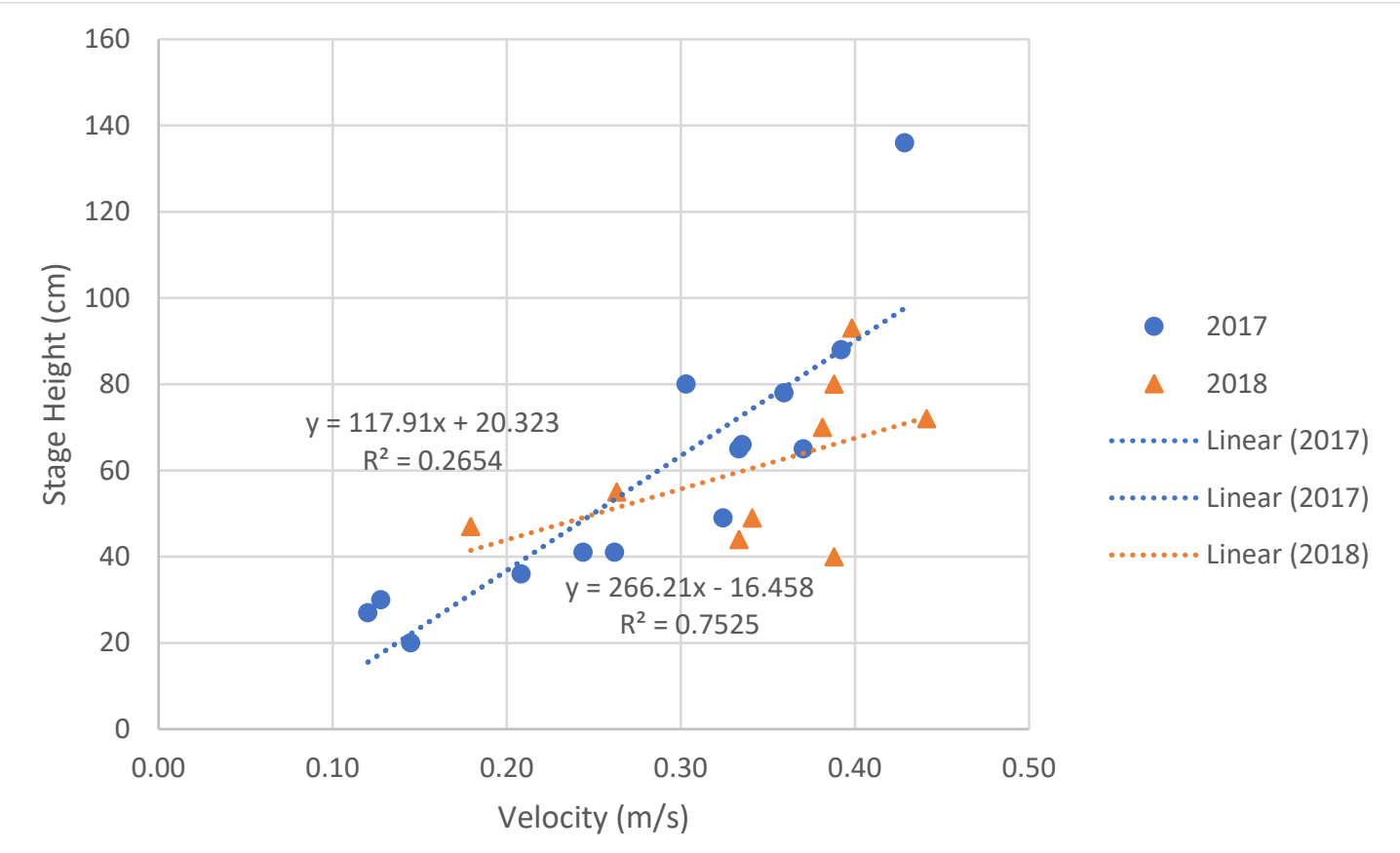

Figure A.9. Stage-velocity data downstream of the $3^{\text {rd }}$ Downstream of Top of Reach location. 


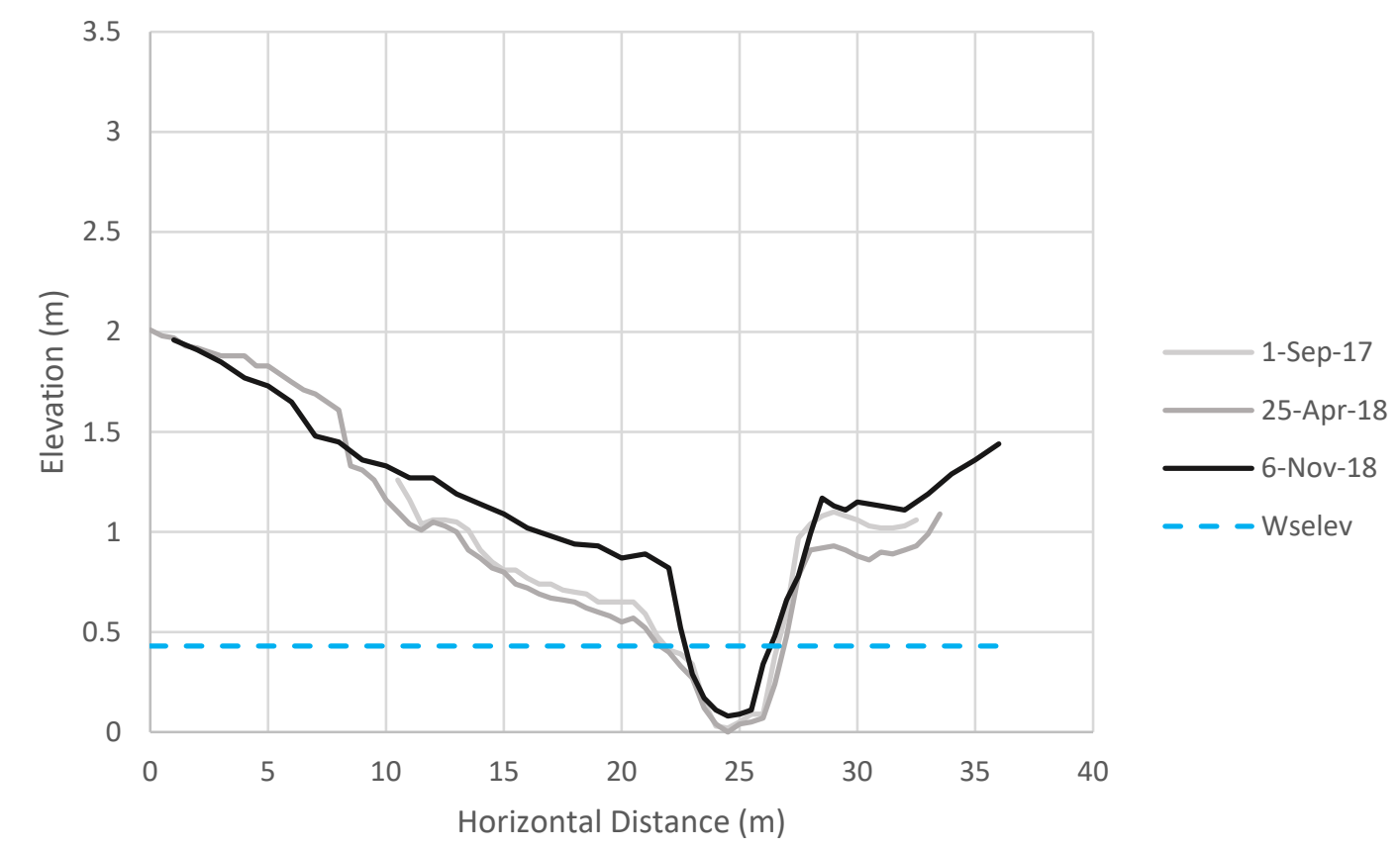

Figure A.10. Cross section data at the Upstream of the Big Erosion Curve location.

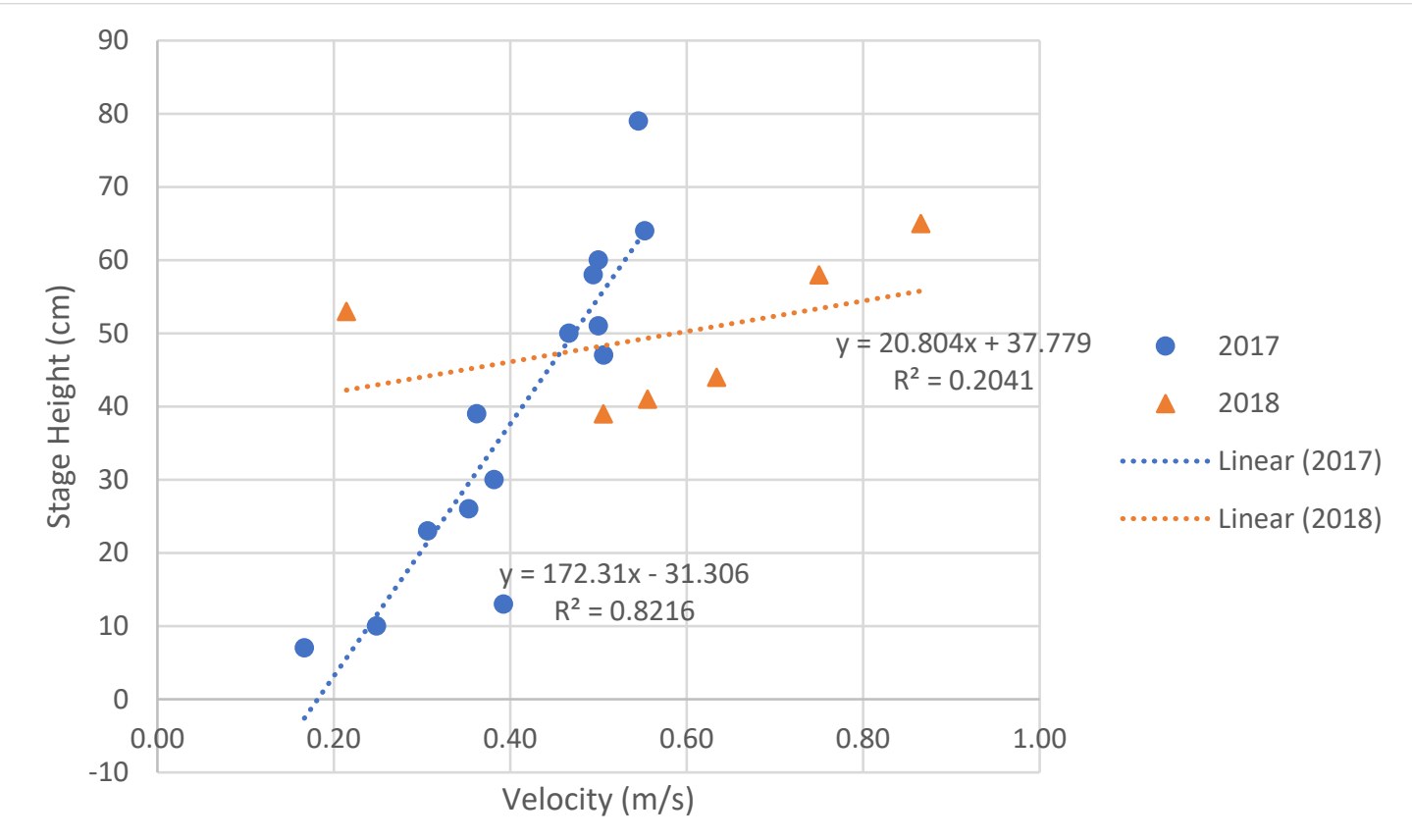

Figure A.11. Stage-velocity data downstream of the Upstream of the Big Erosion Curve location. 


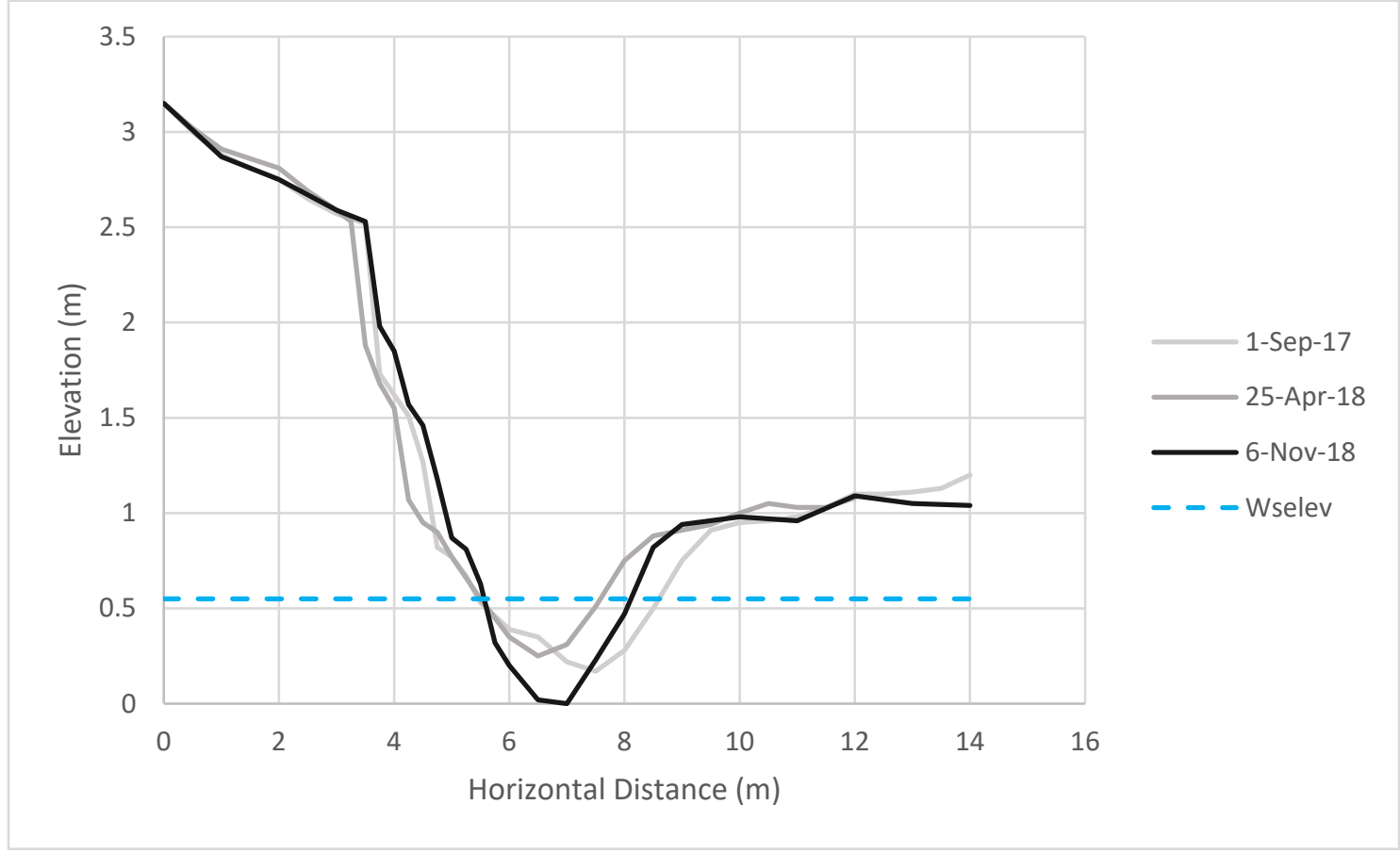

Figure A.12. Cross section data at the Big Erosion Curve location. 


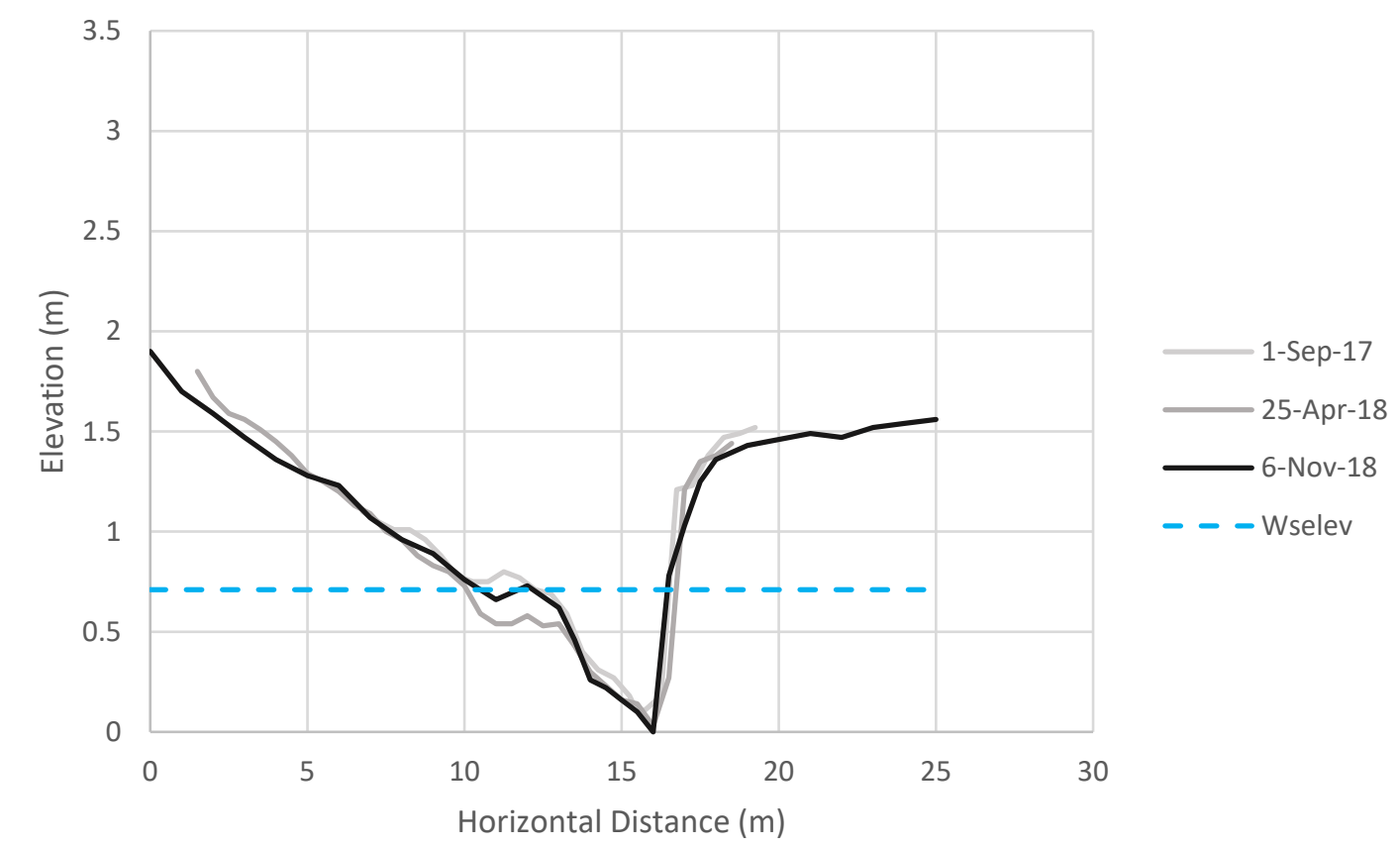

Figure A.13. Cross section data at the Downstream of the Big Erosion Curve location.

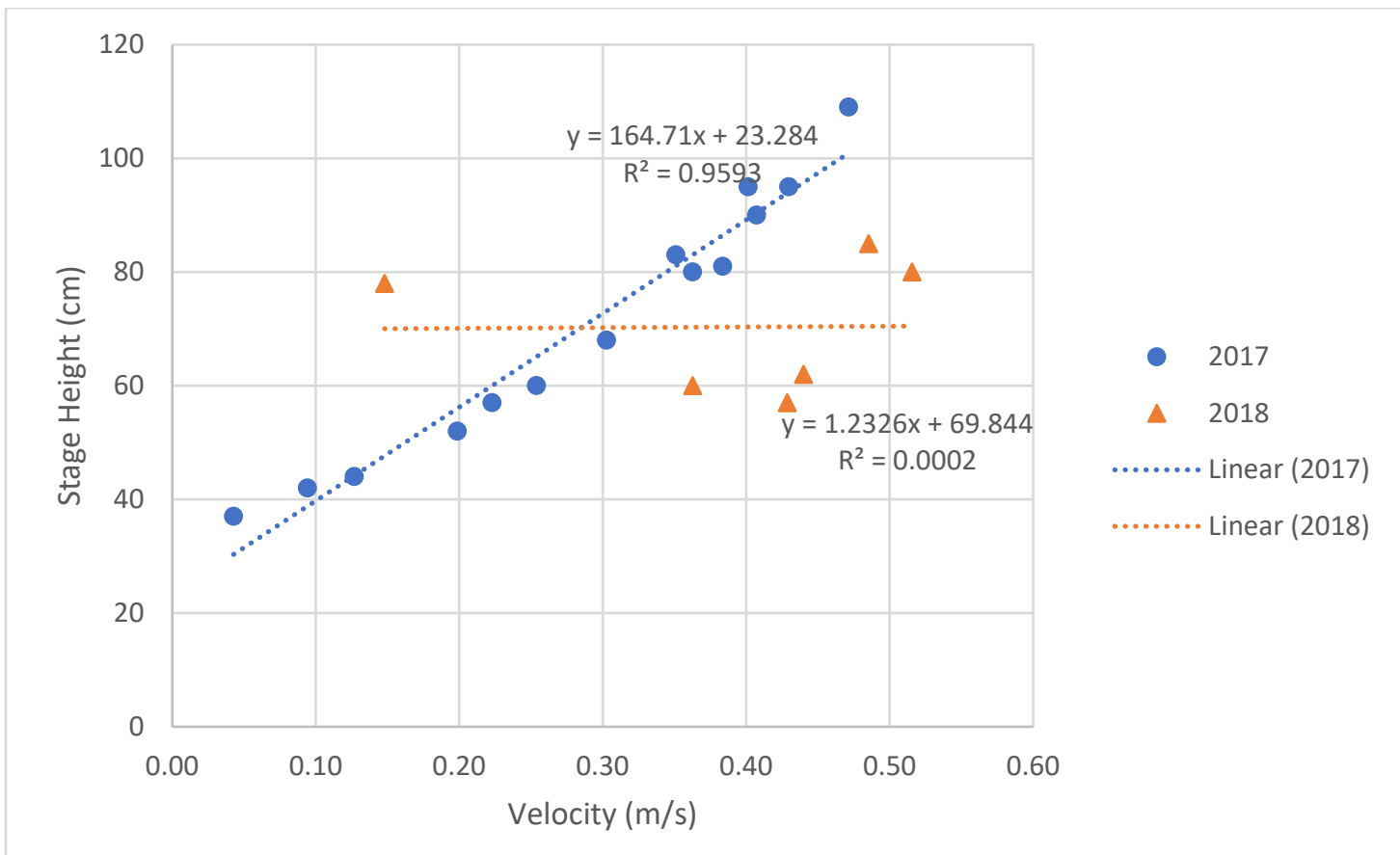

Figure A.14. Stage-velocity data downstream of the Downstream of the Big Erosion Curve location. 


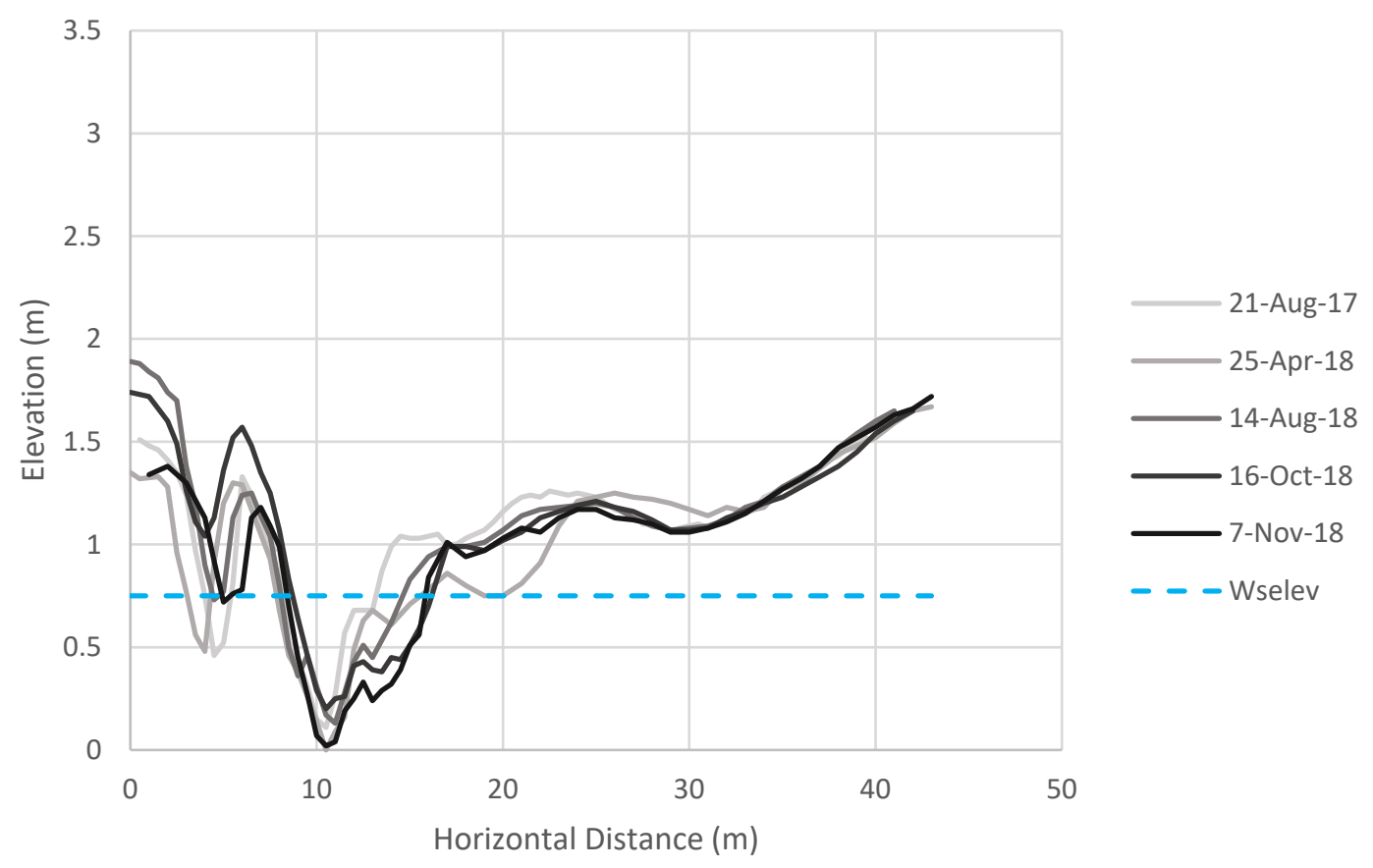

Figure A.15. Cross section data at the Upstream of the TIGER Method location.

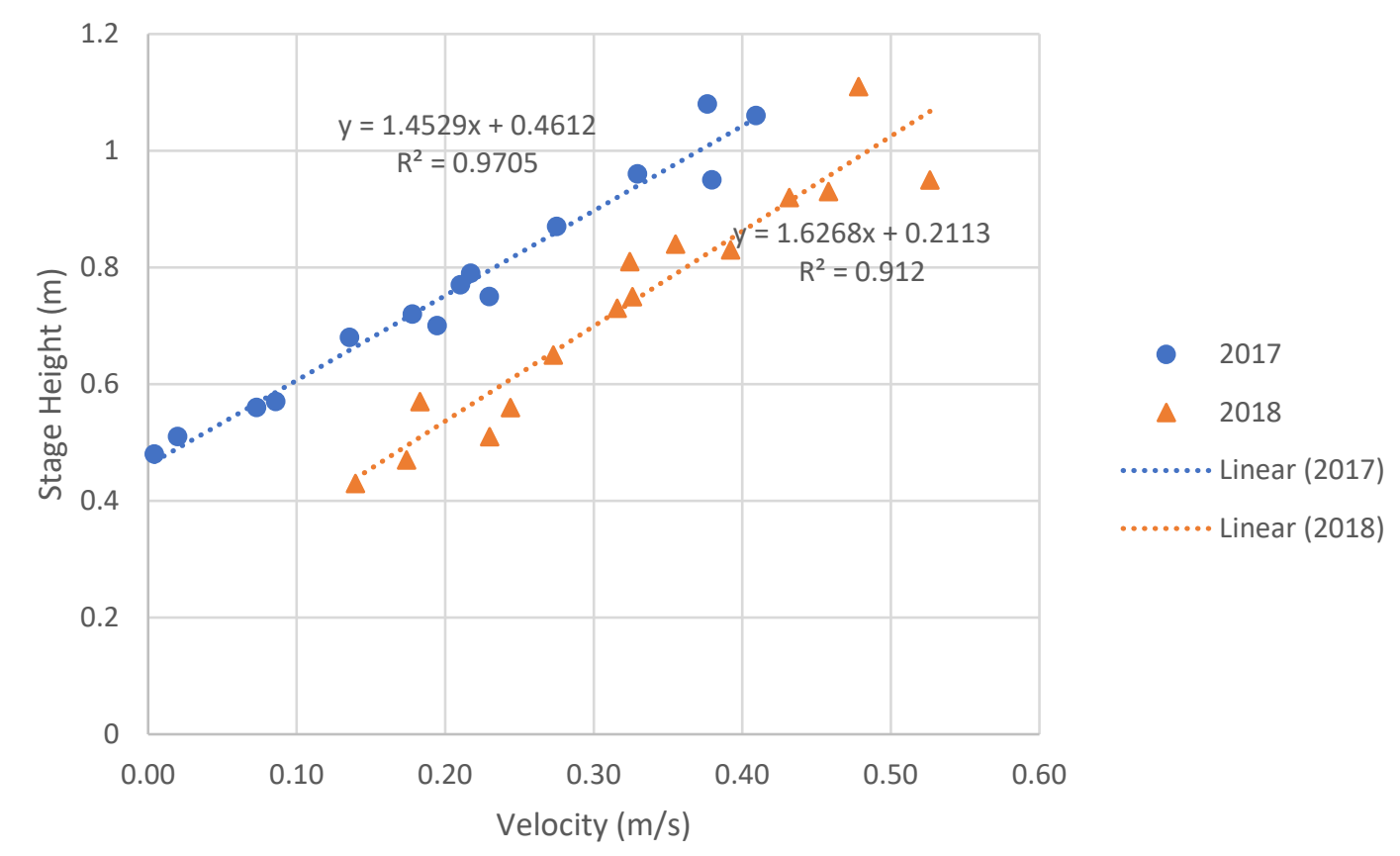

Figure A.16. Stage-velocity data downstream of the Upstream of the TIGER Method location. 


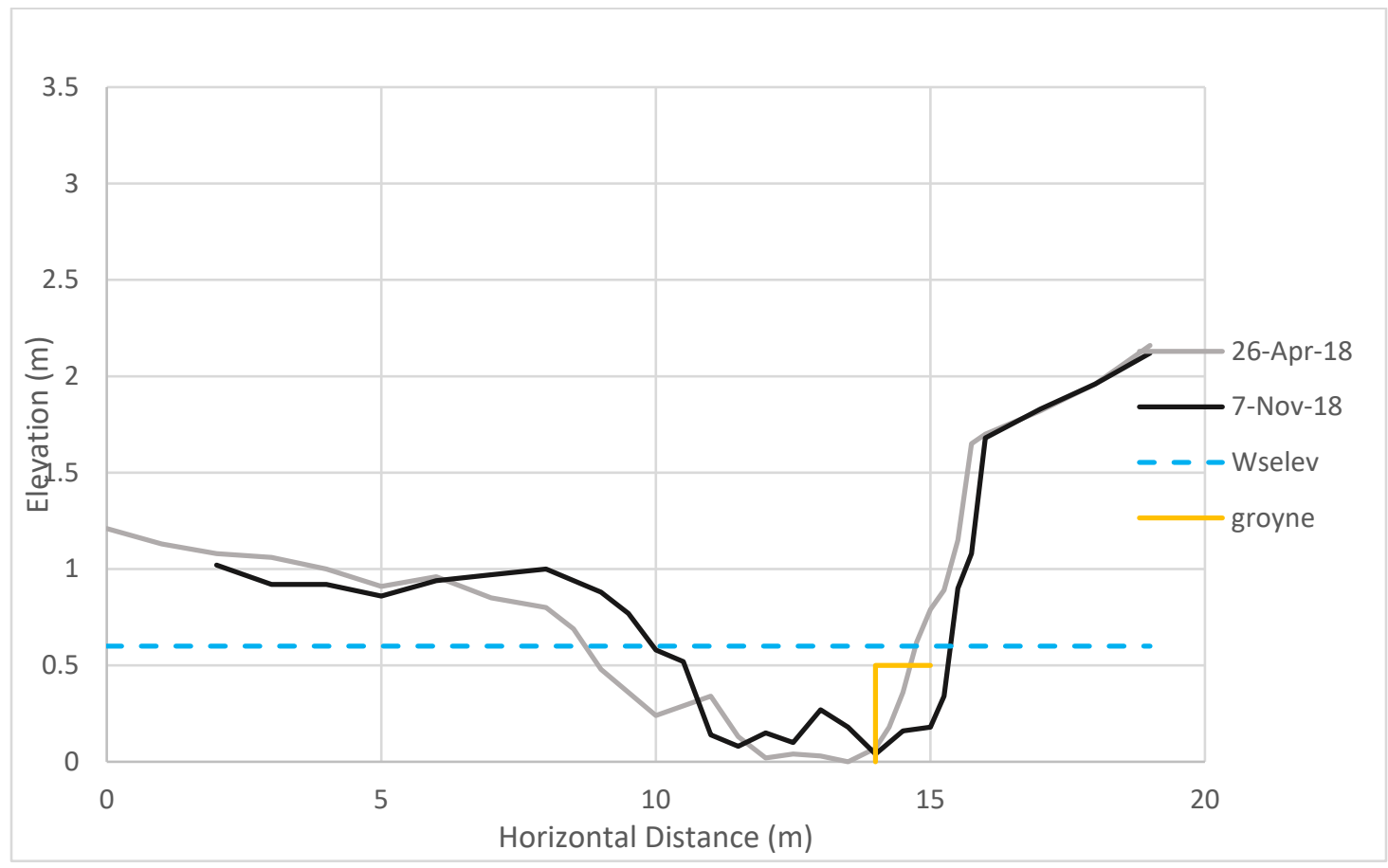

Figure A.17. Cross section data at the Middle of TIGER Method location 


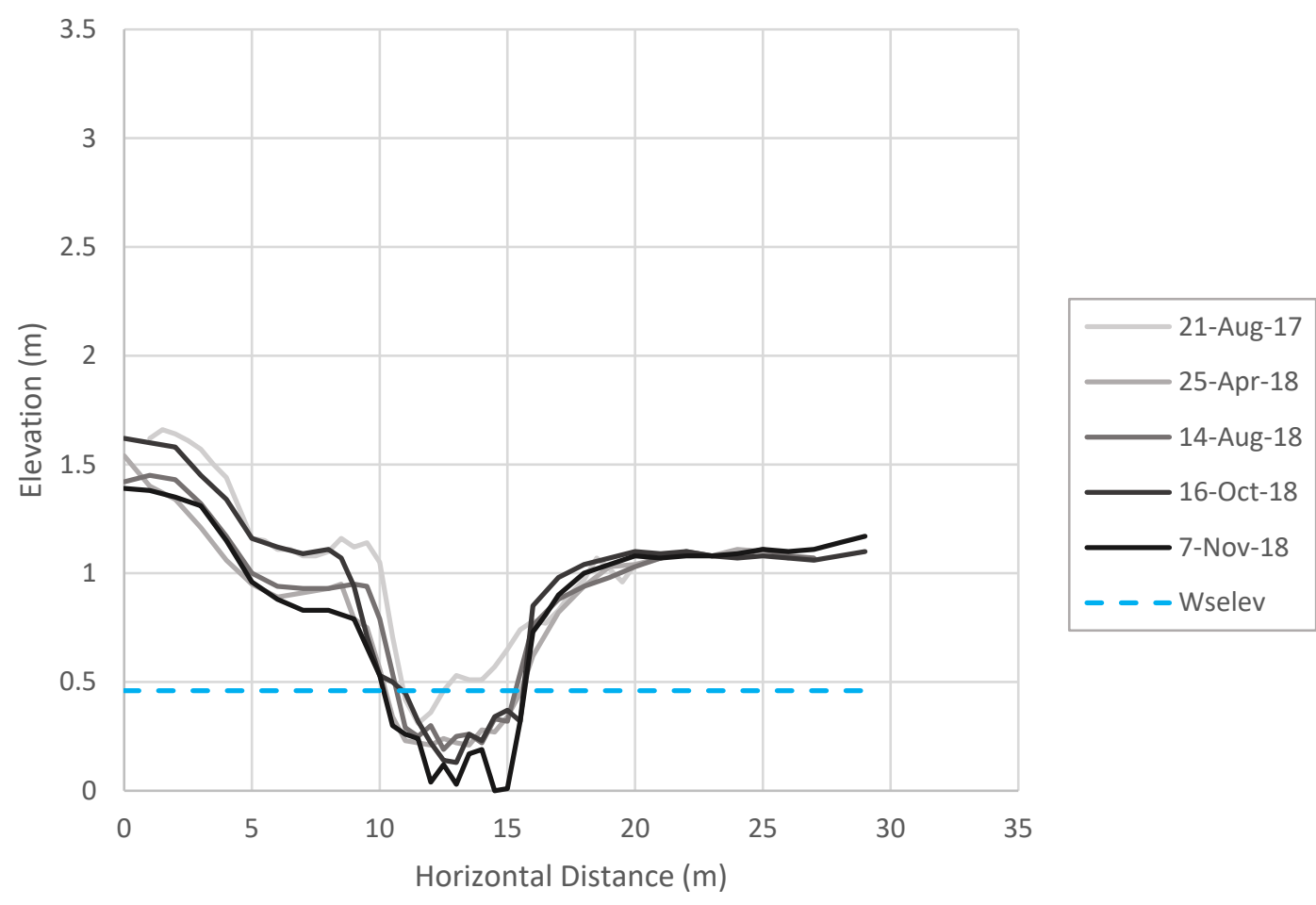

Figure A.18. Cross section data at the downstream of TIGER method location.

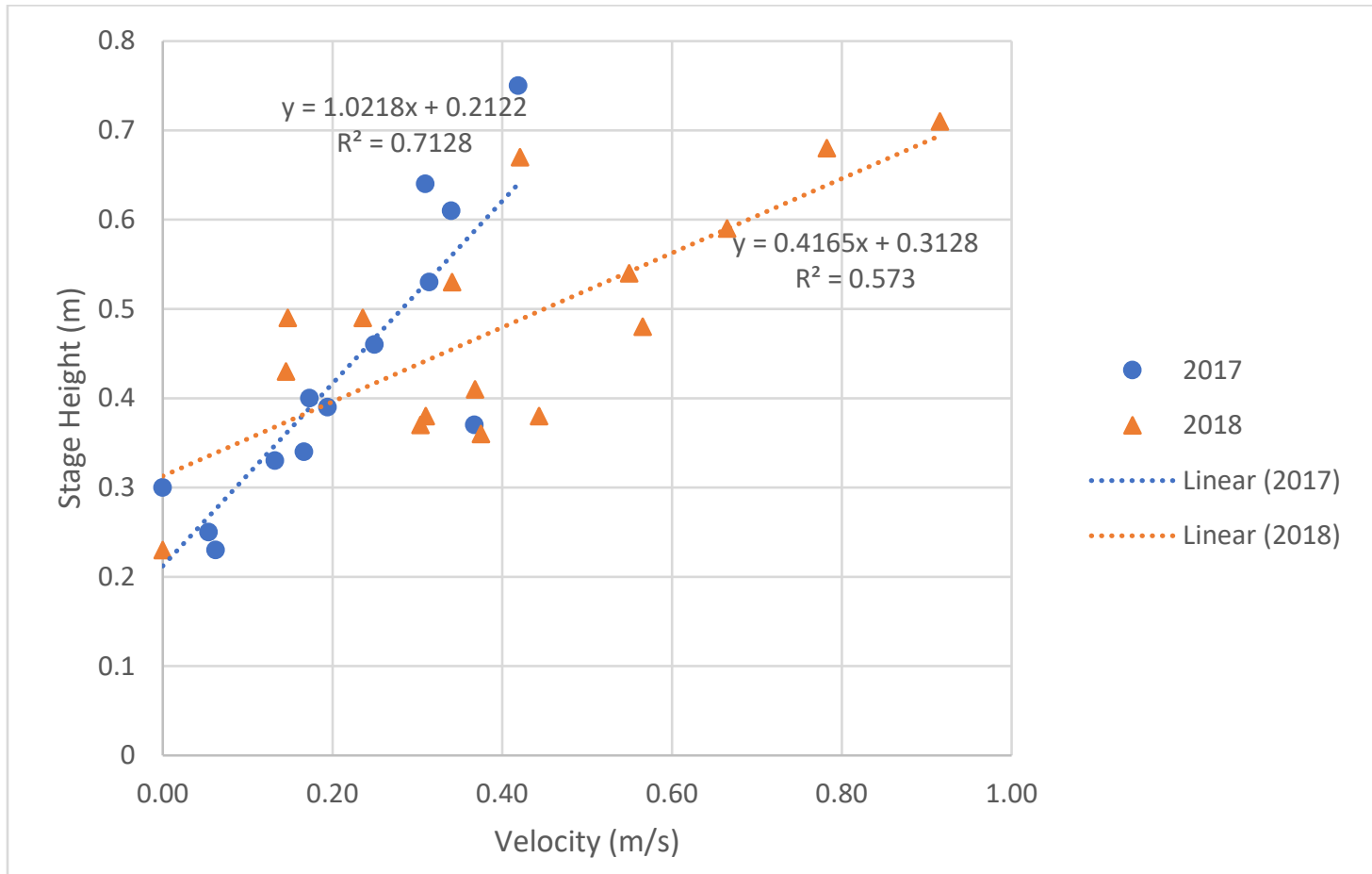

Figure A.19. Stage-velocity data downstream of the TIGER Method location. 


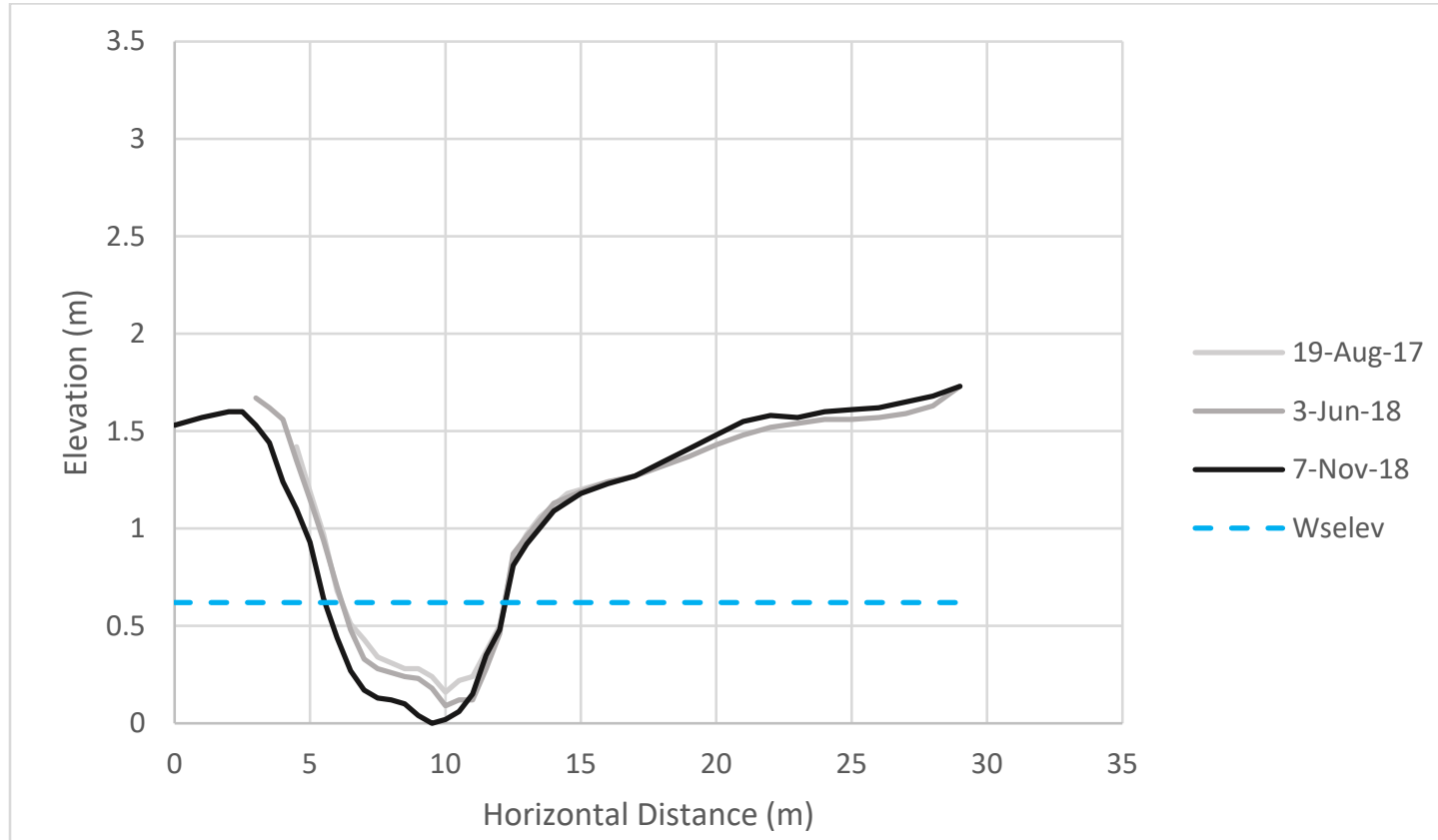

Figure A.20. Cross section data at the $2^{\text {nd }}$ Upstream of the End of Reach location.

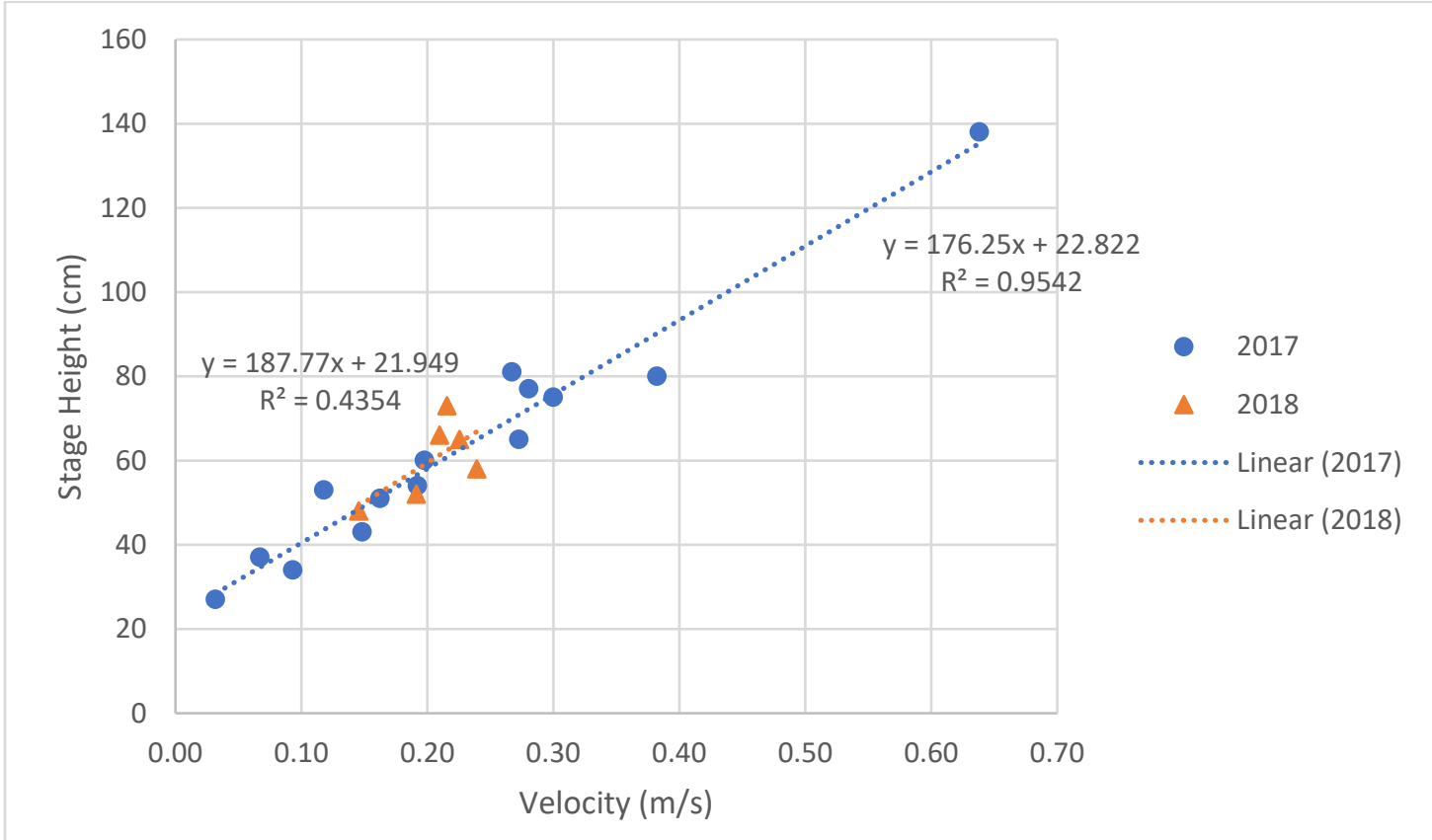

Figure A.21. Stage-velocity data downstream of the $2^{\text {nd }}$ Upstream of the End of Reach location. 


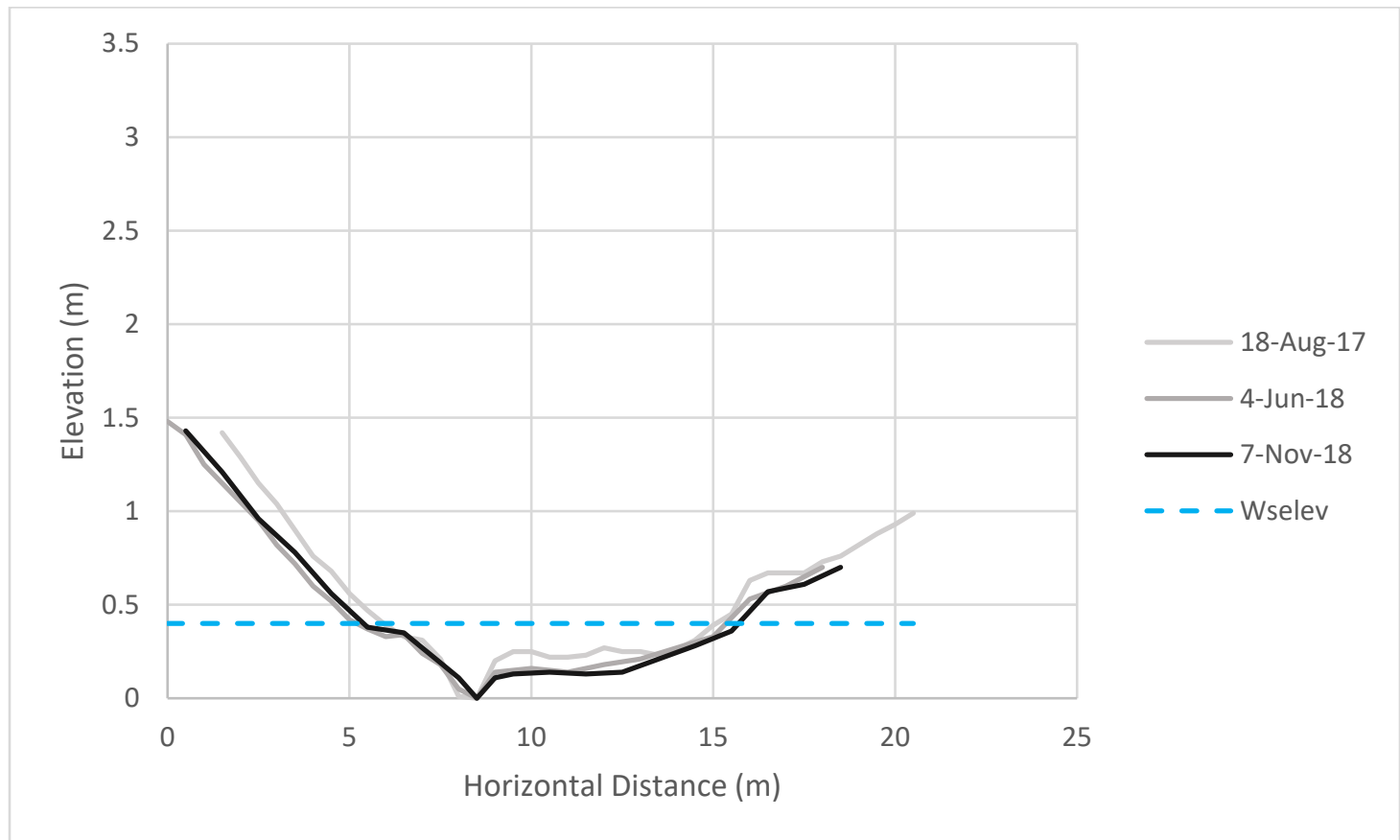

Figure A.22. Cross section data at the End of Reach location.

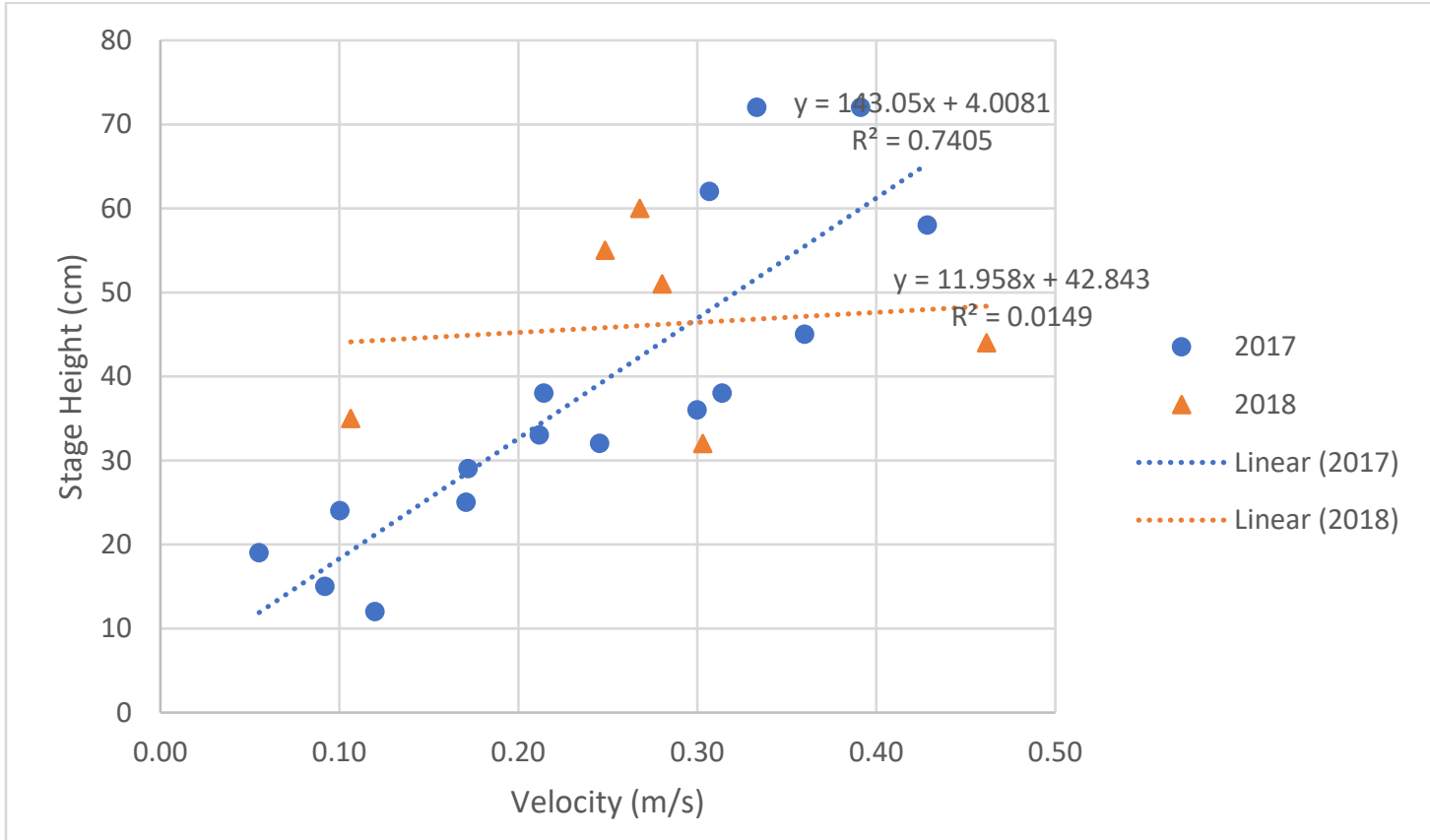

Figure A.23. Stage-velocity data downstream of the End of Reach location. 


\section{Appendix B}

\section{Copyright documentation}

Figure 2 in this document is from Wikipedia. They are all public domain or licensed for reuse under Creative Commons license 3.0. Please see below for full citation and attribution information.

Figure 2: "Senegal, administrative division - en - monochrome" by NordNordWest. United States National Imagery and Mapping Agency data, World Data Base II data, and Agence Nationale de la Statistique et de la Démographie Sénégal. Licensed under Public Domain via Wikimedia Commons

https://commons.wikimedia.org/wiki/File:Senegal,_administrative divisions - en _monochrome.svg. Accessed May 2019. 